\title{
Operation, Manufacturing, and Supply Chain of Lithium-ion Batteries for Electric Vehicles
}

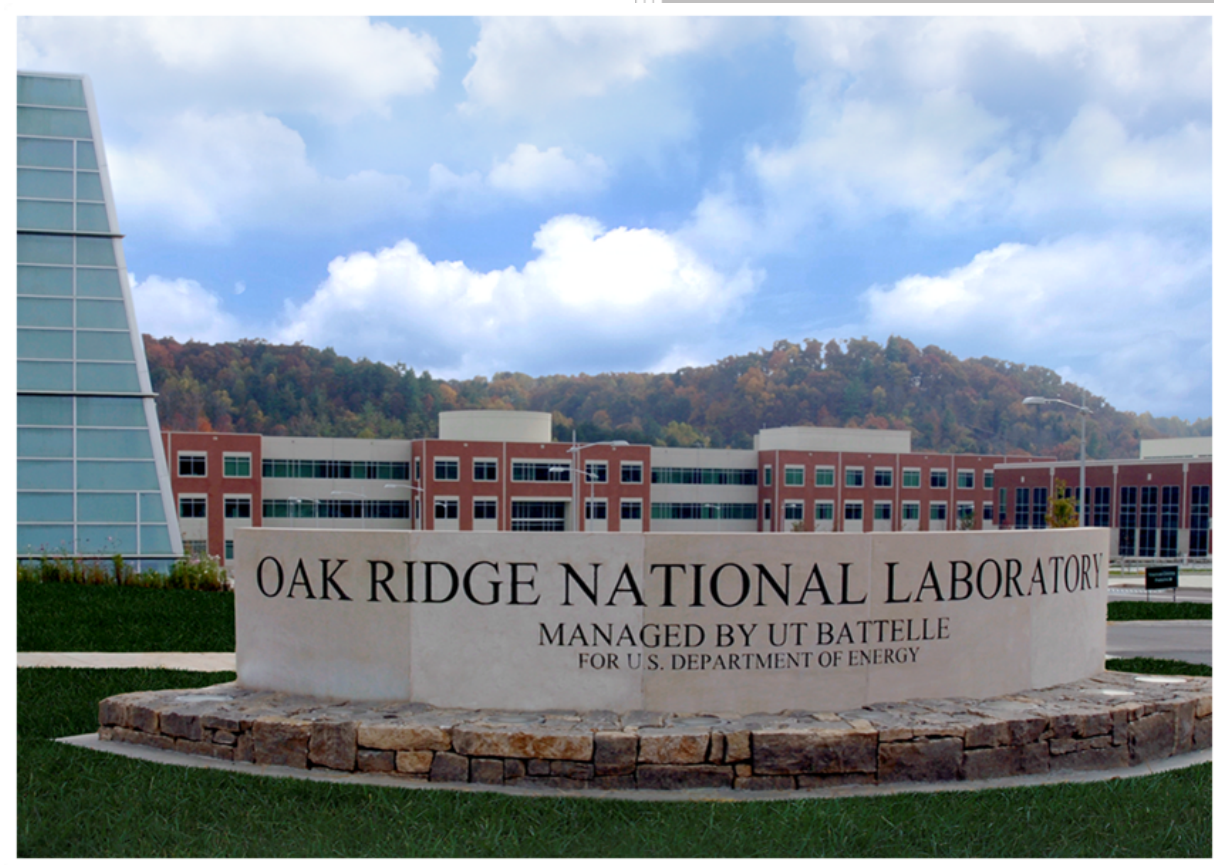

Approved for public release. Distribution is unlimited.
Ilias Belharouak Jagjit Nanda Ethan Self W. Blake Hawley David Wood Zhijia Du Jianlin Li Ronald L. Graves

August 2020 


\section{DOCUMENT AVAILABILITY}

Reports produced after January 1, 1996, are generally available free via US Department of Energy (DOE) SciTech Connect.

Website www.osti.gov

Reports produced before January 1, 1996, may be purchased by members of the public from the following source:

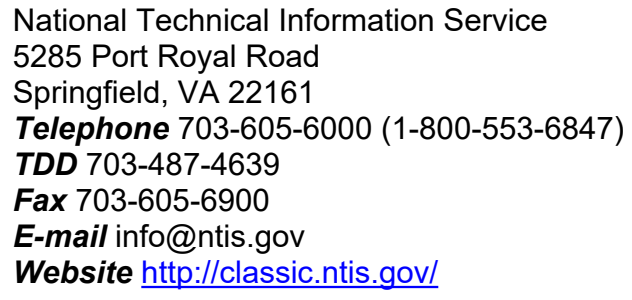

Reports are available to DOE employees, DOE contractors, Energy Technology Data Exchange representatives, and International Nuclear Information System representatives from the following source:

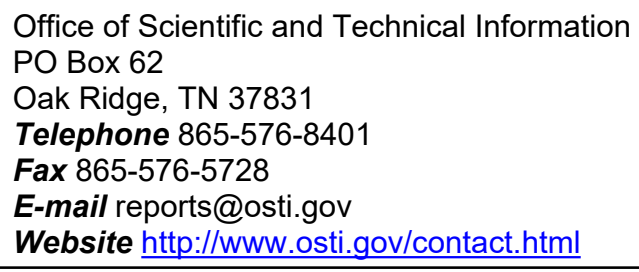

This report was prepared as an account of work sponsored by an agency of the United States Government. Neither the United States Government nor any agency thereof, nor any of their employees, makes any warranty, express or implied, or assumes any legal liability or responsibility for the accuracy, completeness, or usefulness of any information, apparatus, product, or process disclosed, or represents that its use would not infringe privately owned rights. Reference herein to any specific commercial product, process, or service by trade name, trademark, manufacturer, or otherwise, does not necessarily constitute or imply its endorsement, recommendation, or favoring by the United States Government or any agency thereof. The views and opinions of authors expressed herein do not necessarily state or reflect those of the United States Government or any agency thereof.

\section{About Oak Ridge National Laboratory}

Oak Ridge National Laboratory is a US Department of Energy science and energy laboratory, conducting basic and applied research to deliver transformative solutions to compelling problems in energy and security. The laboratory is located at 1 Bethel Valley Rd, Oak Ridge, TN 37830. For more information about ORNL and its Science and Technology programs, see www.ornl.gov

\section{Disclaimer}

The purpose of this review document is to support DOE's Advanced Technology Vehicle Manufacturing Loan Program to give technology background and information which can be used to develop the basis for loan topics and evaluate applications. Other favorable/constructive outcomes are expected as well.

This report has been authored by UT-Battelle, LLC, under contract DE-AC05-000R22725 with the US Department of Energy (DOE). The US government retains and the publisher, by accepting the article for publication, acknowledges that the US government retains a nonexclusive, paid-up, irrevocable, worldwide license to publish or reproduce the published form of this manuscript, or allow others to do so, for US government purposes. DOE will provide public access to these results of federally sponsored research in accordance with the DOE Public Access Plan (http://energy.gov/downloads/doe-public-access-plan) 
Energy and Transportation Science Division Chemical Science Division

\title{
OPERATION, MANUFACTURING, AND SUPPLY CHAIN OF LITHIUM-ION BATTERIES FOR ELECTRIC VEHICLES
}

\author{
Ilias Belharouak ${ }^{1}$ \\ Jagjit Nanda ${ }^{2}$ \\ Ethan Self ${ }^{2}$ \\ W. Blake Hawley ${ }^{1}$ \\ David Wood $^{1}$ \\ Zhijia Du ${ }^{1}$ \\ Jianlin $\mathrm{Li}^{1}$ \\ Ronald L. Graves ${ }^{1}$ \\ ${ }^{1}$ Energy and Transportation Science Division, ORNL \\ ${ }^{2}$ Chemical Science Division, ORNL
}

August 2020

Prepared by

OAK RIDGE NATIONAL LABORATORY

Oak Ridge, TN 37831-6283

managed by

UT-BATTELLE, LLC

for the

US DEPARTMENT OF ENERGY

under contract DE-AC05-00OR22725 



\section{CONTENTS}

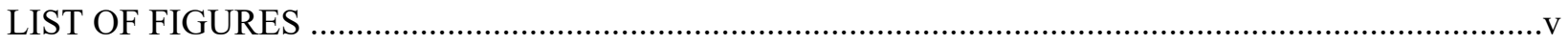

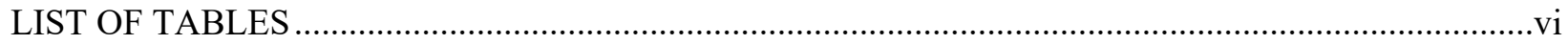

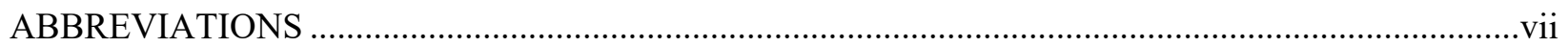

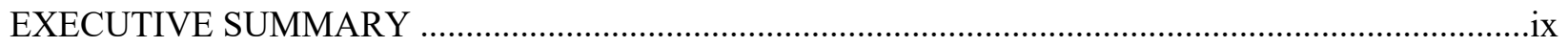

WHY THE UNITED STATES SHOULD ACT NOW ..................................................................

1. LITHIUM-ION BATTERIES: FUNDAMENTALS AND KEY PERFORMANCE

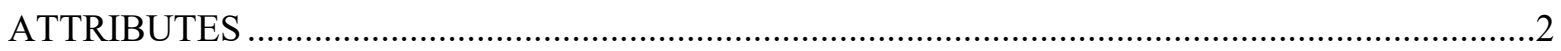

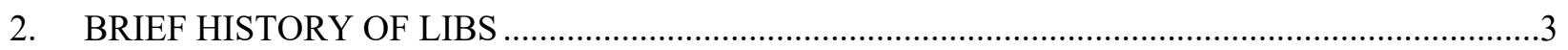

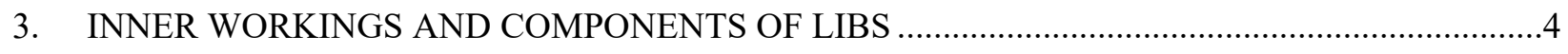

3.1 SUMMARY OF BATTERY FORMATS/CONFIGURATIONS ….......................................

3.2 KEY CELL COMPONENTS (CATHODE, ANODE, COLLECTORS, SEPARATORS,

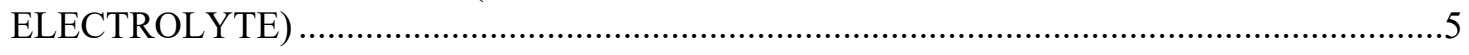

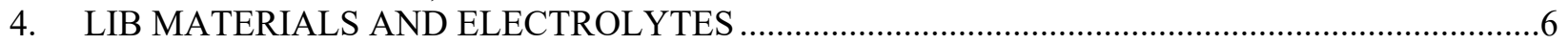

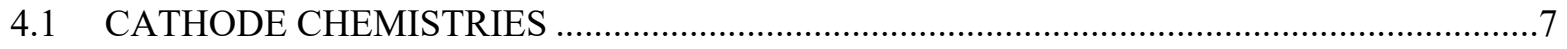

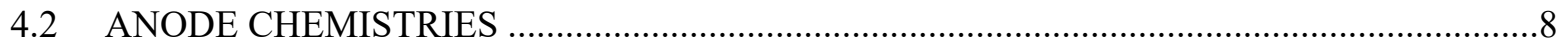

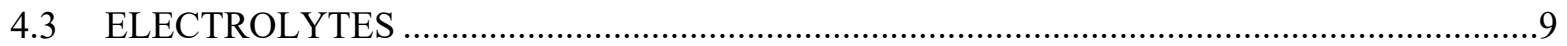

5. FUNCTION AND CONTROL OF EV BATTERIES (VEHICLE-LEVEL SUMMARY) ..................9

6. BRIEF HISTORY OF BATTERY TECHNOLOGIES USED IN EVS ........................................10

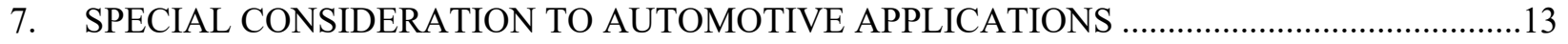

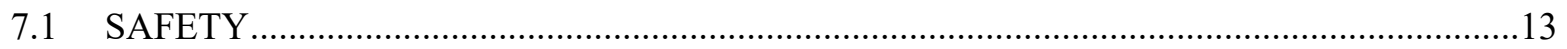

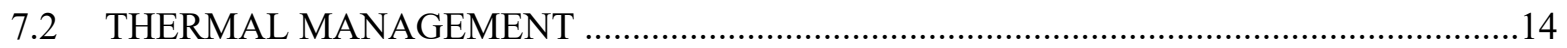

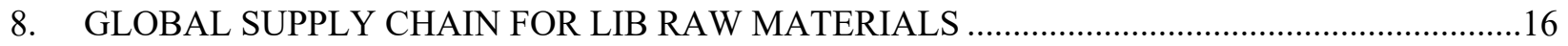

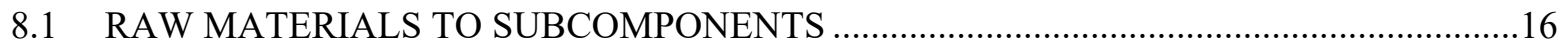

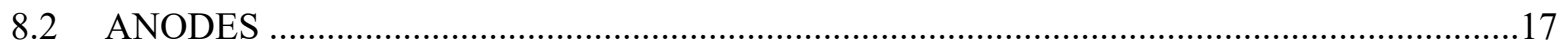

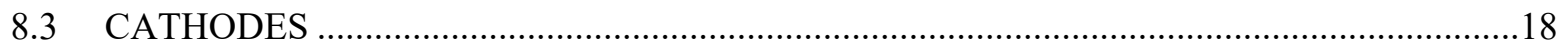

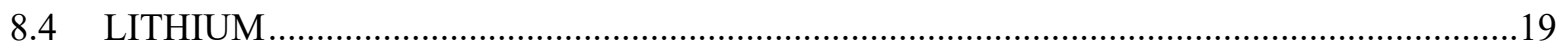

8.5 ELECTROLYTE AND INACTIVE COMPONENTS .......................................................20

9. GLOBAL AND DOMESTIC LIB PRODUCTION CAPACITY ................................................21

10. INDUSTRIAL/COMMERCIAL MANUFACTURING PROCESS DESCRIPTION ........................22

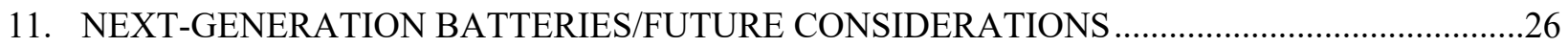

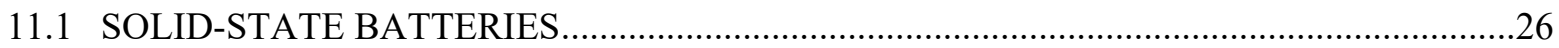

11.2 WOULD THE MANUFACTURING BASE CHANGE FOR BEYOND LIBS? ....................28

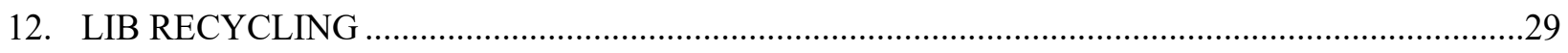

12.1 PRESENT STATUS, CONTRAST TO MATURE RECYCLING OF 12 V LEAD-

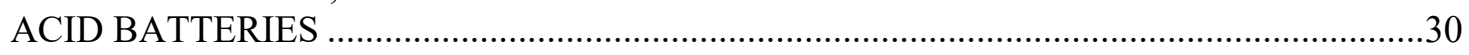

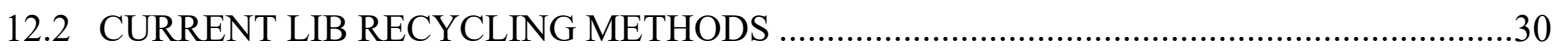

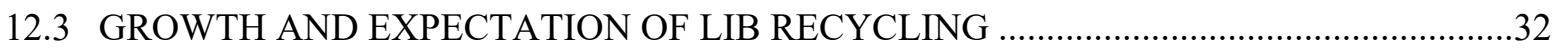

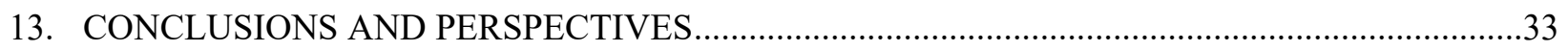

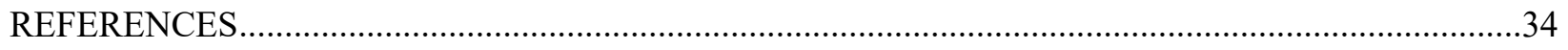





\section{LIST OF FIGURES}

Figure 1.1. Oak Ridge National Laboratory streamlined battery R\&D focused on electric vehicle and grid batteries.

Figure 1.1. (left) Working principle of a LIB and (right) expected capacity

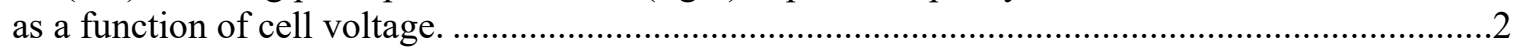

Figure 2.1. Significant events related to the development of LIB materials. ............................................

Figure 3.1. Three representative commercial cell structures: (a) cylindrical-type cell, (b) prismatic-type cell, and (c) pouch-type cell.[8]

Figure 4.1. Specific capacity and operating potentials for (a) intercalation-type cathodes, (b) conversion-type cathodes, (c) conversion-type anodes, and (d) an overview of various anodes and cathodes.

Figure 4.2. Radar plots showing key performance metrics for several Li-ion cathode chemistries.............8

Figure 5.1. Schematic of a typical EV power train illustrating power electronic controllers, converters, and auxiliary battery management.

Figure 5.2. Illustration of a pouch cell, module, battery pack, and a liquid-cooled battery pack...............10

Figure 6.1. DOE technology roadmap for EVs for 2022 and beyond. ..................................................11

Figure 6.2. Monthly global sales of plug-in EVs from 2016 to 2019..................................................13

Figure 7.1. Schematics of the various battery cooling systems (reprinted with copyright permission from Elsevier).[61]

Figure 8.1. Cost breakdown of the major subcomponents comprising LIBs obtained by the $\mathrm{BatPaC}$ model sponsored by VTO and developed by Argonne National Laboratory.

Figure 8.2. Mass per kg of NMC622 of each major LIB subcomponent for NMC622/graphite cell chemistry.

Figure 8.3. (left) Tianqi Greenbushes Li mine in western Australia, and (right) the Orocobre Salinas Grandes Lithium Project in northwest Argentina.

Figure 8.4. Projected major anode and cathode raw materials demand from 2018 to 2030 showing that the demand for $\mathrm{Li}$ metal will be significantly outpaced by $\mathrm{Cu}, \mathrm{Ni}$, and (natural) graphite.[67].

Figure 10.1. Flowchart of the manufacturing process used at DOE's Oak Ridge National Laboratory's Battery Manufacturing Facility to make electrolyte-filled, fully sealed pouch cells.

Figure 10.2. (a) Schematic drawing of a slot-die coater used in coating electrodes.................................25

Figure 10.3. Schematic describing the process/structure/property relationships in the LIB manufacturing process.

Figure 11.1. Summary of key properties for (a) oxide, (b) sulfide, and (c) polymer solid-state $\mathrm{Li}^{+}$ conductors.

Figure 11.2. (a) Crosslinking of acrylated polyurethane oligomers allows for high solid loading and rapid coating speeds.

Figure 12.1. Cell composition comparison between a lead-acid battery and a LIB (based on data from Gaines et al. [143]).....

Figure 12.2. Overview of pyrometallurgical and hydrometallurgical recycling processes. 


\section{LIST OF TABLES}

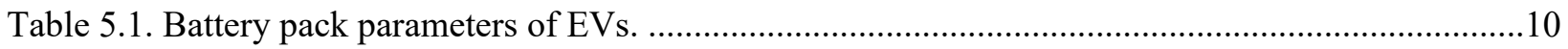

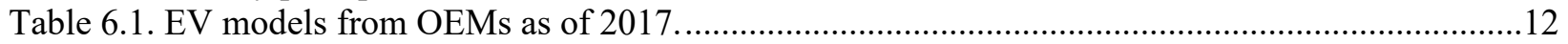

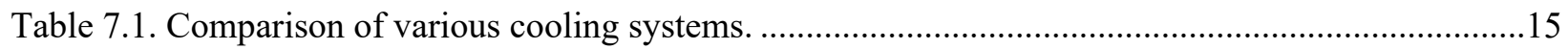

Table 9.1. Annual production capacity of top five LIB factories in the world.[63] 


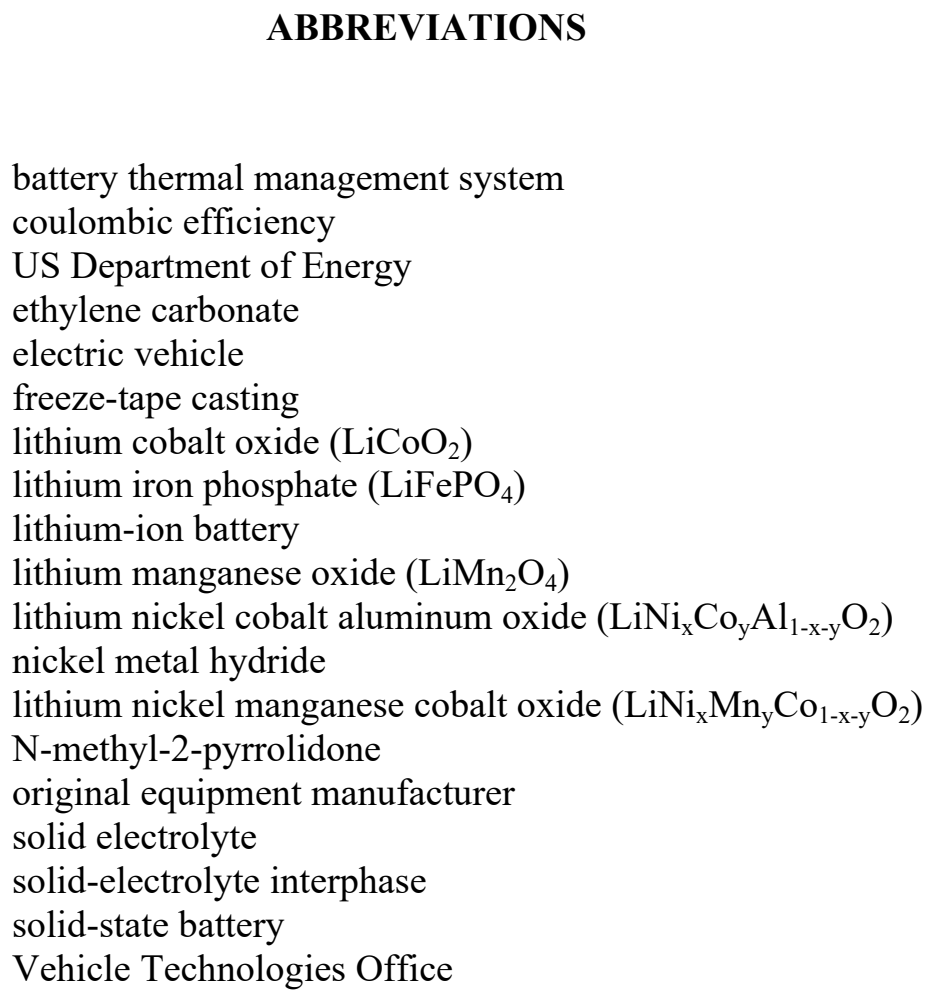

battery thermal management system

coulombic efficiency

US Department of Energy

ethylene carbonate

electric vehicle

freeze-tape casting

lithium cobalt oxide $\left(\mathrm{LiCoO}_{2}\right)$

lithium iron phosphate $\left(\mathrm{LiFePO}_{4}\right)$

lithium-ion battery

lithium manganese oxide $\left(\mathrm{LiMn}_{2} \mathrm{O}_{4}\right)$

lithium nickel cobalt aluminum oxide $\left(\mathrm{LiNi}_{\mathrm{x}} \mathrm{Co}_{\mathrm{y}} \mathrm{Al}_{1-\mathrm{x}-\mathrm{y}} \mathrm{O}_{2}\right)$

nickel metal hydride

lithium nickel manganese cobalt oxide $\left(\mathrm{LiNi}_{\mathrm{x}} \mathrm{Mn}_{\mathrm{y}} \mathrm{Co}_{1-\mathrm{x}-\mathrm{y}} \mathrm{O}_{2}\right)$

$\mathrm{N}$-methyl-2-pyrrolidone

original equipment manufacturer

solid electrolyte

solid-electrolyte interphase

solid-state battery

Vehicle Technologies Office

BTMS

CE

DOE

EC

EV

FTC

LCO

LFP

LIB

LMO

NCA

$\mathrm{NiMH}$

NMC

NMP

OEM

SSB

VTO 



\section{EXECUTIVE SUMMARY}

The US Department of Energy (DOE) has a rich history of funding key innovations in batteries through multiple programs, including the Energy Efficiency and Renewable Energy programs sponsored by the Vehicle Technologies Office and Advanced Manufacturing Office. These DOE-sponsored innovations have been critical in lowering the cost of lithium-ion batteries to less than $\$ 160 / \mathrm{kWh}$ and increasing their energy density to more than $250 \mathrm{Wh} / \mathrm{kg}$, enhancing the nation's electrification system and achieving higher degrees of decarbonization. These investments continue to be crucial for positioning the United States as the hub for the most cumulative battery R\&D programs worldwide. However, major breakthroughs in battery manufacturing are still needed to enable an electrified future evolving to predominantly incorporate rechargeable lithium-ion batteries. This will require a strong battery manufacturing base that will not only enable cutting-edge advancements in materials and manufacturing sciences but will also allow the United States to become a world leader in this fast-growing area. This review aims at supporting DOE's Advanced Technology Vehicle Manufacturing Loan Program to give technology background and information that can be used to develop the basis for loan topics and evaluate battery applications. Such a program can represent a significant stride toward reinforcing the US position in advanced manufacturing by introducing artificial intelligence, machine learning, and sensing and smart controls to facilitate, expedite, and lead the battery industry by 2030 . 



\section{WHY THE UNITED STATES SHOULD ACT NOW}

The need for urgent and intensive actions in favor of manufacturing batteries in the United States is of utmost strategic importance to US national security. Eager to learn from the COVID-19 pandemic, the United States should seek independence in the battery manufacturing value chain (Figure 0.1). The US jobs and way of life are under significant threat by relying on foreign countries for battery manufacturing.. The United States can play to its manufacturing strengths and compete with battery firms around the world by leveraging its superiority in science and technology. Several offices in the US Department of Energy, including the Vehicle Technologies Office and Advanced Manufacturing Office, have portfolios of intellectual property that are ready to materialize. The 2019 Nobel Prize in Chemistry recognized the US foundation in lithium-ion batteries and awarded John Goodenough and Stanley Whittingham on their pioneering works for the development of lithium-ion batteries. However, because of its preexisting electronics industry, Southeast Asia claims an overwhelming market share of lithium-ion battery manufacturing. Japan's lithium-ion battery manufacturing dominance in the 1990s has been challenged by South Korea and later by China in the mid-2000s. According to BloombergNEF, in early 2019 , the global lithium cell manufacturing capcity was $316 \mathrm{GWh}$. China accounted for $73 \%$ of this capacity, followed by the United States at $12 \%$ of global capacity. According to forecasts from BloombergNEF, by 2030 , the battery market will be worth $\$ 116$ billion annually. Battery prices have fallen $87 \%$ to $\$ 156 / \mathrm{kWh}$ in 2019 in comparison with $\$ 1,100$ per kilowatt-hour in 2010. By 2030, average prices will be close to $\$ 60 / \mathrm{kWh}$, according to the latest forecast from BloombergNEF.

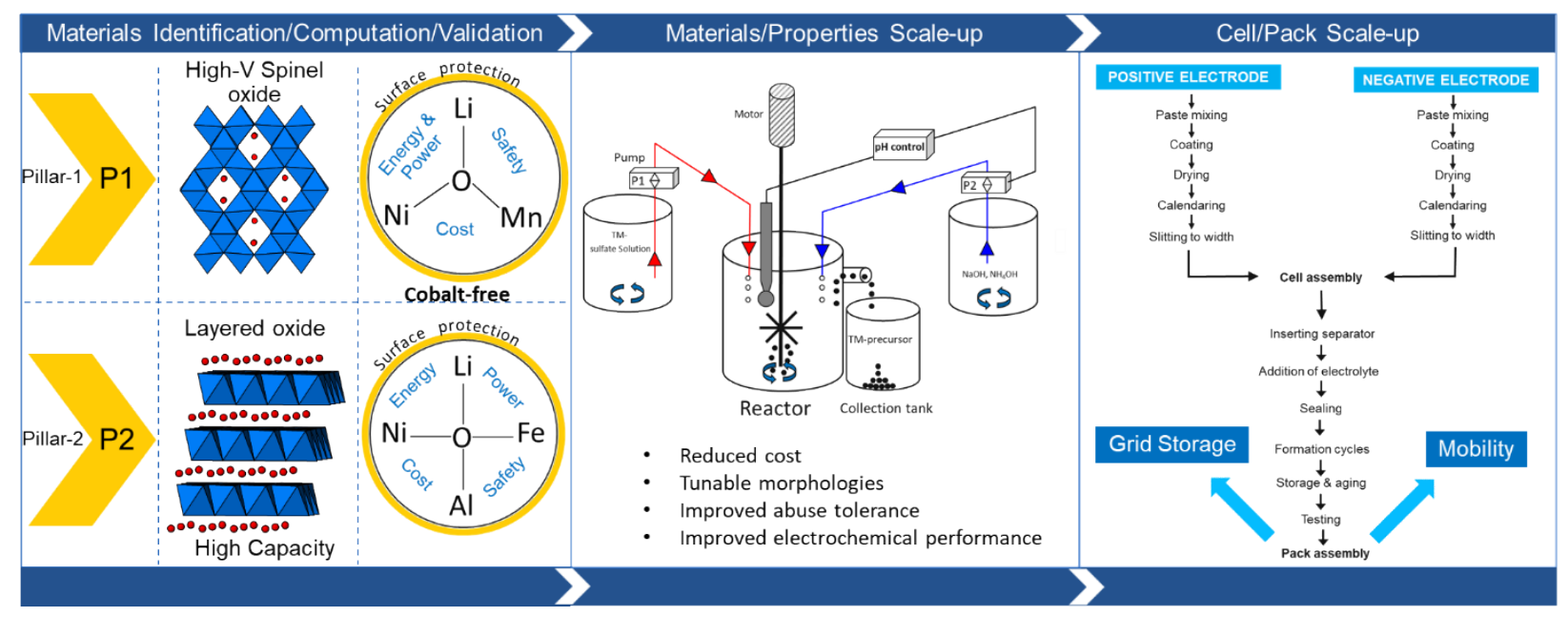

Figure 1.1. Oak Ridge National Laboratory streamlined battery R\&D focused on electric vehicle and grid batteries. 


\section{LITHIUM-ION BATTERIES: FUNDAMENTALS AND KEY PERFORMANCE ATTRIBUTES}

This section provides an overview and working principle of typical lithium (Li)-ion batteries (LIBs) with specific pefromance metrics quantifying their energy density, life and safety that will be frequently used in the following sections. Primarily, a LIB has three physical components: (i) a negative electrode, typically known as anode; (ii) a positive electrode, typically known as cathode, which stores or hosts Li ions; and (iii) a separator containing the liquid electrolyte, which shuttles Li ions between the cathode and anode during battery opertation. The liquid electrolyte is dispersed in all three components of the battery. The separator material is electrically insulating, preventing electrical shorts between the cathode and anode but is wetted by the liquid elelctrilyte to readily conduct $\mathrm{Li}$-ion between its pores. Figure 1.1 is a schematic illustration depicting the working mechanism of a LIB. The cathode described here is Li cobalt oxide $\left(\mathrm{LiCO}_{2}\right)$, which stores $\mathrm{Li}$ ions in the layer structure (green spheres). During the battery charge process, $\mathrm{Li}$ ions leave the cathode structure and transport to the anode through the separator via the liquid electrolyte. This process can be described by a simple chemical equation: $\mathrm{LiCoO}_{2}$ (LCO) $\square \mathrm{Li}_{1-\mathrm{x}} \mathrm{CoO}_{2}+$ $\mathrm{xLi}$, where $\mathrm{x}$ is the fraction of $\mathrm{Li}$ ions leaving the cathode host. Graphite is the prototypical anode material used for LIBs. Li ions are then inserted in the layered structure of graphite after leaving the cathode host as described in Figure 1.1 with the chemical equation $\mathrm{xLi}+6 \mathrm{C} \square \mathrm{xLiC}_{6}$. During the charge process, the electron moves externally via the circuit to the anode to maintain charge neutrality. During this operation, the voltage of the cathode (or positive electrode) gradually increases as shown by the red curve (right panel) with anode voltage (blue) concomitantly going down. The difference between the two voltages (red and blue) defines the cell voltage (Figure 1.1, right panel).
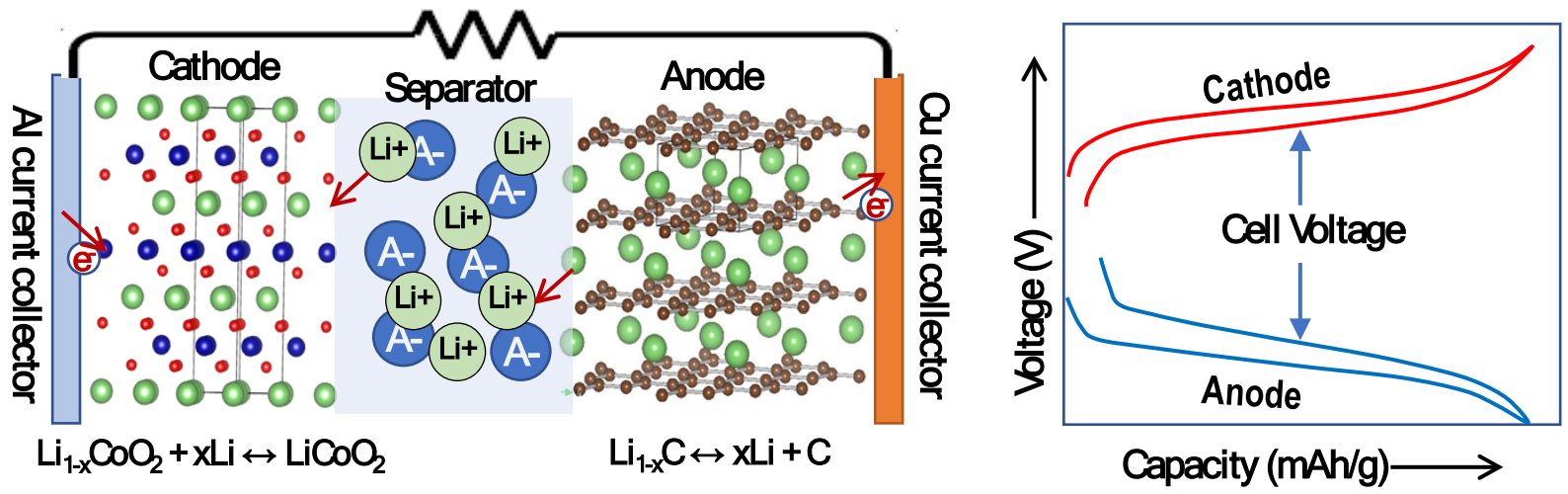

Figure 1.1. (left) Working principle of a LIB and (right) expected capacity as a function of cell voltage.

The discharge process is exactly the reverse, with Li ions leaving the graphitic host and getting back to the LCO through the porous separator with the electrons flowing back in the reverse direction. A single charge-discharge step is defined as one full cycle. The process of repeated ion insertion in LIB cathode and anode materials during charge and discharge is termed as "ion-intercalation." One of the major advantage of LIBs is that such an intercalation process can occur thousand of times without significantly damaging or altering the structure and/or compostion of the cathode or anode materials. The amount of electric charge that a LIB cathode or anode can potentially store is termed as "capacity," which is often expressed as specific capacity normalized either by weight (gravimetric) or volume (volumetric) of the material. The corresponding units in common use are then ampere-hours per kilogram $(\mathrm{Ah} / \mathrm{Kg})$ or ampere-hours per liter $(\mathrm{Ah} / \mathrm{L})$, respectively. The ratio of the discharge capacity to charge capacity is referred to as coulombic efficiency (CE), which is a quatitative measure of the cell efficiency. Typically, commercial LIBs for electric vehicle (EV; e.g., passenger vehicles, buses, medium- and heavy-duty hybrids, electric scooters) applications require a CE of $>99.99 \%$, implying that no Li inventory should be 
lost from parasitic or side reactions. Round-trip energy efficiency of a LIB is the product of CE and operating voltage of the cell. Energy density of a LIB is the product of the nominal cell voltage and the cell capacity expressed in the unit of Watt-hours per kilogram $(\mathrm{Wh} / \mathrm{Kg})$ or Watt-hours per liter $(\mathrm{Wh} / \mathrm{L})$. Another key attribute is the C-rate, which describes how fast the cell can deliver energy based on their nominal capacity. For example, a $1 \mathrm{C}$ rate means that the cell can be charged to full capacity in $1 \mathrm{~h}$. Power density of a cell or pack is describe in units of Watts per kilogram $(\mathrm{W} / \mathrm{Kg})$ or Watts per liter $(\mathrm{W} / \mathrm{L})$. Subsequent secions describe the specific LIB chemistries and materials with a detailed description of cell components providing a comparative landscape of state-of-the-art LIBs for EV applications.

\section{BRIEF HISTORY OF LIBS}

Over the past three decades, LIBs have successfully transitioned from a pure R\&D activity to mass-scale production for commercial applications, including portable electronics, EVs, and grid storage.[1] The foundation of this technology is based on the ion-intercalation reactions discovered in the 1970s to 1980s, wherein alkali metal ions (e.g., $\mathrm{Li}^{+}$) are reversibly stored in layered metal dichalcogenides and oxides (cathodes) and carbon (anodes).[2] These intercalation processes are chemically topotactic, making the ion-insertion process reversible for 1,000+ cycles without causing any chemical and/or structural damage to the host material. This phenomenal scientific breakthrough led to the invention of LIBs, and the 2019 Nobel Prize in Chemistry was awarded to Profs. John Goodenough, Stanley Whittingham, and Akira Yoshino, who pioneered the development of these systems. Figure 2.1 highlights significant events related to development of LIB materials.

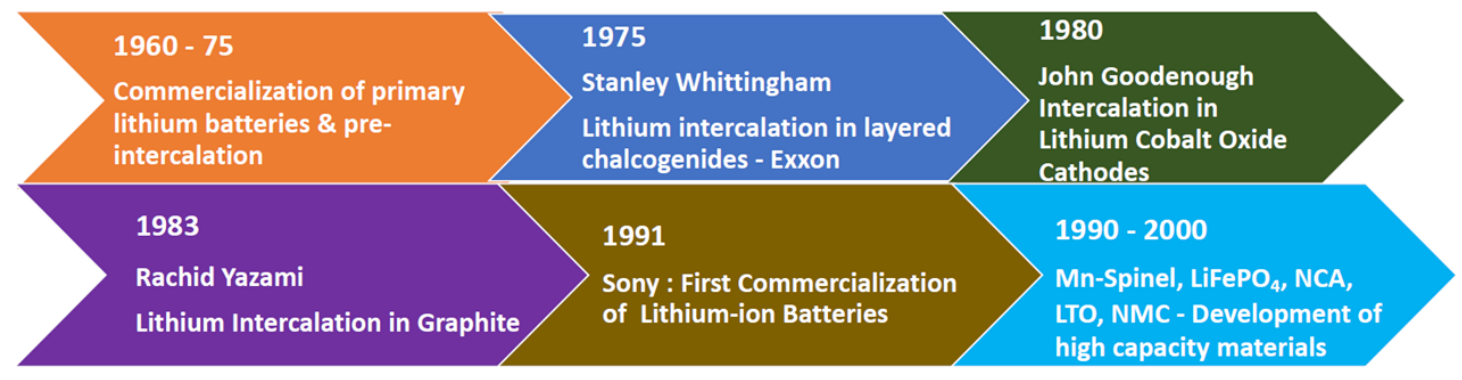

Figure 2.1. Significant events related to the development of LIB materials.

The birth of rechargeable LIBs started in the 1970s when researchers at Stanford University discovered that guest molecules can be intercalated into layered dichalcogenides such as $\mathrm{TiS}_{2}$ to increase their superconducting transition temperature.[3] Subsequently, researchers at Exxon led by Dr. M. Stanley Whittingham discovered that intercalation reactions also proceed electrochemically by electrolyzing dissolved salts or cycling ions between positive/negative electrodes. Among the various layer dichalcogenides, $\mathrm{TiS}_{2}$ was the best choice as an intercalation cathode because of the formation of $\mathrm{Li}_{\mathrm{x}} \mathrm{TiS}_{2}$ $(0 \leq \mathrm{x} \leq 1)$ solid solutions during discharge. Development of $\mathrm{TiS}_{2}$ cathodes ultimately led to commercialization of $\mathrm{Li}_{\mathrm{x}} \mathrm{Al} / \mathrm{TiS}_{2}$ batteries produced by Exxon.[4-5] In a parallel development, Yazami and Touzain demonstrated reversible Li intercalation in graphitic carbons, which offered improved cyclability compared with Li metal anodes plagued by unstable dendrite growth.[6] The period of 1980 to 1990 saw the emergence of layered oxides as positive electrode materials and large-scale commercialization attempts for LIBs. During this time, Goodenough and coworkers realized that layered oxides such as LCO have structures similar to layered dichalcogenides in which Li can be electrochemically removed and re-intercalated, making it a suitable cathode for high-energy density batteries.[7] The discoveries of Goodenough and Yazami led to the commercial debut of LCO/hardcarbon LIBs by Sony in 1991. This battery chemistry dominated the market until the development of mixed transition metal layered oxide cathodes (e.g., $\mathrm{LiNi}_{\mathrm{x}} \mathrm{Mn}_{\mathrm{y}} \mathrm{Co}_{1-\mathrm{x}-\mathrm{y}} \mathrm{O}_{2}[\mathrm{NMC}], \mathrm{LiNi}_{1-\mathrm{x}-\mathrm{y}} \mathrm{Co}_{\mathrm{x}} \mathrm{Al}_{\mathrm{y}} \mathrm{O}_{2}(\mathrm{NCA}$ ), 
and $\mathrm{LiNi}_{\mathrm{x}} \mathrm{Mn}_{\mathrm{y}} \mathrm{Al}_{\mathrm{z}} \mathrm{O}_{2}$ (NMA)), which led to further increases in battery energy density. Detailed cathode and anode chemistries and their performance metrics are discussed in the following sections.

\section{INNER WORKINGS AND COMPONENTS OF LIBS}

\subsection{SUMMARY OF BATTERY FORMATS/CONFIGURATIONS}

Current commercial cells adopt three design types to meet market demand, including cylindrical (spiral wound), prismatic (wound, flat plate, or stacked), and pouch cell designs [8-9] as shown in Figure 3.1. In all the cases, the construction consists of a 16-25 $\mu \mathrm{m}$ thick microporous separator between a positive and negative electrode. It is wound up using a cylindrical mandrel to form the "jelly roll" of a cylindrical cell. The case is typically Ni-plated steel, which is commonly used as the negative terminal. Cylindrical cells use five numbers for marking with the first two digits for the diameter in millimeters and the next three for the length in tenths of millimeters. For example, a 21700 cell is $21 \mathrm{~mm}$ in diameter and $70.0 \mathrm{~mm}$ in length. The most successful standard model of cylindrical cell is a 18650 cell, which can have a volumetric energy density of $\sim 650 \mathrm{Wh} / \mathrm{L}$. Cylindrical cells can have $\sim 20 \%$ higher energy density than prismatic/pouch counterparts because of the higher winding tension during assembly.[8] Tesla Motors' EVs use 18650 cells manufactured by Panasonic since 2013, which is by some accounts one of the most successful designs, yielding long calendar life and reliable performance in the automotive environment.[10]

Prismatic cells have the similar jelly roll as cylindrical cells, except it is wound up using a flat mandrel. Cell cases for prismatic cells have been made of Al, Ni-plated steel, and 304L stainless steel.[9] Prismatic cells are attractive in volume-sensitive applications because the size of the cells can be easily customized for the final product to efficiently use the available space. Prismatic cells use six digits for marking with the first two digits as the thickness in tenths of millimeters, the next two as the width in millimeters, and the last two as the length in millimeters. For example, a 504050 prismatic cell is $5.0 \mathrm{~mm}$ thick $\times 40 \mathrm{~mm}$ wide $\times 50 \mathrm{~mm}$ long.

Pouch cells are very similar to prismatic cells but with a more flexible Al polymer package, which consists of a trilayer of polypropylene/Al foil/polypropylene laminated together by heat. Typically, each positive and negative electrode has a tab, and the tabs are bundled and welded, respectively. The tabs protrude from the packaging after the plastic case is sealed. Nissan Leaf uses pouch cells with a rate capacity of $56.3 \mathrm{Ah}$ and nominal voltage of $3.65 \mathrm{~V}$. The energy density of the cell is $460 \mathrm{Wh} / \mathrm{L}$ and $224 \mathrm{Wh} / \mathrm{Kg}$.[11]

(a) Cylindrical

(b) Prismatic

(c) Pouch

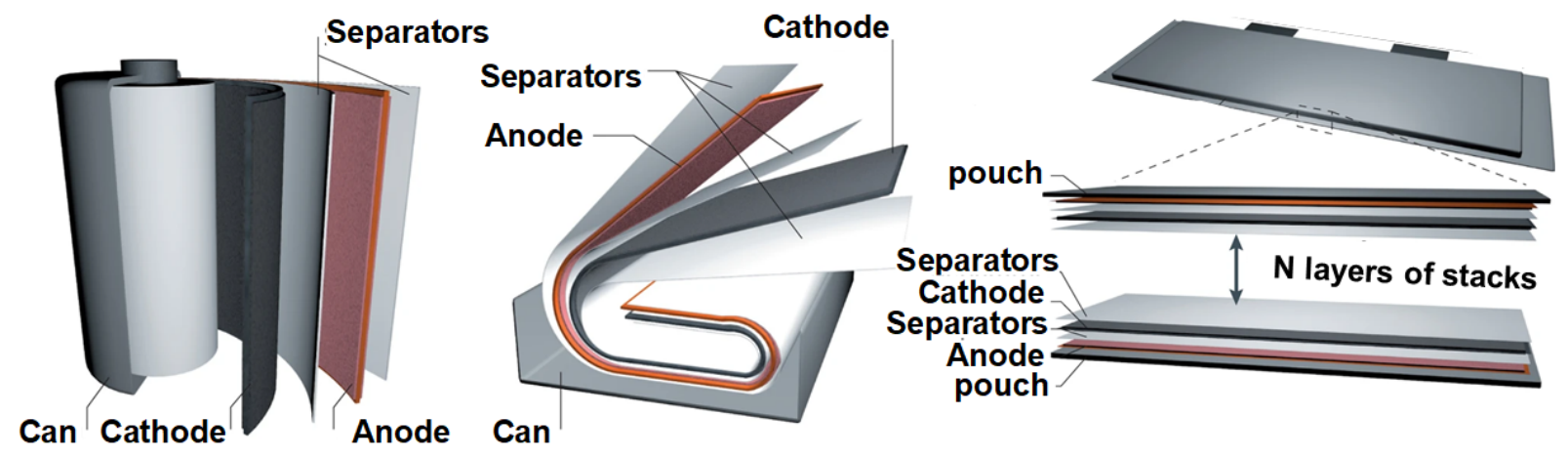

Figure 3.1. Three representative commercial cell structures: (a) cylindrical-type cell, (b) prismatic-type cell, and (c) pouch-type cell.[8] 


\subsection{KEY CELL COMPONENTS (CATHODE, ANODE, COLLECTORS, SEPARATORS, ELECTROLYTE)}

Although different cell formats are used in LIBs, there is not a large difference among the inner working mechanisms for a specific chemistry. Figure 3.1 shows the structure of a Li-ion cell with four of the essential components: a cathode coated on an Al current collector, an anode coated on a $\mathrm{Cu}$ current collector, a microporous separator, and an electrolyte filled in the pores. The cathode and anode materials are often called "active materials" and operate by incorporating Li reversibly in an intercalation process.

Cathode materials in state-of-the-art Li-ion cells use lithiated metal oxides or lithiated metal phosphate. The first generation of commercial cathode material is LCO, which was invented by Goodenough. Because of the cost and scarcity of $\mathrm{Co}$, less costly materials have been developed over the past three decades, such as $\mathrm{LiMn}_{2} \mathrm{O}_{4}(\mathrm{LMO}), \mathrm{LiNi}_{1-\mathrm{x}-\mathrm{y}} \mathrm{Mn}_{\mathrm{x}} \mathrm{Co}_{\mathrm{y}} \mathrm{O}_{2}$ (NMC), $\mathrm{LiNi}_{0.8} \mathrm{Co}_{0.15} \mathrm{Al}_{0.05} \mathrm{O}_{2}(\mathrm{NCA})$, and $\mathrm{LiFePO}_{4}$ (LFP). Co-free cathode materials have become a popular topic in recent research to minimize costs.[12] Cathode materials have several requirements to be satisfactory. They need to have high capacity because they are the source of all the active Li ions in a cell. The material also needs to have little structural change during reversible (de)intercalation so that long cycle life and high CE (the ratio of the discharge capacity to the charge capacity) can be achieved. For high-energy density cells, the material needs to have a high potential (vs. $\mathrm{Li}^{+} / \mathrm{Li}$ ), high specific capacity, and high packing density of the cathode and anode powders. The electrical drive range in EVs depends strongly of the energy density of the cell, both volumetric and massic; the higher the energy density, the longer the electrical drive. The structures of the commercially available materials can be categorized into three types: an ordered rock salt-type structure (NMC, NCA), a spinel-type structure (LMO), and an olivine-type structure (LFP). The ordered rock-salt structure is a layered structure in which the $\mathrm{Li}$ atoms, transition metal atoms, and oxygen atoms occupy octahedral sites in alternate layers as shown in Figure 3.1. Tesla has been using NCA materials in their EVs and recently filed a patent titled, "Method for Synthesizing Nickel-Cobalt-Aluminum Electrodes."[13]

Anode materials in many commercial cells use synthetic or natural graphite, which is available at a very low cost, and is usually highly graphitized to provide the highest specific capacity. As an excellent anode material, graphite has a high specific capacity (e.g., $\sim 2.5 \times$ higher than LCO), high volumetric capacity (around the same as LCO), low average voltage $(\sim 125 \mathrm{mV})$, low voltage hysteresis, good rate capability, low irreversible capacity, low volume expansion during lithiation, good cycle life, high CE, good electronic conductivity, and excellent densification properties in electrode coatings.[14] Graphite has a layered structure with the basic building block of graphene, which is a planar sheet of carbon atoms arranged in a hexagonal array. The graphene layers are stacked in a registered fashion by Van der Waals forces. When $\mathrm{Li}$ is intercalated into graphite, it is stored in between the graphene layers as shown in Figure 1.2. The next-generation anode materials are Si-based materials because of Si's higher capacity compared to graphite $(3,579$ vs. $372 \mathrm{mAh} / \mathrm{g})$. However, volume expansion in the materials is high and the electrolyte/electrode interface is unstable,[14] which has limited its commercialization. Currently, $<5$ wt \% Si has been incorporated into graphite electrode to boost the capacity. However, more R\&D efforts are still needed.[14]

Separators in Li-ion cells are thin $(16-40 \mu \mathrm{m})$ microporous films to electrically isolate the positive and negative electrodes.[9, 15-16] These microporous polyolefin materials are made of polyethylene, polypropylene, or the laminates of the two. Commercial separators have a thermal shutdown (fuse) capability as a safety feature. When the cell temperature increases, the separator can flow and fuse into a denser film by pore-closing. Therefore, the ionic conduction between the electrodes is stopped, which protects batteries from overheating or electrical shorting. In a recent development, a layer of refractory metal oxide (e.g., $\mathrm{Al}_{2} \mathrm{O}_{3}$ ) was coated onto the separator to improve the high-temperature operation 
because it can prevent the direct contact of the cathode and anode even if the polymer separator melts and flows.[17]

An electrolyte is used in Li-ion cells to fill the pores in the porous electrodes and separators. It carries the Li ions to shuttle back and forth between the cathode and anode. A liquid electrolyte consists of organic solvents (typically carbonates) with dissolved $\mathrm{Li}$ salt in them. $\mathrm{LiPF}_{6}$ is a widely used salt because of its well-balanced properties, such as high ionic conductivity and acceptable safety. Besides the requirement for interfacial stability on both the cathode and anode, solvents used for the electrolyte must simultaneously have high dielectric constants (to dissolve the salt) and low viscosity (to facilitate ion transport). Therefore, a mixture of several solvents is used with ethylene carbonate (EC) and a series of linear carbonates. Electrolyte and additive devolvement in future are needed to provide further improvement on interfacial stability, safety and fast charging capability.[18]

\section{LIB MATERIALS AND ELECTROLYTES}

Since their commercial debut in 1991 by Sony, LIBs have become ubiquitous in consumer devices ranging from portable electronics (e.g., cell phones, laptops, power tools) to EV propulsion. An emerging use for LIBs is electrical grid storage to facilitate adoption of renewable energy sources.[19] For a given application, the cell chemistry and electrode design must be optimized to meet power, energy, and cost constraints. Figure 4.1 highlights the electrochemical properties of a wide range of LIB anode and cathode active materials.[20] These materials store $\mathrm{Li}$ in their structure through reversible electrochemical reactions, including intercalation and conversion mechanisms. Brief discussions on these classes of material are provided in this section.

(a)

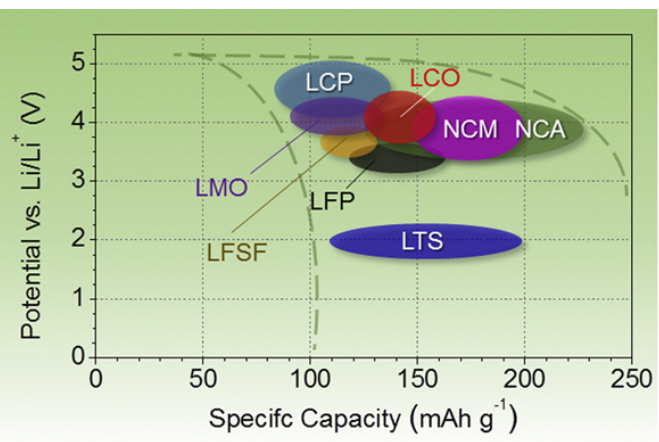

(c)

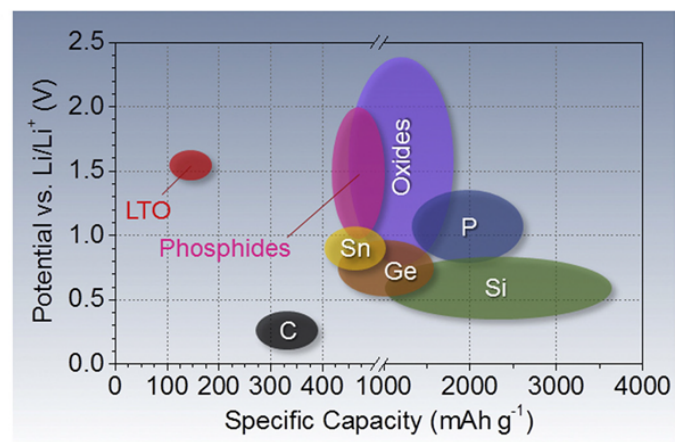

(b)

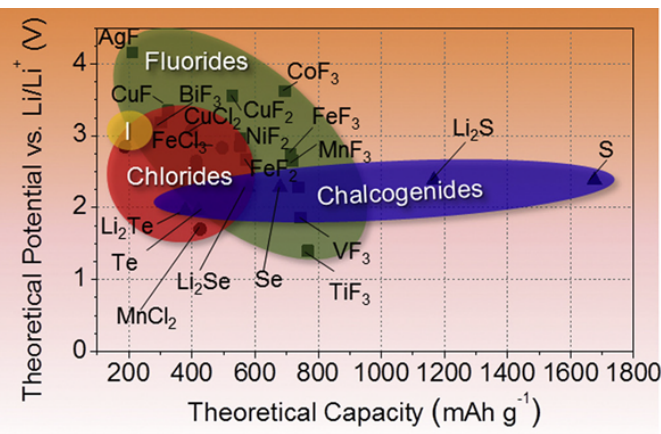

(d)

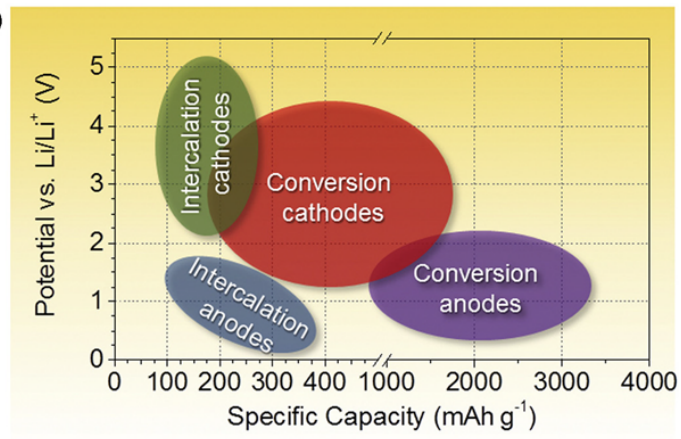

Figure 4.1. Specific capacity and operating potentials for (a) intercalation-type cathodes, (b) conversion-type cathodes, (c) conversion-type anodes, and (d) an overview of various anodes and cathodes. Image reproduced with permission from Nitta et al.[20] 


\subsection{CATHODE CHEMISTRIES}

Intercalation cathodes typically have a layered, spinel, or olivine structure containing redox-active transition metal cations, which are oxidized/reduced during Li removal/insertion.[1, 20] Layered compounds have the general formula $\mathrm{LiMO}_{2}$, where $\mathrm{M}$ is a transition metal and $\mathrm{Li}$ is stored between parallel $\mathrm{MO}_{2}$ layers (e.g., at 3a crystallographic sites in R-3m structures). LCO is the quintessential layered cathode and has a reversible capacity of $140 \mathrm{mAh} \mathrm{g}^{-1}$ available at $\sim 3.9 \mathrm{~V} \mathrm{vs}$. Li/ $/ \mathrm{Li}^{+}$. Although its theoretical capacity is $274 \mathrm{mAh} / \mathrm{g}$, only about half of the cathode's $\mathrm{Li}$ inventory (i.e., $\mathrm{Li}_{1-\mathrm{x}} \mathrm{CoO}_{2}, 0 \leq \mathrm{x} \leq$ $0.5)$ can be reversibly cycled. Extracting more Li from LCO collapses the crystallographic structure, leading to capacity loss and irreversibility.

Rapid development of Li intercalating oxides from 1990 to 2000 was primarily driven by the desire to replace Co, an expensive and limited resource. Development of spinel LMO cathodes was spearheaded by Thackeray and coworkers at the Council for Scientific and Industrial Research[21] and later by Tarascon's team at Bellcore.[22] The spinel structure is a variation of the common layered $\mathrm{NaFeO}_{2}$ structure with cubic close-packed oxygen anions only differing in the distribution of cations among the available octahedral and tetrahedral sites. Despite the relatively low specific capacity of LMO $(\sim 120$ $\mathrm{mAh} / \mathrm{g}$ ), its high rate capability secured its use in first-generation EVs containing LIBs (Chevy Volt and Nissan Leaf).

Layered cathodes based on pure $\mathrm{Ni}$ - or $\mathrm{Mn}$-based oxides (e.g., $\mathrm{LiNiO}_{2}$ and $\mathrm{LiMnO}_{2}$ ) were structurally unstable during extended cycling.[23-24] This limitation led to efforts from several groups around the world (Delmas, Dahn, Ohzuku, and others) developing mixed transition metal layered oxides such as $\mathrm{LiNi}_{1-\mathrm{x}} \mathrm{Mn}_{\mathrm{x}} \mathrm{O}_{2}, \mathrm{LiNi}_{1-\mathrm{x}-\mathrm{y}} \mathrm{Co}_{\mathrm{x}} \mathrm{Al}_{\mathrm{y}} \mathrm{O}_{2}$, and $\mathrm{LiNi}_{1-\mathrm{y}} \mathrm{Co}_{\mathrm{y}} \mathrm{O}_{2 \cdot[25-27]}$ Among these compositions, $\mathrm{LiNi}_{1-\mathrm{x}-\mathrm{y}} \mathrm{Co}_{\mathrm{x}} \mathrm{Al}_{\mathrm{y}} \mathrm{O}_{2}$, commonly known as "NCA," has been commercialized by SAFT, Panasonic, and Samsung for use in EVs and other markets. During the same time, numerous researchers from Japan were trying to develop cathode materials based on $\mathrm{Fe}$ oxides; however, $\mathrm{LiFeO}_{2}$-based cathodes exhibited sluggish reaction kinetics during Li extraction. The focus changed rapidly in 1997 when Padhi et al. reported reversible electrochemical activity for the olivine-phase LFP.[28] This finding opened up the potential for developing low-cost, earth-abundant, and environmentally safe LIB cathodes. LFP exhibits very stable electrochemical performance with a nominal discharge potential of $3.4 \mathrm{~V} \mathrm{vs}$. $\mathrm{Li} / \mathrm{Li}^{+}$and capacity of $170 \mathrm{mAh} / \mathrm{g}$. LFP is currently the dominant chemistry capturing the market for battery packs used in electric buses, power tools, and grid-scale storage.

A major limitation of $\mathrm{Ni} / \mathrm{Mn}$-based mixed oxide cathodes is cation mixing, in which $\mathrm{Li}^{+}$and $\mathrm{Ni}^{2+}$ swap positions in the layered structure, resulting in sluggish Li transport (rate performance) and low reversible capacity. Researchers discovered that a small amount of Co substitution can stabilize the structure to mitigate these antisite defects, leading to significant efforts toward optimizing the composition of NMC in terms of capacity, structural stability, and cycle life. One of the compositions, $\mathrm{LiNi}_{1 / 3} \mathrm{Mn}_{1 / 3} \mathrm{Co}_{1 / 3} \mathrm{O}_{2}$ (nominally called NMC333) ${ }^{[29]}$ exhibited a stable capacity of $\sim 150 \mathrm{mAh} / \mathrm{g}$ when charged to $4.2 \mathrm{~V}$ vs. $\mathrm{Li} / \mathrm{Li}^{+}$and very high initial capacities of $\sim 200 \mathrm{mAh} / \mathrm{g}$ when charged to $4.6 \mathrm{~V}$ vs. $\mathrm{Li} / \mathrm{Li}^{+}$, demonstrating

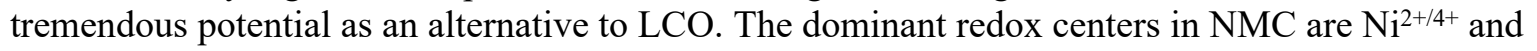
$\mathrm{Co}^{3+/ 4+}$, whereas Mn primarily remains electrochemically inactive with a stable oxidation state of $4^{+}$. Since the development of NMC333, researchers around the world have worked toward increasing the Ni content in NMC for the past two decades. These efforts have led to newer practical Ni-rich compositions cathodes with compositions including $\mathrm{LiNi}_{0.5} \mathrm{Mn}_{0.3} \mathrm{Co}_{0.2} \mathrm{O}_{2}$ ( $\mathrm{NMC532}$ ), $\mathrm{LiNi}_{0.6} \mathrm{Mn}_{0.2} \mathrm{Co}_{0.2} \mathrm{O}_{2}$ ( $\mathrm{NMC622}$ ), and $\mathrm{LiNi}_{0.8} \mathrm{Mn}_{0.1} \mathrm{Co}_{0.1} \mathrm{O}_{2}$ (NMC811).[30] NMC532 and NMC622 are currently used as the dominant cathode materials for several applications, including EVs. Key performance, safety, and cost metrics of representative Li-ion intercalation cathodes are compared in the radar plots shown in Figure 4.2. 

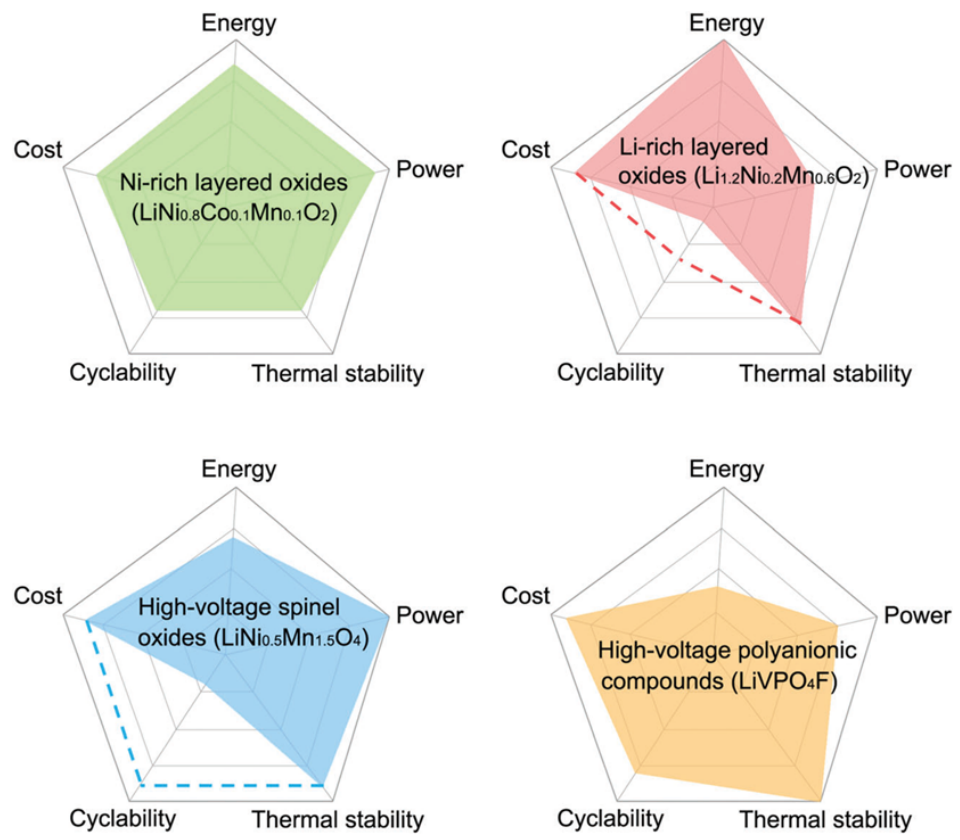

Figure 4.2. Radar plots showing key performance metrics for several Li-ion cathode chemistries. Dashed lines exhibit the cyclability of the two samples $\left(\mathrm{Li}_{1.2} \mathrm{Ni}_{0.2} \mathrm{Mn}_{0.6} \mathrm{O}_{2}\right.$ and $\left.\mathrm{LiNi}_{0.5} \mathrm{Mn}_{1.5} \mathrm{O}_{4}\right)$ obtained in Li-metal half cells. Image reproduced with permission from $\mathrm{Li}$ et al.[31]

Conversion-type cathodes have very high theoretical capacities because of multi-electron transfer processes (e.g., 1,675 mAh/g for S $+2 \mathrm{e}^{-}+2 \mathrm{Li}^{+} \leftrightarrow \mathrm{Li}_{2} \mathrm{~S}$; see Figure 4.1b).[20] However, these materials typically exhibit poor cycling stability because of low ionic/electronic conductivity of the active material and/or discharge products; large volumetric expansion/contraction during battery operation; and/or poor reversibility of the electrochemical reactions (e.g., $\mathrm{FeS}_{2}+4 \mathrm{Li}^{+}+4 \mathrm{e}^{-} \leftrightarrow \mathrm{Fe}+2 \mathrm{Li}_{2} \mathrm{~S}$ ). New synthesis and engineering approaches to resolve these issues must be developed for conversion materials to compete with the intercalation cathodes.

\subsection{ANODE CHEMISTRIES}

Most LIBs use carbonaceous anodes because of their moderate capacity (e.g., $372 \mathrm{mAh} / \mathrm{g}$ for graphite) and very negative operating potential $\left(<1 \mathrm{~V}\right.$ vs. $\left.\mathrm{Li} / \mathrm{Li}^{+}\right)$as shown in Figure 4.1c. The first commercial devices contained hard carbons with randomly oriented graphene layers where Li was stored between layers, at the edges of graphene planes, and on crystallite surfaces. Hard carbons typically suffer from poor first-cycle efficiency because of trapping Li in some sites; thus, highly ordered graphite anodes are used in most of today's commercial devices.[20, 32-33] Nanostructured carbons such as carbon nanotubes and graphene have attractive properties for use in LIB anodes because of their high surface area to volume ratio, high electronic conductivity, and good mechanical properties. However, these materials are not yet practical for widespread adoption because of their prohibitively high cost. Ti-based anodes in which the active material is either $\mathrm{TiO}_{2}$ or $\mathrm{Li}_{4} \mathrm{Ti}_{5} \mathrm{O}_{12}$ are attractive alternatives to carbon anodes because of their low volumetric strain during lithiation/delithiation (e.g., $0.2 \%$ for $\mathrm{Li}_{4} \mathrm{Ti}_{5} \mathrm{O}_{12}$ vs. $\sim 8 \%$ for graphite), which enables outstanding cycling stability; and high operating potential $\left(\sim 1.5-1.8 \mathrm{~V} \mathrm{vs.} \mathrm{Li} / \mathrm{Li}^{+}\right)$, which lies within the electrochemical stability of common liquid electrolytes and thus avoids solid-electrolyte interphase (SEI) layer formation.[34] These advantages are offset by the materials' lower energy density and ionic/electronic conductivities, which limit their rate capabilities.

Active materials, which electrochemically alloy with Li (e.g., Si, Ge, and Sn), have much higher capacities (theoretical values of 3,579, 1,600, and $994 \mathrm{mAh} \mathrm{g}^{-1}$, respectively) compared to intercalation- 
based compounds.[20] Of these alloying anodes, Si has received the most attention because of its earth abundance, low cost, and very negative operating potential $\left(<0.5 \mathrm{~V} v \mathrm{vs} \mathrm{Li} / \mathrm{Li}^{+}\right)$. Lithiation of $\mathrm{Si}$ is accompanied by an active material volumetric expansion $>300 \%$, and repeated expansion and contraction of Si during battery cycling results in capacity fade due to Si pulverization, Si electronic isolation, and formation of an unstable SEI layer. Although Si pulverization can be mitigated by using nanoscale active materials, effective electrode designs that prevent $\mathrm{Si}$ electronic isolation and unstable SEI layer formation are not yet developed.[35] Carbon/silicon composite anodes with low Si content ( $<10 \mathrm{wt} . \%)$ have been developed for commercial cells, but additional research is needed to resolve the aforementioned limitations in electrodes with high Si loadings.

\subsection{ELECTROLYTES}

The electrolyte is an ionically conductive/electronically insulating medium that transports $\mathrm{Li}^{+}$between electrodes during cycling. The electrolyte can be a liquid, solid (ceramic/polymer/composite), or gel.[3637] Liquids offer significant advantages because of their good wetting of porous electrodes for large electrode/electrolyte interfacial contact, high ionic conductivity (around $1 \times 10^{-2} \mathrm{~S} / \mathrm{cm}$ at room temperature), and simple processability. Therefore, most commercial cells contain a porous polyolefin separator soaked in a liquid electrolyte containing a Li-based salt (e.g., $\mathrm{LiPF}_{6}$ ) dissolved in a mixture of organic carbonates (e.g., EC and ethyl methyl carbonate). Various electrolyte additives (e.g., vinylene carbonate, fluoroethylene carbonate, biphenyl) have been developed to optimize device performance and safety.[36] Beyond liquid-based electrolytes, major advances have been made on solid-state electrolytes in the past 15 years as discussed in Section 11.

\section{FUNCTION AND CONTROL OF EV BATTERIES (VEHICLE-LEVEL SUMMARY)}

EVs are an important part in the transportation sector. However, the market penetration worldwide is still considerably low. One major barrier is the high cost of the battery pack in EVs, which currently accounts for $30-40 \%$ of the total EV cost.[38] Therefore, the cost of battery packs will be the controlling factor in the future of EVs to be economically available to consumers.

Figure 5.1 reprsents a schematic of the main components of an EV powertrain where the electric motor plays the role of converting the electrical energy to mechanical energy. A battery pack is the power source of an EV, which consists of individual modules and cells organized in parallel and/or series as shown in Figure 5.2. A cell is the basic unit that stores and releases energy electrochemically by charging and discharging. A typical cell (NMC622/graphite) has a voltage of $\sim 3.7 \mathrm{~V}$ and energy level of $\sim 220 \mathrm{Wh} / \mathrm{kg}$ and $\sim 540 \mathrm{Wh} / \mathrm{L}$. [39] Here, the cell volumetric energy is much more important than gravimetric considerations for EV battery pack designs. A certain number (which varies by manufacturer and cell type) of cells are put into a case with attached terminals to form a battery module, ${ }^{[40]}$ which can protect the cells from external shocks, heat, or vibration.[41] Battery packs are the final products from EV battery manufacturing, which consist of a series of modules, electrical connections, a battery management system, and cooling equipment. A typical battery pack can have $\sim 76.5 \mathrm{kWh}$ energy, $\sim 260 \mathrm{~kW}$ power, $\sim 900 \mathrm{~V}$ voltage, and a pack level energy density of $\sim 177 \mathrm{Wh} / \mathrm{kg}$ and $\sim 312 \mathrm{Wh} / \mathrm{L}$.[39] Table 5.1 lists the battery packs in some EVs. Because the battery pack is the ultimate power source for EV, the R\&D focus on efficient design and structure of packs/modules is also increasing besides the R\&D on battery materials and cell development. ${ }^{[42-44]}$ The design of the battery pack depends significantly on the dimensions of the products, the interconnecting circuits, safety, and temperature control aspects. The slimness of a pack can determine if the design of an EV can be more or less stylish. ${ }^{[41]}$ 


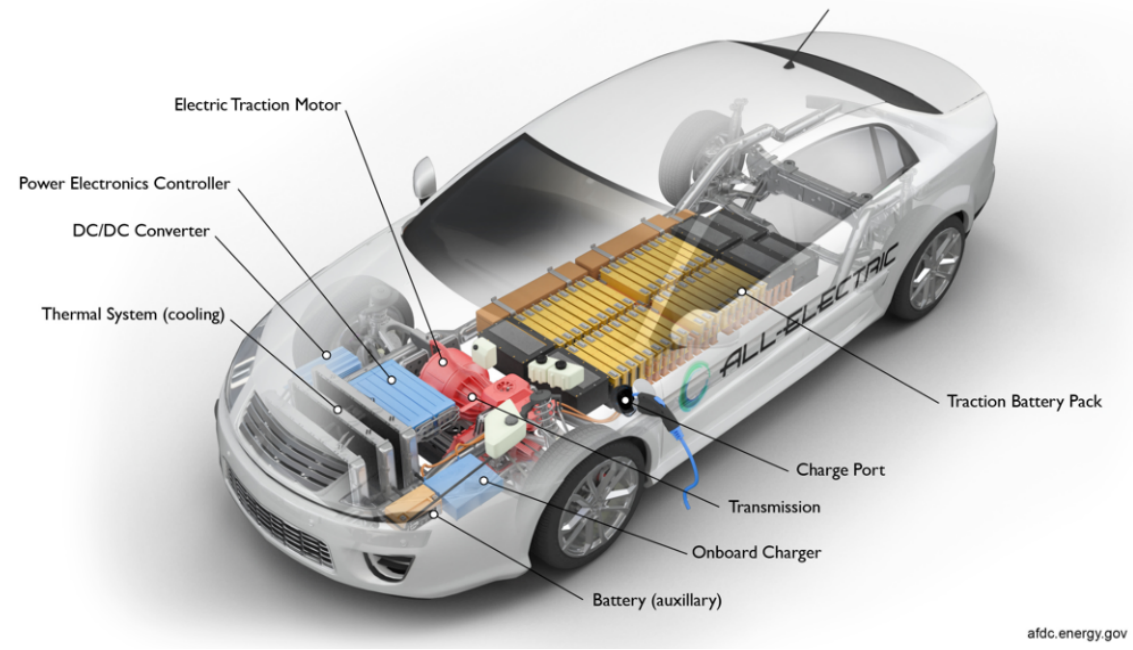

Figure 5.1. Schematic of a typical EV power train illustrating power electronic controllers, converters, and auxiliary battery management.
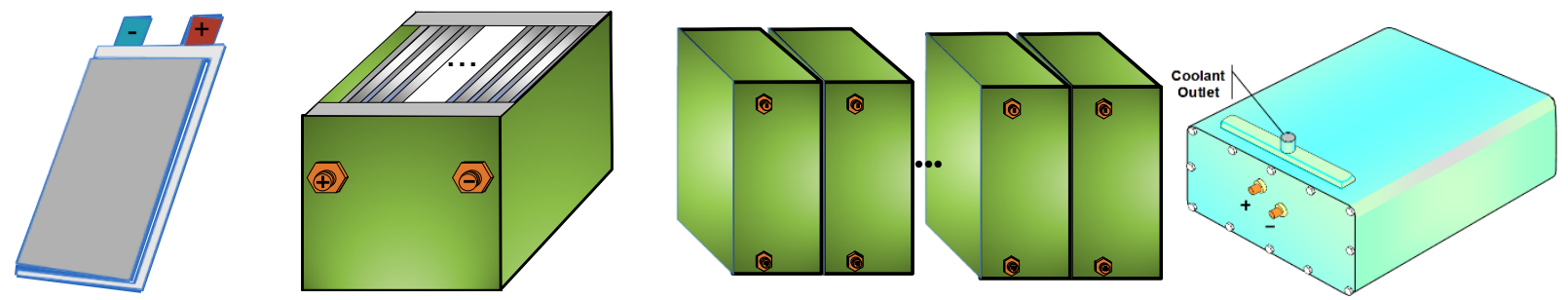

Figure 5.2. Illustration of a pouch cell, module, battery pack, and a liquid-cooled battery pack.

Table 5.1. Battery pack parameters of EVs.

\begin{tabular}{llllll}
\hline \multicolumn{1}{c}{ OEM } & Car Model & Pack energy $(\mathbf{k W h})$ & $\begin{array}{c}\text { Nominal range } \\
(\mathbf{m i l e s})\end{array}$ & Voltage (V) & Cell geometry \\
\hline BMW & i3 & 42.2 & 153 & 360 & Prismatic \\
Chevrolet & Bolt & 60 & 238 & 350 & Prismatic \\
FIAT & $500 \mathrm{e}$ & 24 & 84 & 364 & Prismatic \\
Nissan & Leaf & 66 & 259 & 350 & Pouch \\
Tesla & Model 3 & 75 & 322 & 350 & Cylindrical \\
VW & e-golf & 35.8 & 144 & 323 & Prismatic \\
\hline
\end{tabular}

\section{BRIEF HISTORY OF BATTERY TECHNOLOGIES USED IN EVS}

Battery-powered cars are not a modern invention. The first EV dates back to the 1830s by Scottish inventor Robert Anderson. By the end of the nineteenth century, EVs had sizeable growth and volume compared with vehicles powered by steam and internal combustion engines. The first generation EVs used lead-acid batteries until 1901, when Thomas Edison introduced Ni-Fe batteries. However, Ni-Fe cells had low CE (as low as 50\%) and a high self-discharge rate. For the next half-century, EVs were almost nonexistent because of widespread adoption of internal combustion engine-powered cars, which were facilitated by the invention of the electric starter that replaced manual cranking and improved road 
conditions, higher engine efficiency, and cheap crude oil. The oil crisis in the 1970s again revived interest in EVs, and models such as Sebring Vanguard's CitiCar had a driving range of 50 to 60 miles. Further motivated by environmental considerations, several legislative incentives in the 1980s and 1990s led to new EV battery chemistries, including molten salt (Na-S)[45] and ZEBRA batteries.[46] These technologies had several advantages over lead-acid batteries, including nearly 4-times higher energy density, significantly higher CE, and lower self-discharge rates. Several EV models using variants of Na$\mathrm{S}$ chemistries were introduced by automotive original equipment manufacturers (OEMs; e.g., BMW E1\&E2 and Ford Ecostar), but high-temperature operation, reactivity, and corrosion marred their further commercialization prospects. The 1990s saw development of Ni metal hydride (NiMH) batteries with specific energies up to $120 \mathrm{Wh} / \mathrm{kg}$, which enabled EVs with driving ranges up to 100 miles on a single charge. Full EVs, such as the General Motors EV1 and Toyota RAV4EV, were developed based on NiMH battery packs, but NiMH became more popular for hybrid electric vehicles. The hybrid electric vehicle market experienced rapid growth with popular models, including the Ford Escape Hybrid and Toyota Prius.

The modern era of EVs began with the development and commercialization of intercalation-based rechargeable LIBs in 1991 by Sony.[47] The next three decades witnessed rapid growth in LIBs with improved energy density, safety, cycle life, and lower costs (details discussed in Section 5). Over the years, the US Department of Energy's (DOE's) Vehicle Technologies Office (VTO), in association with the US Advanced Battery Consortium, a joint consortium between DOE and US Automakers (GM, Ford, FCA, and Tesla), developed a technical road map for LIB-powered EVs. Figure 6.1 shows current stateof-the-art LIB technologies with performance and cost projections through 2022.[48]

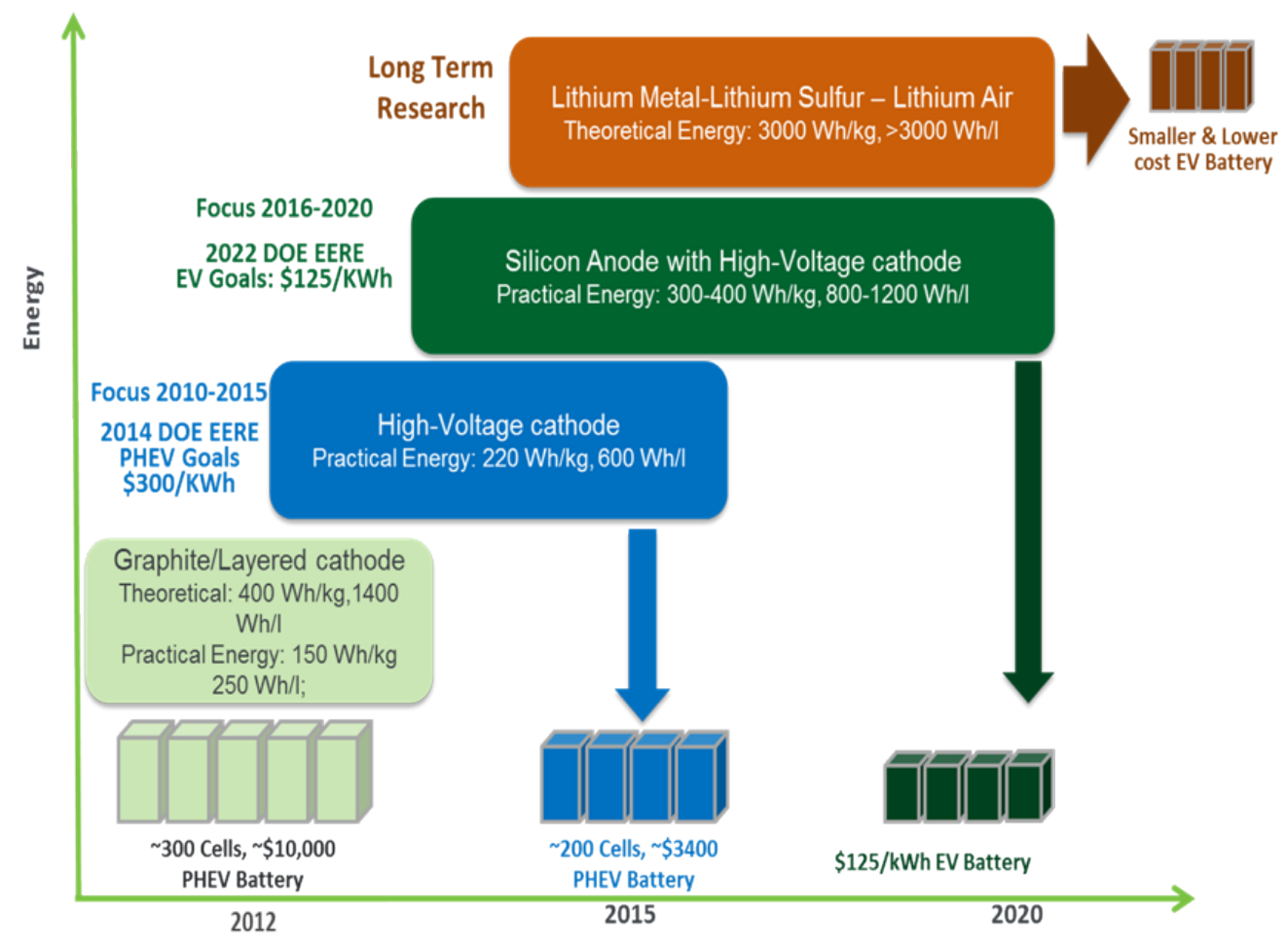

Figure 6.1. DOE technology roadmap for EVs for 2022 and beyond. Courtesy of David Howell and Brian Cunningham: VTO-Office of Energy Efficiency and Renewable Energy, DOE.

LIBs based on transition metal oxide cathodes (Mn-spinel, NCA, NMC) and graphite anodes have achieved cell-level specific energies of $220 \mathrm{Wh} / \mathrm{kg}$, giving EVs with driving ranges of 100 to $250+$ miles 
on single charge depending on the battery module size and vehicle type.[49] Higher-energy density LIBs containing Si-based anodes and state-of-the-art high voltage cathodes can further reduce cost and increase EV range (Figure 6.1). Advances in Li-S and all-solid-state batteries (SSBs) are part of a long-term R\&D strategy to further improve battery performance and cost metrics.[37, 50] Beyond development of new cell chemistries, rapid advances in cell and pack design, power electronics, and battery management systems have dramatically reduced cost from $\sim \$ 340 / \mathrm{kWh}$ in 2015 to $\sim \$ 125 / \mathrm{kWh}$ in 2020 . Table 6.1 shows several EV models from OEMs as of 2017 along with number of units sold, estimated battery pack costs, and manufacturing location.[40]

Table 6.1. EV models from OEMs as of 2017. Source: Journal of International Commerce and Economics, 2018, United States International Trade Commission. Battery size is given in units of $\mathrm{kWh}$.

\begin{tabular}{lrrllrr}
\hline Vehicle model & $\begin{array}{r}2017 \text { unit } \\
\text { sales }\end{array}$ & $\begin{array}{r}\text { Battery } \\
\text { size }\end{array}$ & $\begin{array}{l}\text { Battery pack } \\
\text { assembly }\end{array}$ & $\begin{array}{l}\text { Cell } \\
\text { manufacturing }\end{array}$ & $\begin{array}{r}\text { Battery cost } \\
\text { per vehicle }(\$)\end{array}$ & $\begin{array}{r}\text { Total value added } \\
(\$)^{d}\end{array}$ \\
\hline Tesla Model S & 27,060 & 75.0 & United States & Japan & $14,250^{\circ}$ & 6,413 \\
\hline Tesla Model 3 & 1,772 & 50.0 & United States & United States & $9,500^{\circ}$ & 4,275 \\
\hline Tesla Model X & 21,315 & 75.0 & United States & Japan & $14,250^{\circ}$ & 6,413 \\
\hline Ford Focus Electric & 1,817 & 33.5 & United States & United States & $7,002^{\circ}$ & 3,151 \\
\hline Chevy Bolt & 23,297 & 60.0 & United States & South Korea & $12,500^{\circ}$ & 5,625 \\
\hline Fiat 500e & 5,380 & 24.0 & United States & United States & $5,016^{\circ}$ & 2,257 \\
\hline VW e-Golf & 3,534 & 35.8 & Hungary & South Korea & $7,482^{\circ}$ & 3,367 \\
\hline BMW i3 & 6,276 & 22.0 & Hungary & South Korea & $4,598^{\circ}$ & 2,069 \\
\hline Nissan Leaf & 11,230 & 26.0 & United States & United States & $5,434^{\circ}$ & 2,445 \\
\hline Kia Soul EV & 2,157 & 27.0 & South Korea & South Korea & $5,643^{\circ}$ & 2,539 \\
\hline
\end{tabular}

In 2019, about 2.2 million plug-in EVs were sold worldwide (Figure 6.2), among which 74\% were pure EVs with the Tesla Model S alone selling over 367,000 units. ${ }^{[51]}$ Estimates predict that LIB costs should be brought down to $\$ 80 / \mathrm{kWh}$ at a pack level to be competitive with gasoline-powered drive trains. ${ }^{[2-53]}$ Developing fast-charging batteries and widespread charging infrastructure are also needed for rapid market penetration of EVs. 


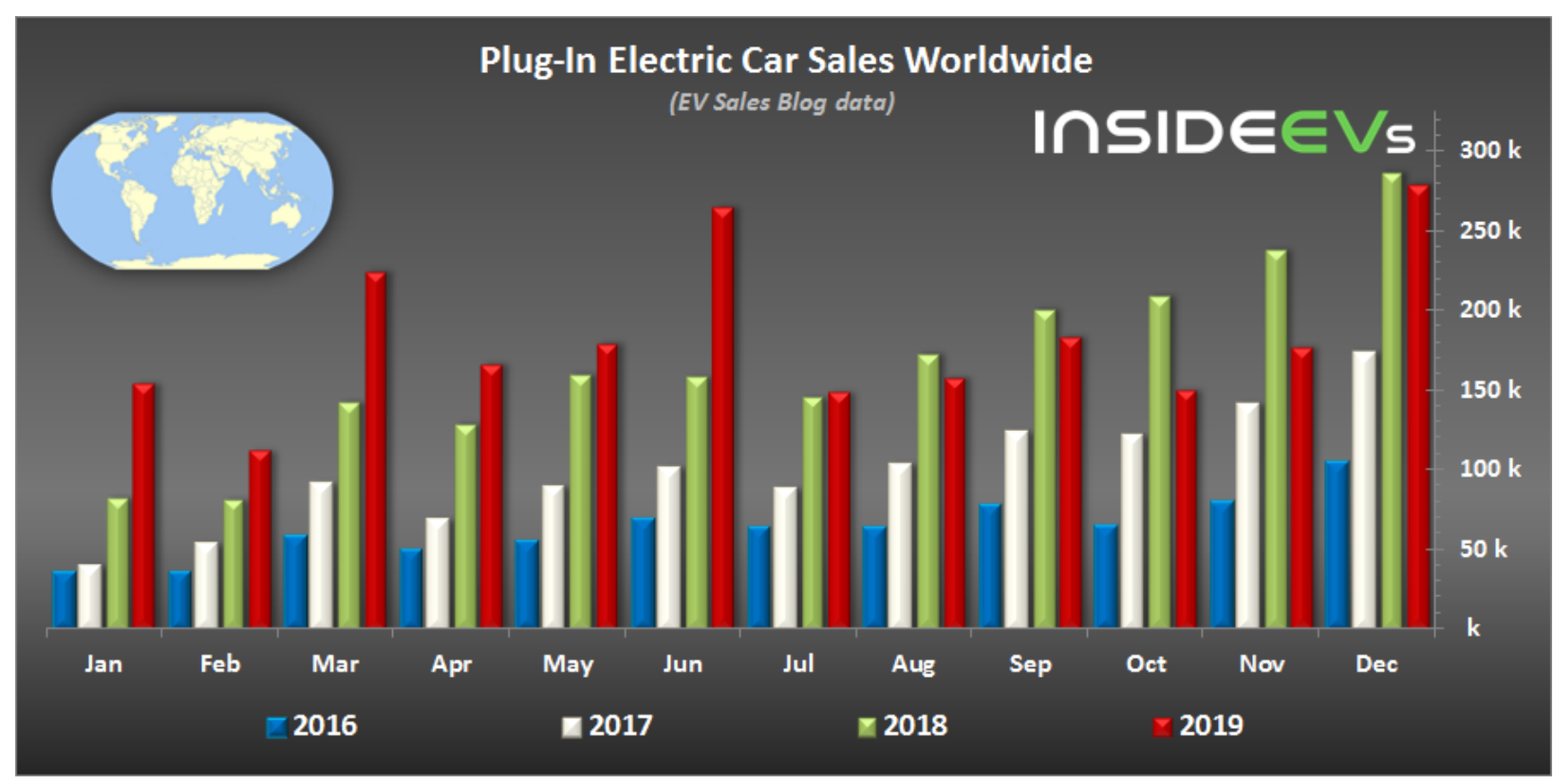

Figure 6.2. Monthly global sales of plug-in EVs from 2016 to 2019. Source: EV Sales Blog.

\section{SPECIAL CONSIDERATION TO AUTOMOTIVE APPLICATIONS}

Application of LIBs in EVs relies on several factors: high energy density ensuring driving range, acceptable battery cost to be comparable with internal combustion engine for life cycle, relatively fast charging time, enhanced safety, and so on. Tremendous progress has been achieved since LIBs were first commercialized in early $1990 \mathrm{~s}$. Specifically, from 2008 to 2015, the battery pack cost has been reduced from $\$ 1,000 / \mathrm{kWh}$ to $\$ 268 / \mathrm{kWh}$ with a simultaneous increase in battery pack energy density from 55 to $295 \mathrm{Wh} / \mathrm{L}$. The progress was realized by advancements in material development and cell engineering. On the material side, high-voltage and high-energy cathode materials, such as Ni-rich NMC, were used to replace LCO. Si is also being added to graphite anodes to increase the anode capacity. Advancement on the engineering side is even more pronounced, which significantly increased the active material contents in the electrodes and expanded the operation window of the cells, increasing the portion of usable energy. Nevertheless, battery cost needs to be further reduced to at least $\$ 150 / \mathrm{kWh}$ to enable battery EVs to become cost-competitive with internal combustion vehicles. The US Advanced Battery Consortium's targets for battery packs for EVs are $\$ 125 / \mathrm{kWh}, 235 \mathrm{Wh} / \mathrm{kg}$, and $500 \mathrm{Wh} / \mathrm{L}$ by 2020.[54] The continuous increase in energy density and size of the cells presents challenges to battery safety and requires even further advancement in safety improvement.

\subsection{SAFETY}

Battery safety is one of the most important aspects for EV application. The safety of batteries is enhanced and ensured in various ways. Within a cell, a shutdown separator is the main component responsible for safety, which melts at elevated temperatures $\left(120-150^{\circ} \mathrm{C}\right)$, blocks the pores, stops Li ions from transporting between the anodes and cathodes, and shuts down the cells before catastrophic failures takes place. Controlling the operating voltage and temperature is another way to enhance battery safety. Additional safety components can be used to prevent thermal runaway, such as a positive thermal coefficient barrier layer, current interruption device, shear thickening electrolyte, thermal fuses, vents, and breakable current collectors/electrodes. These safety mechanisms respond to a critical temperature or current and shut down an entire cell under failure conditions. Battery safety is also enhanced by encapsulating the cells/packs in a solid case, which serves as a mechanical safeguard and provides 
protection upon mechanical impact. The devices providing safety features induce additional weight, volume, and cost to the LIBs and may offset some benefits from the high-voltage and high-energy density chemistries, which tend to have lower stability.

\subsection{THERMAL MANAGEMENT}

Temperature significantly affects LIB performance. For example, when charged at low temperature, the LIB will have reduced capacity and CE, which accelerates cell degradation. Low temperature results in lower conductivity of electrolyte, higher charge-transfer resistance and slower reaction rate of the redox reaction. All these resulted in high resistance and lower capacity and power.[55] The low temperature can also facilitate lithium plating, which reduces battery capacity and poses safety concern.[56] It has been reported that, when reducing temperature from $25^{\circ} \mathrm{C}$ to $-40^{\circ} \mathrm{C}$, the power and energy densities of Parasonic $18650 \mathrm{LIBs}$ decreased from $800 \mathrm{~W} / \mathrm{L}$ and $100 \mathrm{Wh} / \mathrm{L}$ to $10 \mathrm{Wh} / \mathrm{L}$ and $5 \mathrm{Wh} / \mathrm{L}$, respectively.[57]

Meanwhile, operating at increased temperatures can also result in reduced capacity and accelerated capacity fade. Moreover, high temperature can have serious implications for safety, with thermal runaway being a major concern. The battery temperature is controlled by a battery thermal management system (BTMS), the purpose of which is to dissipate heat timely and maintain the battery temperature within an appropriate range. Effectively managing heat can enhance performance, range, charging, longevity, and safety. Heat generated in LIBs can ben generally categorized into three types - activation irreversible heat from the electrochemical reaction polarization, joule heating causing ohmic losses, and reversible reaction heat from entropy change during charging and discharging. When increasing energy of LIBs, which means more energy is packed in the LIBs, the amount of heat generated during operation can be significant.

Although thermal management is a key consideration for any EV, there is no consensus on the best design because of the diversity of configurations in EVs. Battery cooling systems can be classified in various ways - air cooling, liquid cooling, and phase change material cooling — based on medium.[58] The systems can also be divided by power consumption into passive cooling — only uses the ambient environment and active cooling - which relies on an energy source to provide cooling based on power consumption;[59] direct cooling; and indirect cooling, depending on whether the medium is in direct contact with the battery or not.[60] The BTMS can also be divided into two main groups: BTMS with or without the vapor compression cycle. Figure 7.1 shows the schematics of the various cooling systems. Detailed information can be found from Kim et al.[61]

Selecting an appropriate BTMS depends on many factors, including the battery configuration, size, capacity, energy, charge/discharge rate, and so on. Table 7.1 compares the advantages and disadvantages of the various cooling systems. 


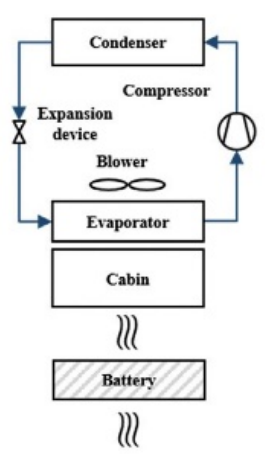

(a) Cabin air cooling system

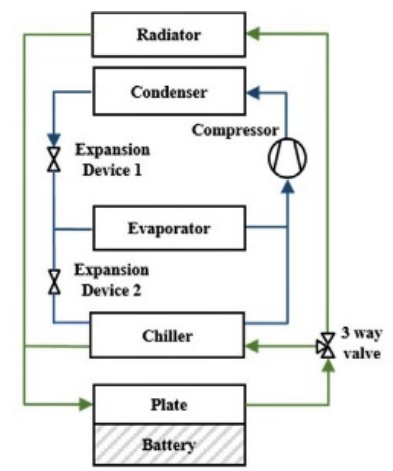

(b) Secondary loop liquid cooling system
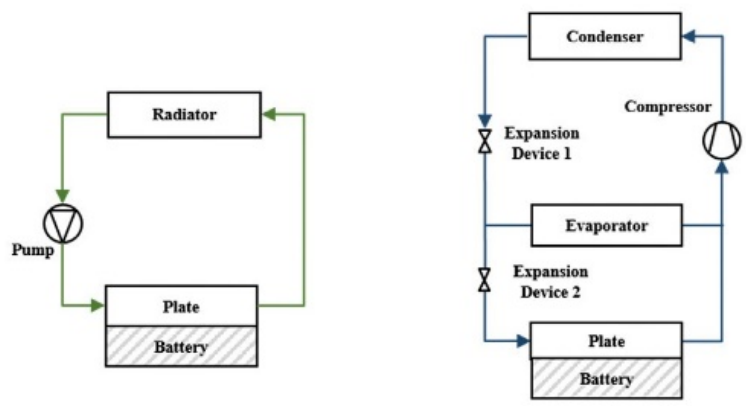

(c) Radiator liquid cooling system (d) Direct refrigerant two-phase cooling

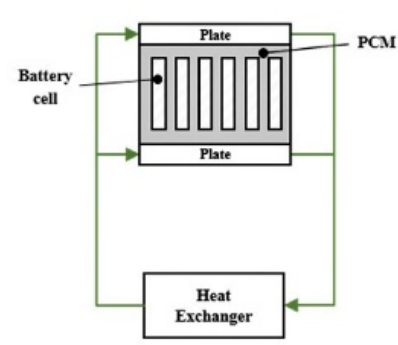

(e) Phase change material cooling system

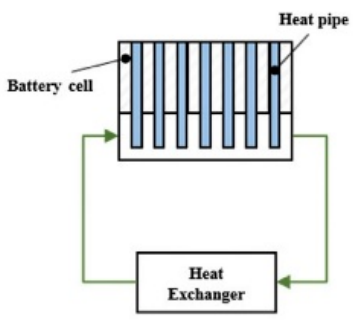

(f) Heat pipe cooling system

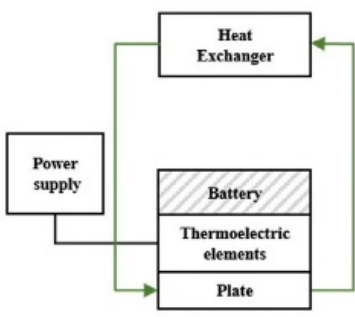

(g) Thermoelectric element cooling system

Figure 7.1. Schematics of the various battery cooling systems (reprinted with copyright permission from Elsevier).[61]

Table 7.1. Comparison of various cooling systems.

\begin{tabular}{lll}
\hline \multicolumn{1}{c}{ Cooling systems } & \multicolumn{1}{c}{ Advantages } & \multicolumn{1}{c}{ Disadvantages } \\
\hline Cabin air cooling system & $\begin{array}{l}\text { Simple structure, low cost, easy maintenance, } \\
\text { high reliability } \\
\text { Higher heat capacity from the liquid coolant, } \\
\text { enabling dissipating heat quickly and } \\
\text { maintaining proper battery temperature; } \\
\text { capable of cooling and heating batteries } \\
\text { system }\end{array}$ & $\begin{array}{l}\text { Low cooling performance } \\
\text { Complex system with increased } \\
\text { risk of leakage }\end{array}$ \\
$\begin{array}{l}\text { Direct refrigerant two- } \\
\text { phase cooling system }\end{array}$ & $\begin{array}{l}\text { Higher cooling rate; more compact than the } \\
\text { secondary loop cooling system }\end{array}$ & $\begin{array}{l}\text { Large power consumption } \\
\text { Phase change material } \\
\text { cooling system }\end{array}$ \\
$\begin{array}{l}\text { Capable of containing high latent heat; no } \\
\text { energy consumption }\end{array}$ & $\begin{array}{l}\text { Unable to continuously respond to the } \\
\text { thermal load, volume change, low } \\
\text { thermal conductivity }\end{array}$ \\
$\begin{array}{l}\text { Heat pipe cooling system } \\
\text { Thermoelectric element } \\
\text { cooling system }\end{array}$ & $\begin{array}{l}\text { required } \\
\text { Compact size with moderate weight, low } \\
\text { maintenance effort, wide operating } \\
\text { temperature range, high reliability, noiseless, } \\
\text { long life }\end{array}$ & $\begin{array}{l}\text { Low capacity and efficiency; small } \\
\text { contact area }\end{array}$ \\
\hline
\end{tabular}




\section{GLOBAL SUPPLY CHAIN FOR LIB RAW MATERIALS}

\subsection{RAW MATERIALS TO SUBCOMPONENTS}

Most of the world's supply of raw materials, chemical precursors, active and inactive materials (subcomponents), electrodes, and finished cells are not sourced from or manufactured in the United States. Active materials, cell subcomponents, and finished cells are generally produced in Asia (Japan, South Korea, and China) and exported around the world to pack assembly plants managed by OEMs in the consumer electronics and transportation industries. The United States heavily depends on raw materials and subcomponent imports for cell manufacturing at the few US cell manufacturing plants.[6263] The major elements used in manufacturing are $\mathrm{Li}, \mathrm{C}, \mathrm{F}, \mathrm{Al}, \mathrm{Si}, \mathrm{P}, \mathrm{Mn}, \mathrm{Fe}, \mathrm{Co}, \mathrm{Ni}$, and $\mathrm{Cu}$, and they are sourced from mines and ores located in specific geographic regions around the world.

Raw materials and precursors are used to make subcomponents consisting of current collectors, electrode active materials, electronically conducting additives, electrode binders, and polymer separators. Electrodes are then made by combining various subcomponents in a controlled manner to make anodes supported on $\mathrm{Cu}$ current collector foils and cathodes supported on $\mathrm{Al}$ current collector foils with a polyolefin separator film in between. The most important parts of a LIB cell are the electrodes because they are where the electrochemical reactions occur. Anodes and cathodes are made by dispersion or slurry, in which the solvents, active materials, conductive carbon additive, and binder are mixed together uniformly, coated onto the current collectors (typically by slot-die coating), and dried to form a consolidated electrode film (see Figure 10.1). In industry, the anodes and cathodes are made by coating both sides of the metal foils to give double-side electrodes. The LIB subcomponents and raw materials that comprise them are listed as follows:

- $\mathrm{Cu} \rightarrow$ anode current collector

- Graphite (natural and/or synthetic) $\rightarrow$ anode active material

- Polyolefins (polyethylene and/or polypropylene) $\rightarrow$ separator and pouch cell housing material

- $\mathrm{Li}, \mathrm{Ni}, \mathrm{Mn}, \mathrm{Co}, \mathrm{Fe}, \mathrm{Al}$ (and combinations thereof) $\rightarrow$ cathode active material

- $\mathrm{Al} \rightarrow$ cathode current collector foil, cathode tab, pouch cell housing material

- Styrene butadiene rubber $\rightarrow$ anode binder

- Fluoropolymers, acrylate latexes, carboxymethyl cellulose $\rightarrow$ cathode binders

- Carbon black $\rightarrow$ anode and cathode electronically conductive additive

- $\quad \mathrm{Ni} \rightarrow$ anode tab

- Deionized water $\rightarrow$ anode electrode processing aide

- $\quad \mathrm{N}$-methyl-2-pyrrolidone (NMP) $\rightarrow$ cathode electrode processing aide

- Stainless steel $\rightarrow$ cylindrical cell housing material

Figure 8.1 shows a cost breakdown for the major LIB subcomponents, which shows that the anode and cathode active materials, $\mathrm{Cu}$ foil, electrolyte, and separator are the most expensive components. The mass breakdown of the main subcomponents is shown in Figure 8.2 relative to a $1 \mathrm{~kg}$ of NMC622 cathode material. 


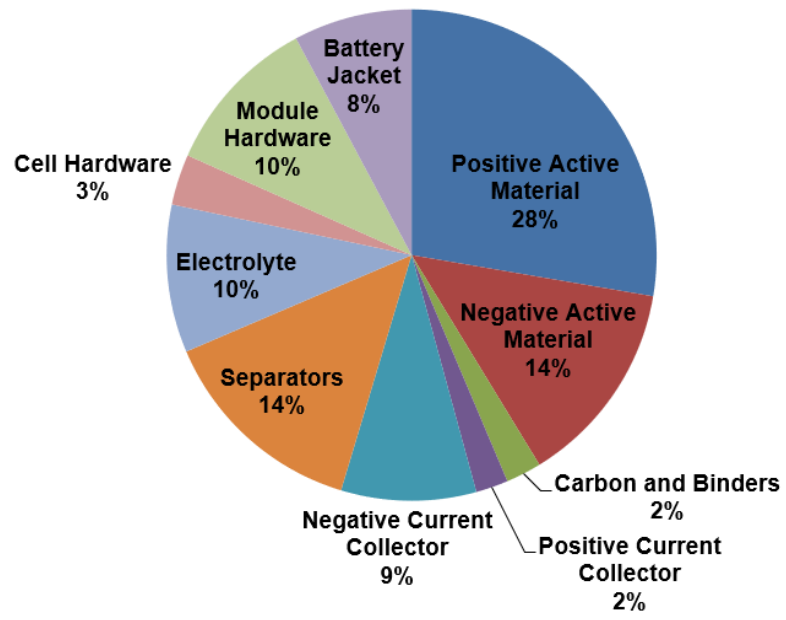

- Positive Active Material

- Negative Active Material

- Carbon and Binders

- Positive Current Collector

- Negative Current Collector

- Separators

Electrolyte

- Cell Hardware

$\square$ Module Hardware

Battery Jacket

Figure 8.1. Cost breakdown of the major subcomponents comprising LIBs obtained by the BatPaC model sponsored by VTO and developed by Argonne National Laboratory.

1.2

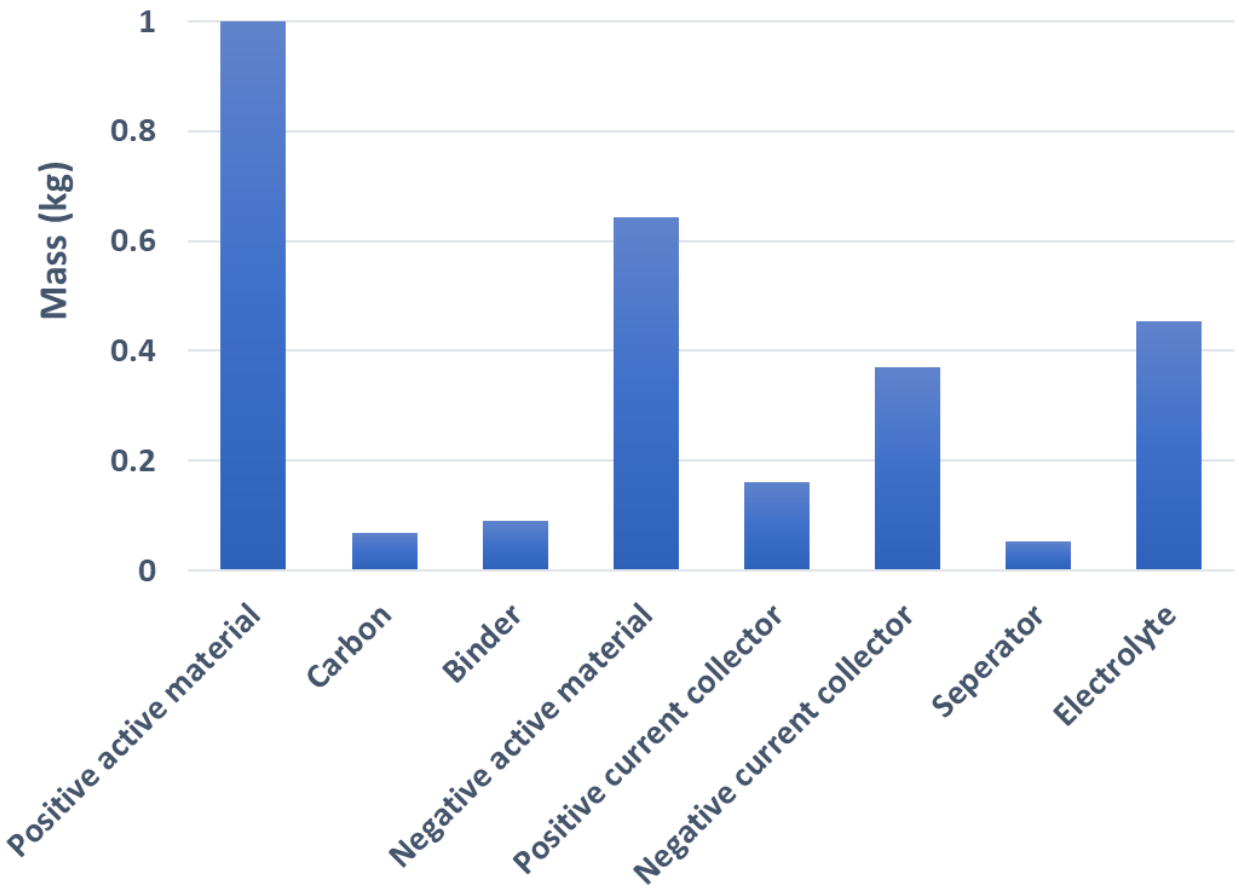

Figure 8.2. Mass per kg of NMC622 of each major LIB subcomponent for NMC622/graphite cell chemistry.

\subsection{ANODES}

Anodes for conventional liquid-electrolyte cells are made of natural or synthetic graphite, and most anodes comprise mined natural graphite that must have the right shape, particle size, and crystalline properties with significant post-processing involved to make the material suitable for (de)intercalation. Around $20 \%$ of the world's natural graphite supply goes to LIB anodes, and this will continue to grow as the EV market expands.[63] Currently, the major natural graphite sources are located in China, Brazil, 
and Canada, with additional planned capacity coming from Mozambique, Tanzania, and Australia. Some of the major suppliers of refined battery grade graphite are Hitachi Chemical, BTR New Energy, and Superior Graphite in the United States.[63]

The natural graphite must be properly heat-treated to obtain a high degree of graphite crystalline domains with exposed edge planes and surface treated (forming gas, nitric acid, and so on) to obtain the appropriate surface chemistry for SEI formation. Both oxygen-free surfaces[64] and oxygen-rich surfaces[65-66] can be beneficial for performance, depending on the electrolyte composition, cathode cell chemistry, and cycling conditions.

In solid-state electrolyte-based Li cells, Li metal is used in place of graphite with no intercalation reaction taking place. Rather, it is a Li plating and stripping reaction, where the starting thickness of the Li metal is the most critical parameter. However, all-SSBs are still in their infancy in terms of R\&D and will likely not see commercial applications for 5 to 10 years. These solid-state cells will also likely see first applications in the consumer electronics space. Over the coming decade, transportation will be dominated by implementation and evolution of advanced liquid-electrolyte LIBs, which means the major demand for anodes will be in the natural graphite area, not Li metal.

\subsection{CATHODES}

Modern cathodes are made of various mixtures of transition metal oxides known as "layered materials," such as LCO or NMC, or olivine materials, such as LFP. Another class of materials known as the "spinel structures," such as $\mathrm{LMO}$ or $\mathrm{LiMn}_{1.5} \mathrm{Ni}_{0.5} \mathrm{O}_{4}$, are used less frequently but are worth noting because they can handle high cathode potentials, which means more energy per unit mass. The common thread among these cathode active materials is that they all employ transition metals that must be mined and purified from the ores. However, it is important to note that the mined metals are provided to the cathode active material manufacturers in salt solution form for the reaction processes that are conducted to make ceramic oxide (or phosphate) secondary particles. The reason is that the ores must be converted and purified to individual salts for the chemical synthesis processes that are used to make the final mixed transition metal oxide active materials. LCO is the predominant cathode used in consumer electronics such as laptops and smart phones because it is an established, safe material. Where cell cost is important, Ni-rich NMC materials with much lower Co content are used. Some of the major suppliers of cathode active materials are BASF, Umicore, Nichia, L\&F, SMM, and Reshine.

Co is the most expensive raw material in a LIB, is mined under inhumane conditions often using child labor, and is ecotoxic.[63] It is essential to consider how this raw material will be recycled over the coming decade and ultimately eliminated from cathode active materials altogether. Approximately twothirds of the world's Co comes from the Congo, with 90,000 tons produced in 2019.[63] It is relatively abundant in the earth's crust, but it is often in low concentrations and must be purified with $\mathrm{Ni}$ and $\mathrm{Cu}$ ores, which primarily consist of sulfides and oxides. With the growing demand in EVs and consumer electronics, it is estimated that by 2030, the demand for Co for LIBs alone will be approximately 285,000 tons, which exceeds by a factor of two the total world output of Co in 2019 of $~ 145,000$ tons. [63] This trend is expected despite major efforts by international government agencies, including a major initiative by DOE known as the "Next Generation Cathode Deep Dive" to dramatically reduce the Co intensity in LIB cathodes or eliminate it altogether.

$\mathrm{Ni}$ is mined worldwide, but little comes from the United States, with the largest producers being Indonesia, Philippines, New Caledonia, Russia, Canada, and Australia.[63] With Ni-rich cathodes (stoichiometric contents as high as $80-95 \%$ in layered NMC materials) becoming more important for high specific capacity, high cathode potentials, and high energy density, the demand for LIB Ni is expected to 
grow exponentially from about 70,000 tons in 2020 to 700,000 tons in 2030.[63] Therefore, a stable supply of Ni will be critical as the effort to reduce Co content continues.

\subsection{LITHIUM}

In conventional liquid-electrolyte LIBs, the source of $\mathrm{Li}$ is contained in the cathode material crystal structure. Solid-state Li batteries have both a Li metal anode layer and the cathode Li source. Therefore, a source of Li-containing salt precursors and Li metal foil will ultimately be needed when SSBs replace conventional LIBs. Li ores consist primarily of Li carbonate or Li hydroxide. The main historical source has been the former material, but the latter is more important for synthesizing the Ni-rich cathodes, such as NMC622, NMC811, or NCA.[63] Historically, Li carbonate has been used successfully for low-Ni cathodes, and Li hydroxide has been used for high-Ni cathodes because of the intrinsic synthesis conditions used for these materials. Most of the world's Li resources are concentrated in South America, with about $60 \%$ located in Argentina, Chile, and Bolivia. Researchers estimate that by 2030, the amount of Li needed to support the EV market will be 2.3 times the total amount mined in 2018, underscoring the importance for Li recycling. The world's leading producer of $\mathrm{Li}$ is Australia, which produces about 270,000 tons per year of Li carbonate equivalent and accounts for about $60 \%$ of the refined Li supply.[63] The three largest Li producing companies are Albemarle (United States), SQM (Chile), and Tianqi Lithium (China). Albemarle is still the world's largest producer of Li, but it is experiencing a market share erosion from Chinese companies such as Tianqi Lithium and Ganfeng.[63] Examples of two different types of Li mines are shown in Figure 8.1.

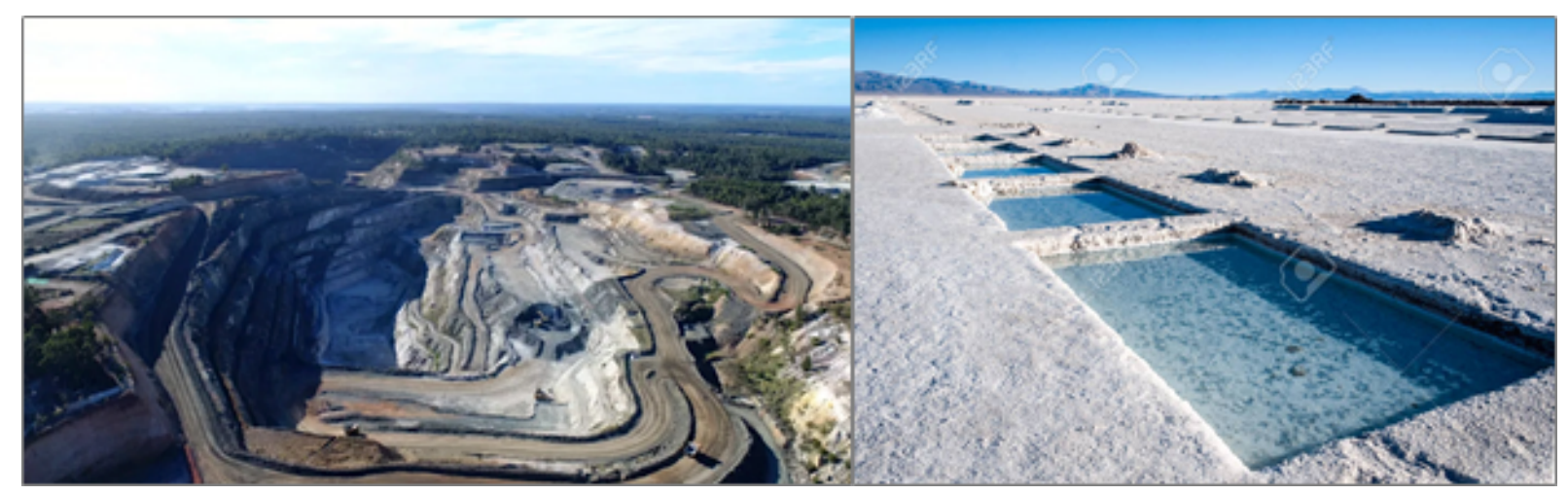

Figure 8.3. (left) Tianqi Greenbushes Li mine in western Australia, and (right) the Orocobre Salinas Grandes Lithium Project in northwest Argentina.

Li salts such as $\mathrm{LiPF}_{6}$ ( $\mathrm{Li}$ hexafluorophosphate) are also an important part of the Li equation because they are responsible for conducting the $\mathrm{Li}$ ions (in a solvated state) back and forth from the anode to cathode through the separator. $\mathrm{LiPF}_{6}$ is the preferred salt for liquid-based LIBs because of its high Li-ion conductivity and the low viscosity in solution, and it is generally synthesized through the reaction of the inorganic $\mathrm{F}$-containing compounds $\mathrm{LiF}, \mathrm{PF}_{5}$, and hydrofluoric acid.[63]

The actual mass of Li metal that goes into an LIB cell is small compared with many of the other metals, particularly the $\mathrm{Al}$ and $\mathrm{Cu}$ current collectors and active cathode transition metals. The reason is that the molecular weight of $\mathrm{Li}$ is low compared with the cathode transition metals, so a much higher mass of, for example, $\mathrm{Ni}, \mathrm{Mn}$, and $\mathrm{Co}$, is needed to balance the cathode compound stoichiometry. The $\mathrm{Cu}$ anode foil is also much denser than Li. Figure 7.2 shows this difference as a function of time for 2018 to 2030, and it illustrates that the mining and recycling of other materials such as $\mathrm{Co}, \mathrm{Cu}, \mathrm{Ni}$, and natural graphite may become even more important over this decade as EV demand continues to grow.[67] 


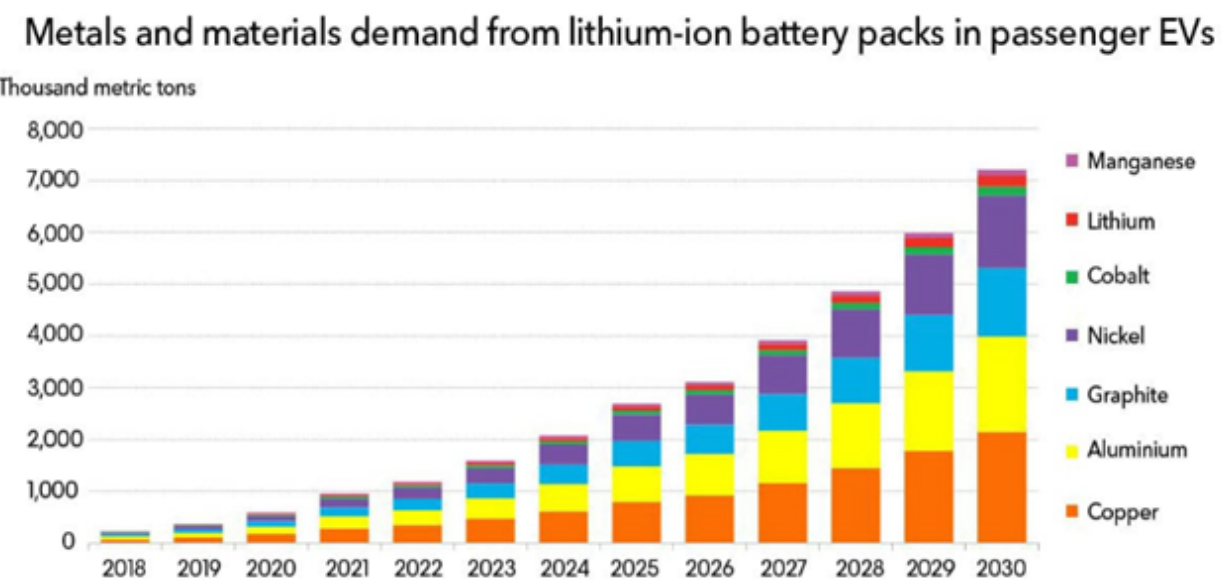

Figure 8.4. Projected major anode and cathode raw materials demand from 2018 to 2030 showing that the demand for Li metal will be significantly outpaced by $\mathrm{Cu}, \mathrm{Ni}$, and (natural) graphite.[67]

\subsection{ELECTROLYTE AND INACTIVE COMPONENTS}

LIB liquid electrolytes are another critical subcomponent of LIBs because they are the ionic bridge between the anode and cathode active materials and facilitate (de)intercalation. These electrolytes are composed of expensive Li salts $\left(\mathrm{LiPF}_{6}\right.$ or $\left.\mathrm{LiClO}_{4}\right)$ and mixtures of low-molecular-weight organic solvents such as cyclic EC, propylene carbonate, linear dimethyl carbonate, ethyl methyl carbonate, and diethyl carbonate. Additives for optimizing the SEI composition, thickness, and morphology, such as fluoroethylene carbonate and vinylene carbonate, are also used to a certain degree. Most of the suppliers of the salts and solvents are located outside the United States (in Japan, South Korea, and China) with a few exceptions such as $3 \mathrm{M}$ and Arkema, which make salts, and Huntsman Chemical, which makes solvents.[63]

Another important inactive component in conventional LIBs is the polyolefin separator, which electronically separates the anode and cathode. It is typically made of polyethylene, polypropylene, or combinations thereof, and it may also be coated on one or both sides with a ceramic, such as silica, alumina, or titania, to boost thermal and mechanical properties, protect the cell from thermal runaway, and decrease the leak current. These separators contain mesopores that are filled with the liquid electrolyte to allow Li-ion conduction. All major manufacturers of this component are located in Asia, including Asahi Kasei in in Japan who now owns the Hipore Celgard trademarks.[63] The three largest separator suppliers are Asahi Kasei, Toray, and SK Innovation (South Korea), which have announced plans to produce a combined volume of greater than one billion $\mathrm{m}^{2}$ in 2021.[63]

Inactive subcomponents in the electrodes are the conductive carbon additive- (which may be carbon black, carbon microfibers, carbon nanotubes, or mixtures thereof) for electronically conducting the electrons from the carbon/active material interface to the current collectors - and the binder, which is for holding the electrode together once it is coated and dried. The binder is responsible for coating mechanical integrity by providing good interparticle cohesion and good electrode adhesion to the current collector foils. It is also important for providing good dispersion of the conductive additive and active materials to maximize the surface area between the two phases for high active material use.

Thin $\mathrm{Cu}$ foil, used as the anode current collector, is one of the major subcomponent expenses for LIBs. Unlike on the cathode side, $\mathrm{Al}$ foil cannot be used because $\mathrm{Li}$ alloys with $\mathrm{Cu}$ at the low anode operating potentials. Therefore, efforts to increase the thickness (or areal capacity) of the electrodes are underway so that fewer $\mathrm{Cu}$ current collectors are needed per unit volume and mass. 


\section{GLOBAL AND DOMESTIC LIB PRODUCTION CAPACITY}

Similar to the raw materials supply chain, the LIB production capacity is also dominated by Asian companies such as Toshiba and Panasonic in Japan; LG Chem, Samsung SDI, and SK Innovation in South Korea; and CATL, A123 Systems, and BYD in China. Japan's market share has been eroding over the past decade because of fierce competition from South Korea and China in particular, and Chinese and South Korean companies are positioning themselves to dominate conventional liquid-electrolyte LIB space internationally over the next decade. In fact, Sony. the commercialization pioneer of the LIB in 1991, removed itself from the LIB market in 2019. Additionally, four of the top five largest factories belong to LG Chem and CATL, although the largest one is Tesla's Gigafactory located in Reno, Nevada.[63] Table 9.1 shows the annual capacity and location of the top five factories in the world. In fact, LG Chem alone is expected to double its annual production capacity from $50 \mathrm{GWh}$ in 2019 to over $100 \mathrm{GWh}$ in 2021.[63] Tesla's factory in the United States was designed and built, and is also in large part operated by, Panasonic. It is set to expand capacity from 22 to 35-50 GWh by the end of this year to keep pace with demand for its Model $3 \mathrm{EV}$. The global LIB capacity today is about $200 \mathrm{GWh}$ and is expected to grow by 10 times by 2030.[63]

Table 9.1. Annual production capacity of top five LIB factories in the world.[63]

\begin{tabular}{llc}
\hline \multicolumn{1}{c}{ Company } & \multicolumn{1}{c}{ Location } & $\begin{array}{c}\text { Annual production capacity } \\
\text { (GWh) }\end{array}$ \\
\hline Tesla & Reno, Nevada, United States & 22 \\
LG Chem & Nanjing, China & 20 \\
CATL & Ningde, China & 20 \\
CATL & Liyang, China & 18 \\
LG Chem & Wroclaw, Poland & 15 \\
\hline
\end{tabular}

There are two basic types of LIB cell designs: pouch and cylindrical. Cylindrical cells are slowly being phased out in favor of pouch cells because their capacity per cell can be much higher than a cylindrical cell. Therefore, fewer cells are needed in an EV, which makes the power electronics simpler to design. The maximum energy density and power density also increase with cell capacity, and the energy density will peak around $350 \mathrm{Wh} / \mathrm{kg}$ for conventional liquid electrolyte-based cells. There are notable exceptions to this trend. For example, Tesla has chosen to use thousands of smaller cylindrical cells in its EVs rather than fewer (100-200) large-capacity pouch cells for safety reasons. Cylindrical cells are inherently safer because the chemical energy is contained in a stainless steel can, and the cells capacities are much lower (2-5 vs. 20-100 Ah for EV pouch cells). The latter point means that less energy per cell releases if an uncontrolled event such as shorting, thermal runaway, or over-charging occurs. The consumer electronics industry also still uses cylindrical cells, although these are being replaced by higher-capacity pouch cells with a rectangular form factor more appropriate for smart phones, laptops, and portable electronic devices.

Domestic production of LIBs by United States-owned companies, other than Tesla's Gigafactory, is negligible in terms of the worldwide output. However, several significant players in the United States produce LIBs for defense and aerospace applications, such as XALT Energy, Navitas Systems, and Yardney Technical Products (a Division of EaglePicher Technologies). There are also significant production facilities in Michigan by foreign-owned companies such as LG Chem and A123 Systems. For the most part, US automotive companies are locked into either having to import LIBs from Asia or buy domestically designed and produced LIBs from Asian-controlled companies. 
The demand for EVs is projected to dominate the production capacity of LIBs by 2030. Currently, consumer electronics consumption of LIBs is about $45 \mathrm{GWh}$ annually compared to the transportation sector, which is about $230 \mathrm{GWh}$ annually and equates to $83.6 \%$ of the total production capacity. By 2030 , these values are expected to grow to $63 \mathrm{GWh}$ for consumer electronics and 1,480 $\mathrm{GWh}$ for transportation.[63] IDTechEx also projects that the almost nonexistent stationary LIB market (frequency regulation, load leveling, and so on for the electricity grid) will grow to about $60 \mathrm{GWh}$ by 2030 , as well, on par with consumer electronics.[63] However, both sectors will be dwarfed by the transportation demand, which will consume $92.3 \%$ of the world's LIB capacity.[63]

A lingering question is whether the LIB production capacity can match the EV LIB demand. IDTechEx has projected that over the next 5 to 8 years, capacity will exceed demand by about $450 \mathrm{GWh}$ in 2026 and $300 \mathrm{GWh}$ in 2028 , but that by 2030 , the demand will exceed production capacity by about 140 $150 \mathrm{GWh} .[63]$ These projections assume that the key subcomponents of the cells and the raw materials that make them up (discussed in Section 7) can also continue to be produced at the same rate as the cell production capacity. This situation will create an enormous opportunity for the United States to create and maintain its own LIB raw material supply chain and cell manufacturing base over the coming decade.

So-called "gigafactories" can be built in about two years and commissioned and ramped to full production in about another two years, based on timelines of LIB factories of this scale constructed by Samsung SDI, LG Chem, Tesla/Panasonic, and SK Innovation and sited in China, the United States, and Eastern Europe.[63] With the implementation of novel, disruptive manufacturing technologies, the United States could catch and surpass the competition by the late 2020s. This will not occur by simply reproducing the LIB manufacturing plants in Asia and Eastern Europe, as the labor rates are too low in these regions and the plant designs are too established. Instead, the United States must seek ways to produce LIBs in new ways or by borrowing manufacturing technologies from other industries. Novel electrode production, cell design, and newer, less expensive cathode active materials are other ways to pass the competition. Another possibility is to lead the way in all-SSB R\&D and manufacturing, as these cells are widely thought to be the next generation of Li-based batteries since they offer higher energy densities and are much safer to operate since they use no flammable liquid electrolyte. However, these scenarios would need to involve significant public-private partnership.

Average LIB cell costs are currently about two times the ultimate DOE target of $\$ 80 / \mathrm{kWh}$, but this figure is down substantially from about $\$ 380 / \mathrm{kWh}$ in 2015.[48] The average worldwide cell cost is projected by IDTechEx to reach this target by 2024 and exceed it at $\$ 63 / \mathrm{kWh}$ by 2030,[63] which will enable expansive adoption of electrified transportation.

\section{INDUSTRIAL/COMMERCIAL MANUFACTURING PROCESS DESCRIPTION}

The widely used commercial procedure for LIB manufacturing is summarized in Figure 10.1. The process can be summarized succinctly as follows:

- Mixing electrode components in a thick but castable suspension, coating this slurry onto the current collecting foil, and drying out the solvent (Figure 10.1a, b)

- Removing sections of the dry film to precise dimensions as dictated by the cell configuration and removing residual moisture in secondary drying (Figure $10.1 \mathrm{c}, \mathrm{d}$ )

- Assembling electrodes and a separator into a roll or stack, adding electrolye to the cell, and forming the interphases on the electrodes (Figure 10.1e-j) 
These processes are discussed in further detail in the following paragraphs using Figure 10.1 as an outline.

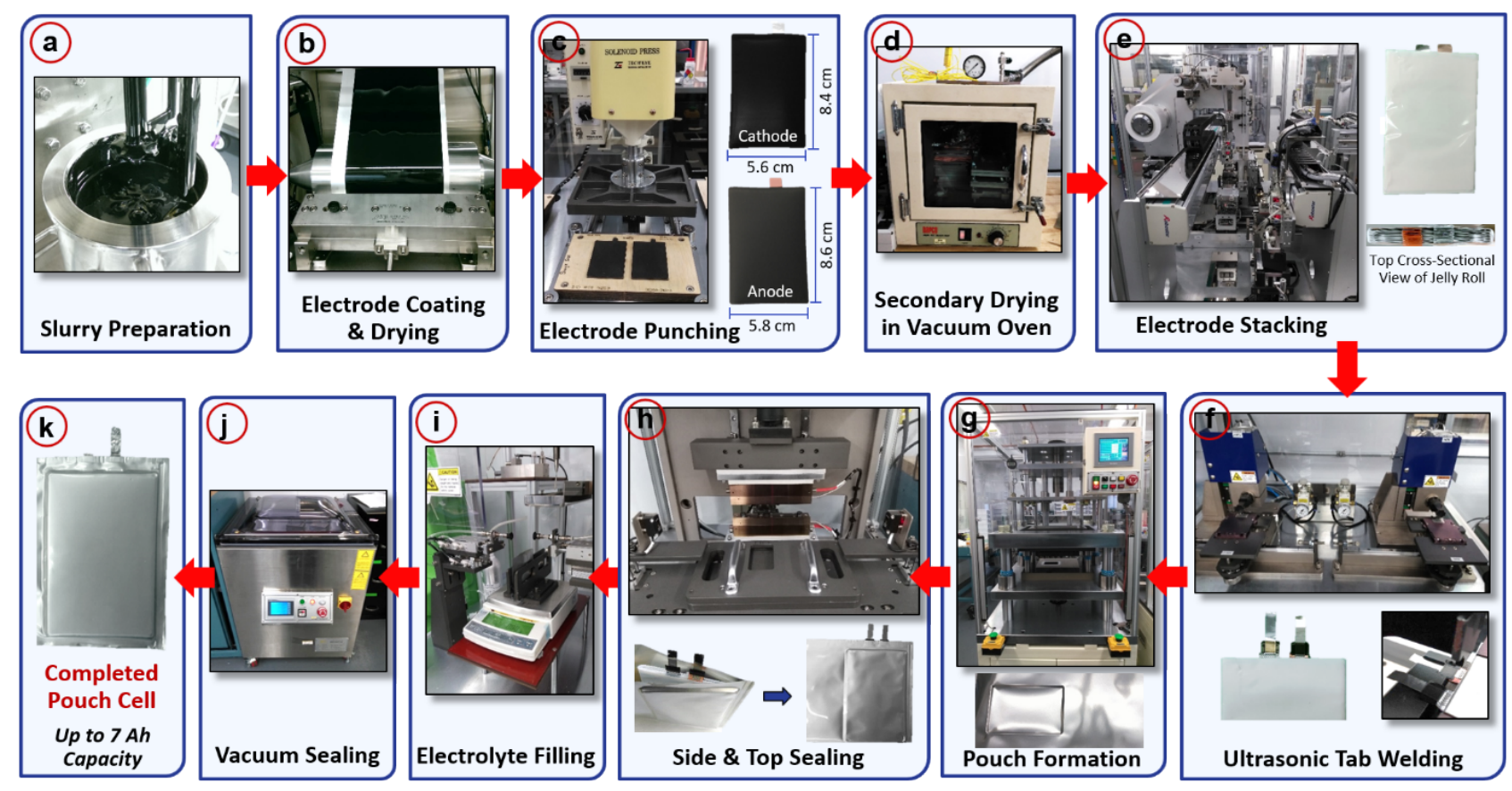

Figure 10.1. Flowchart of the manufacturing process used at DOE's Oak Ridge National Laboratory's Battery Manufacturing Facility to make electrolyte-filled, fully sealed pouch cells. Reprinted and modified with permission.[68]

(Figure 10.1a, b) The LIB electrode manufacturing process begins by preparing a suspension consisting of active materials, conductive additives, and binders dispersed in solvent (Figure 10.1a). In the case of the negative electrode, the solvent is deionized water; for the positive electrode, the solvent is NMP, a toxic, hazardous chemical that is roughly 100 times more expensive than water.[54, 69] After mixing, the resulting slurry is coated onto the current collecting foil ( $\mathrm{Cu}$ for anodes, $\mathrm{Al}$ for cathodes) using a slot-die coater (Figure 10.1b, Figure 10.2a). Modern coating speeds can reach 100-200 ft/min [68] before rapid air bubble formation occurs[70] and the presence of various coating defects, such as pinholes, agglomerates, and nonuniformity, arises.[71-73]

Once coated, the slurry is rapidly dried to remove the solvent. For NMP-based electrodes, the solvent must be collected and recycled, which is an energy-intensive process[74] that requires millions of dollars in capital costs to operate.[75] Another concern during the drying process is microstructure rearrangement, and specifically the migration of binder and conductive additives to the surface of the coating. As solvent particles are pulled to the top of the coating for evaporation, binder strands and conductive additive particles are dragged along with them, resulting in an electrode with insufficient adhesion, higher interfacial resistance, and inhomogeneous current density.[76] Industrial drying typically takes place within a few minutes[75] and is an early process bottleneck because of the capital cost of installing longer drying lines necessary to match an increased coating speed.

These first steps (mixing, coating, and drying) are a function of the same parameters, namely the viscosity and stability of the slurry. Slurries must possess a relatively high low shear viscosity to mitigate sedimentation of large active material particles ( $\sim 10 \mu \mathrm{m}$ in diameter) and to form coatings with sharp edges to minimize cutoff waste. Similarly, slurries need a relatively low high shear viscosity to be easily spreadable at high coating speeds (Figures 10.1b and 10.2b).[77] 
During the drying stage, the trade-off between migration and drying speed can be optimized when a threestage primary drying protocol is enacted. Initially, the rate of evaporation is high because many solvent molecules are near the surface of the coating. Vaporizing these molecules at a relatively low temperature will minimize migration. Drying reaches a steady-state regime when there is constant supply of solvent molecules to the surface of the coating; as it becomes more difficult to extract the final remaining solvent molecules, the rate of evaporation slows. Therefore, there are two points of interest: the point at which the drying rate becomes constant and the point at which the drying rate begins decreasing. At both points, the temperature can be increased to strike a balance between drying speed and microstructure preservation. Finally, reducing the drying time (and, in the case of NMP-based electrodes, energy and cost of recycling) can be achieved by increasing the solid loading of the slurry, with careful attention being paid to the effect on the rheology of the slurry.

Once dry, the film is pressed (or calendered) to the target thickness and porosity. This step is necessary to maximize the energy density of the cell, although there is a trade-off between porosity and tortuosity.[7879] "Tortuosity" refers to the ratio of the average distance travelled by an ion to the total thickness of the electrode. Tortuosity, then, is a rough measure of the extra distance an ion must travel through a porous electrode to reach its intercalation site. Additionally, calendering must be well-calibrated to ensure wrinkles do not form at the edge of the coating.[80]

(Figure 10.1c, d) After the electrode is dry and calendered, pieces with precise dimensions depending on the cell structure (see Section 3.1) are punched out of the sheet (Figure 10.1c). A secondary drying step (Figure 10.1d) is also recommended to ensure that the moisture content of the coating is well below $400 \mathrm{ppm}$. Residual solvent can react with the Li salt in the electrolyte and form corroding agents, particularly hydrofluoric acid, which can dramatically decrease cell lifetime and negatively affect safety.

(Figure 10.1e-j) Next, the anode and cathode sheets are cut to the desired length, paired with a separator, and are (most commonly) wound into a jelly roll, although they may also be stacked in a stack-cell configuration (Figure 10.1e, f). During packaging, the jelly roll is welded to the cap assembly, taking care to not wrinkle the current collector or contaminate electrode sheets. Electrolyte is then added to the cell in a days-long process to fully wet the pores of the separator and the electrodes (Figure 10.1g-i). The electrolyte imbibition rate has been found to be inversely proportional to calendering intensity.[81] Once the cell is fully wetted, the edges of the pouch are sealed to prevent any leaking electrolyte or air contamination (Figure 10.1j). 

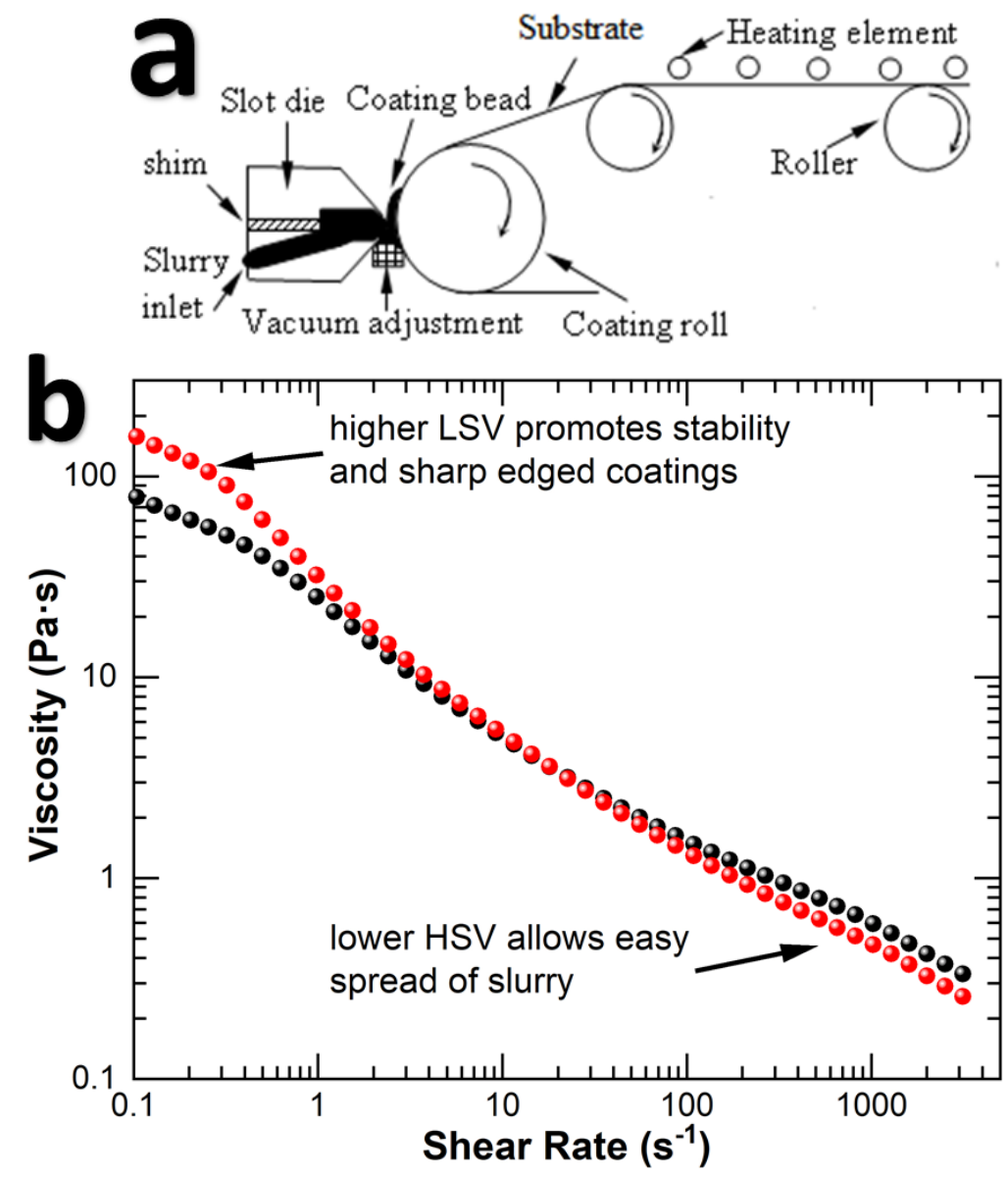

Figure 10.2. (a) Schematic drawing of a slot-die coater used in coating electrodes. Reprinted and modified with permission.[77] (b) A rheological comparison between (black) a baseline cathode slurry and (red) a slurry with preferred characteristics. Reprinted and modified with permission.[70]

After the cell is sealed, it is cycled through several slow charge and discharge cycles. These formation cycles build the SEI on the negative electrode and the cathode electrolyte interphase on the positive electrode. Forming the cells also takes several days, leading to another process bottleneck. Recently, a fast formation protocol ( $<1$ day) was developed that quickly charges the cell, discharges and charges three times between 80 and $100 \%$ state-of-charge, and then quickly discharges the cell. When applied to a full pouch cell consisting of NMC532 and graphite, this fast protocol led to nearly identical performance to the standard protocol $(0.05 \mathrm{C} /-0.05 \mathrm{C}$ for four cycles $)$ when cycling at $1 \mathrm{C} /-1 \mathrm{C}$ for 300 cycles.[82]

In summary, LIB production requires a firm understanding of process/structure/property relationships (Figure 10.3). The mixing and coating stages require knowledge of colloidal interactions to create stable, castable suspensions, while the drying stage consists of heat transfer and mass transfer in three phases (solid, liquid, and gas). Downstream processes, particularly electrolyte filling and cell formation, are a significant function of the microstructure, which is determined in the preliminary stages of production. 


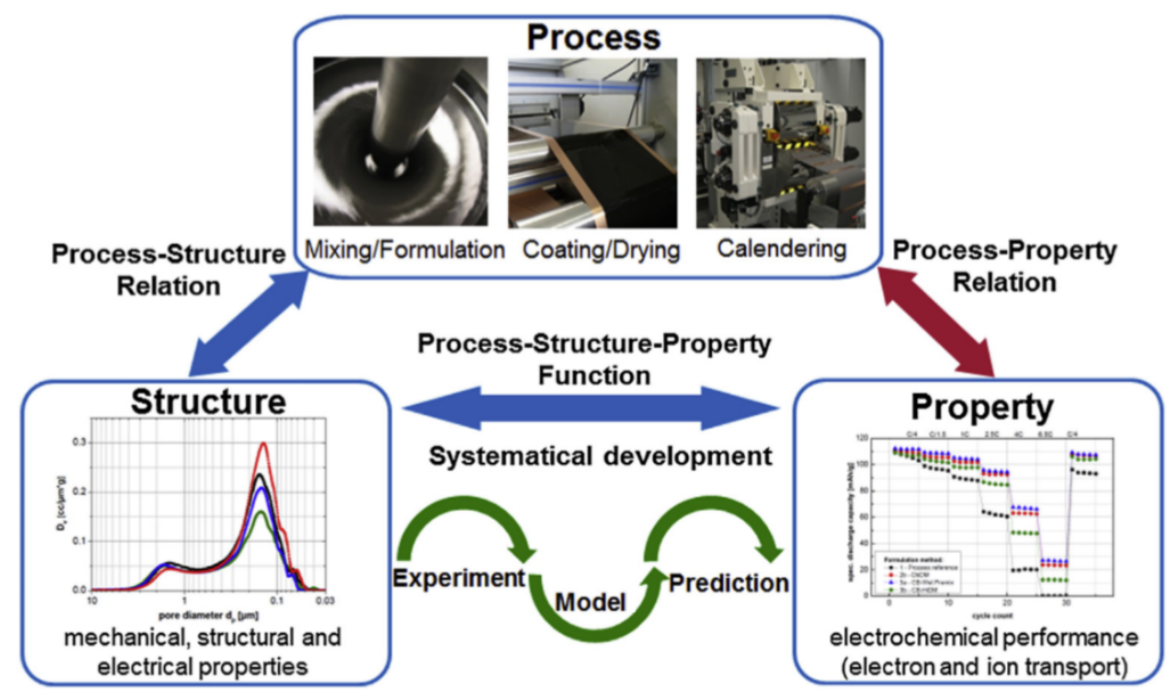

Figure 10.3. Schematic describing the process/structure/property relationships in the LIB manufacturing process. Reprinted and modified with permission.[83]

Analysis of each of the steps of LIB production indicates that need for improvement still exists in each step to expedite production, cut costs, and minimize safety hazards. The chief research needs include the following:

- Increasing drying speeds by maximizing slurry solids loadings and gaining more fundamental process knowledge

- Preventing binder and conductive additive migration during drying

- Understanding how to increase electrolyte imbibition rates through engineering controls

- Expediting cell formation by understanding SEI and cathode electrolyte interphase formation mechanics

- Improving means of in-line quality control to minimize waste generation and ensure product consistency

\section{NEXT-GENERATION BATTERIES/FUTURE CONSIDERATIONS}

\subsection{SOLID-STATE BATTERIES}

Li-based SSBs containing a Li metal anode, high-voltage cathode (e.g., Ni-rich NMC), and $\mathrm{Li}^{+}-$ conducting solid electrolyte (SE) can potentially achieve specific energies of 350+ Wh/kg.[37] A critical challenge for SSBs is the development of SEs, which exhibit high $\mathrm{Li}^{+}$conductivity comparable to that of liquid organic electrolytes $(\sim 1-10 \mathrm{mS} / \mathrm{cm}$ at room temperature) and good electrochemical and mechanical compatibility with Li metal anodes and high-energy density cathodes. Furthermore, the thickness of the SE layer should be kept at $<30 \mu \mathrm{m}$ to ensure high energy densities that exceed that of $\mathrm{Li}$-ion technologies. ${ }^{[84]}$ To date, a wide range of $\mathrm{Li}^{+}$-conducting SEs have been developed, with the most prominent classes including oxides, sulfides, and polymers. ${ }^{[85]}$ 
As shown in Figure 11.1, no single SE material satisfies all the electro-chemo-mechanical requirements for SSBs. Although polymer electrolytes have excellent processability, they suffer from relatively low $\mathrm{Li}^{+}$ conductivity $\left(\sim 1 \times 10^{-6} \mathrm{~S} / \mathrm{cm}\right.$ at room temperature $)$ and cannot prevent Li dendrite growth. On the other hand, a wide range of ceramics with high $\mathrm{Li}^{+}$conductivity (up to $\sim 1 \times 10^{-3} \mathrm{~S} / \mathrm{cm}$ at room temperature) have been reported, but producing these materials in thin layers $(<30 \mu \mathrm{m})$ presents manufacturing challenges. To leverage unique advantages of different classes of SEs, recent work has focused on composite SEs that contain a ceramic phase to attain high $\mathrm{Li}^{+}$conductivity and a polymer to improve material processability (e.g., for casting films of SEs via roll-to-roll processing). An alternative to this approach is use of thin film batteries, most notably those containing a lithium phosphorus oxynitride SE $(\sim 1 \mu \mathrm{m})$ developed at Oak Ridge National Laboratory, which are fabricated through a layer-by-layer sputtering process. Although the packing efficiency and cycling performance of such thin film batteries are excellent, scalability issues of the deposition methods have hindered their commercial adoption.[37, 86-87]

a. Oxides

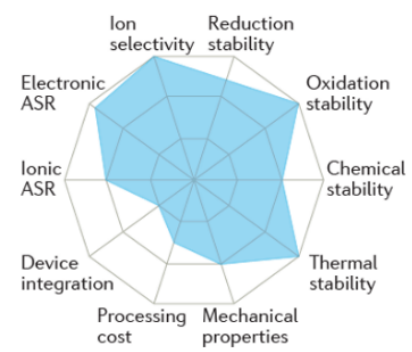

b. Sulfides

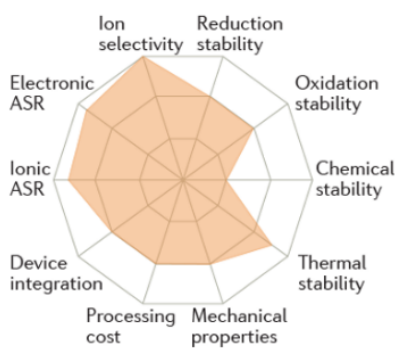

c. Polymers

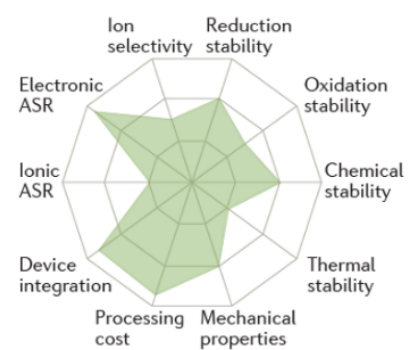

Figure 11.1. Summary of key properties for (a) oxide, (b) sulfide, and (c) polymer solid-state $\mathrm{Li}^{+}$conductors. Figure adapted with permission from Manthiram et al.[85]

Integrating SEs with Li metal anodes and high-voltage cathodes is a nontrivial process, and device performance is largely dictated by the quality of the electrode/electrolyte interfaces. For example, SE decomposition at an interface occurs when an electrode operates outside the SE's electrochemical stability window. Ideally, these interfacial decomposition products are electronically insulating with high $\mathrm{Li}^{+}$conductivity, which ensures formation of kinetically stabilized passive films similar to the SEI layer in conventional LIBs.[88-89] Recent reports have shown that cathode coatings and buffer layers (e.g., $\mathrm{LiNbO}_{3}$ coated on LCO) improve compatibility of high-voltage cathodes with SEs, but the mechanism by which these coatings improve performance is not yet fully understood.[90] In addition to cathode/electrolyte stability issues, nonuniform current densities across the anode/SE interface can lead to unstable Li growth and internal shorting during SSB charging. Several factors affect the morphology of plated $\mathrm{Li}$, including the microstructure of the SE (e.g., nano-/polycrystalline vs. amorphous), Li wettability at the interface, and mechanical properties of the SE.[91-92] In addition to optimizing the SE surface chemistry/microstructure, the use of thin Li metal layers $(\leq 30 \mu \mathrm{m})$ is critical to properly identify technical challenges associated with Li plating/stripping in SSBs.[93] Finally, the influence of external factors on battery performance, such as cell packaging, stack pressure, and abuse conditions, require further investigation.

The past several years have witnessed significant advances in the field of high energy density SSBs. A wide range of inorganic SEs with $\mathrm{Li}^{+}$conductivities rivaling liquid electrolytes have been developed and integrated with high-voltage cathodes and Li metal anodes. Notably, a 2020 study reported stable performance over 800 cycles for a large format $\mathrm{Li}\left|\mathrm{Li}_{6} \mathrm{PS}_{5} \mathrm{Cl}\right| \mathrm{NMC} \mathrm{SSB}$ with an energy density of $900 \mathrm{Wh} / \mathrm{L}$.[94] Despite these exciting advances, additional research aimed at solving key interfacial and processing challenges is required to create low-cost SSBs with performance exceeding that of Li-ion technologies. 


\subsection{WOULD THE MANUFACTURING BASE CHANGE FOR BEYOND LIBS?}

Traditional NMP-based manufacturing of LIBs will need to be replaced to cut costs, make production safer, and lessen environmental effects. One such avenue is processing cathodes in a water solvent, which is roughly 100 times cheaper than NMP and eliminates the need for expensive and energy-intensive solvent recovery. However, aqueous processing has many technical challenges that need to be overcome, such as (1) replacement of polyvinylidene fluoride binder with a water-soluble binder; (2) higher propensity for active material and conductive additive agglomeration[95-96]; (3) relatively poor wettability onto $\mathrm{Al}$ current collector ${ }^{[97]}$; (4) high slurry $\mathrm{pH}$ leading to current collector corrosion and active material particle surface damage ${ }^{[98-99]}$; (5) cation exchange $\left(\mathrm{Li}^{+} / \mathrm{H}^{+}\right)$causing Li deficiencies in the active material[100]; and (6) higher residual moisture content post-primary drying due to hydrophilic binders. ${ }^{[101]}$ To suppress agglomerate formation, dispersants have been shown to impart electrostatic, steric, or electrosteric hinderance. ${ }^{[102-108]}$ Surface energy manipulation of the slurry ${ }^{[109]}$ and the current collector ${ }^{[110]}$ have been shown to improve wettability. Direct contact between the slurry and the current collector has been avoided by using current collector and active material coatings. ${ }^{[11-113]}$ However, the more cost-effective route may be $\mathrm{pH}$ modification, which has been achieved most commonly by adding acids. $^{[14-120]}$ Some of these acids have been shown to provide the additional benefit of protecting the surface of active materials from further Li depletion.

Minimizing the amount of (or completely eliminating) solvent used during manufacturing is advantageous due to the inevitable microstructural rearrangement, specifically binder and conductive additive migration, that occurs during wet slurry drying. One such method is ultraviolet or electron-beam curing of small binder oligomers into long-chained polymers during processing (Figure 11.2a). Although ultraviolet curing has a relatively low operation cost, it has insufficient penetration depth to cure polymers in coatings of necessary thickness $\left(6-8 \mathrm{mAh} / \mathrm{cm}^{2}\right)$.[68] Electron-beam curing, with its high penetration depth and ability to function with no photoinitiator, seems to be the more compelling technology, even if it has relatively high equipment and operation costs. Curing of electrodes can take place in less than $1 \mathrm{~s}$ and can achieve slurry solids loadings up to $90 \mathrm{wt}-\%$, roughly $30 \%$ higher than that in traditional NMP processing. Additionally, the coating speed can be increased by a factor of five to $500-1,000 \mathrm{ft} / \mathrm{min}$. [121122]

Dry manufacturing of electrodes has been demonstrated using electrostatic spray deposition, in which powders are blended and fed to a spray gun, which charges the particles. Once sprayed, the particles are drawn to an electrically ground current collector and then hot rolled to a desired thickness and porosity. Studies have shown that the hot roller temperature must be near the melting point of the binder (in these studies, polyvinylidene fluoride) to promote better adhesion. ${ }^{[123-125]}$

In addition to exchanging, minimizing, and eliminating solvent, the thickness of electrodes must be increased to minimize battery costs. ${ }^{[69]}$ Thicker electrodes reduce the amount of inactive materials (namely current collectors and separators) needed in a battery pack but create longer diffusion lengths for Li ions, thus restricting mass transport. By creating a pore network with near-unit tortuosity (i.e., straightline diffusion lengths), this transport restriction is minimized and more active material in the electrode is used. Many strategies exist for creating such hierarchical pore structures, such as coating of active material particles with magnetically receptive agents and using a magnetic field to align them during processing.[126] Other techniques include laser structuring ${ }^{[127]}$ and coextrusion[128-129] to cut out aligned pore pathways. Freeze-tape casting (FTC) is another promising solution (Figure 11.2b); in FTC, the coated substrate passes onto a freeze bed where the solvent is frozen and removed via sublimation. Efforts to use FTC as a means of producing Li battery electrodes are ongoing and FTC has already been used to create aligned pore structures in solid oxide fuel cell materials[130-136] and in oxide-based electrolytes for all-SSBs.[137-138] 

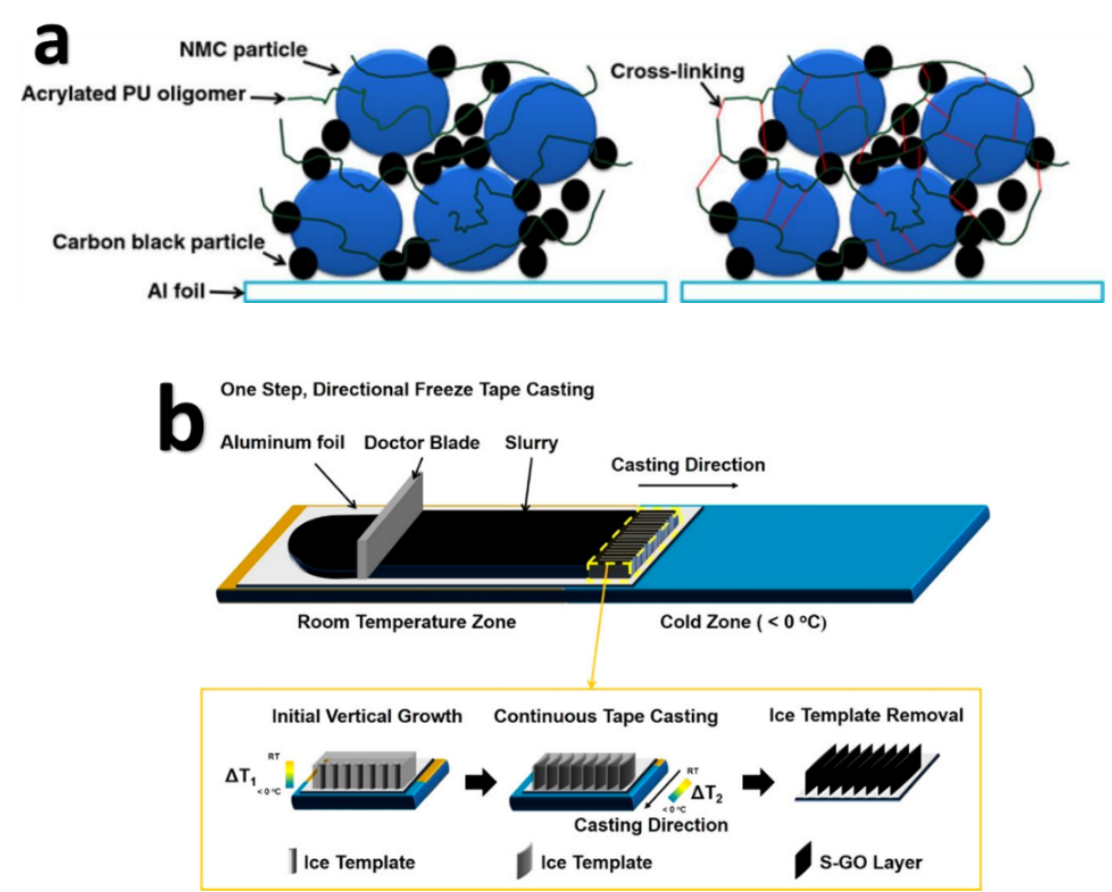

Figure 11.2. (a) Crosslinking of acrylated polyurethane oligomers allows for high solid loading and rapid coating speeds. Reprinted with permission.[121] (b) FTC scheme for Li-S battery cathodes. Reprinted with permission.[139]

There are currently no established manufacturing processes for technologies beyond LIBs, specifically Li metal all-SSBs. Many issues must be resolved, including (1) densifying the cathodes in a time-efficient manner; (2) densifying the solid-state electrolyte and maintaining good contact at the cathode/electrolyte interface; (3) coating the electrolyte onto the cathode if a polymer electrolyte is used; and (4) constructing the Li metal/electrolyte interface. The traditional calendering process can densify cathodes and electrolytes to a great extent but still may not be high enough for good conductivity. Sintering is another method of densification but suffers from long processing times, a high-temperature requirement, and potential incompatibility between the cathode and solid-state electrolyte. From a processing perspective, using soft electrolytes (i.e., gel polymers or polysulfides) can reduce the manufacturing challenges, although inherit disadvantages exist with these materials, such as low ionic conductivity and transference number.

\section{LIB RECYCLING}

By 2030, 11 million metric tons of end-of-life LIBs are expected to be generated cumulatively, and the annual waste flows of EV batteries will reach as high as 340,000 metric tons by 2040.[140-141] The EV battery part of the automotive sector is projected to dominate the LIB recycling market from 2025 to 2030 in terms of both value and volume.[142] According to the US Advanced Battery Consortium standards, an EV battery reaches the end of its usable life when its current cell capacity is less than $80 \%$ of the rated capacity. Those end-of-life EV batteries can be reused/repurposed, recycled, or disposed in landfills. To extend the life of those batteries and to increase their overall value, the repurposing pathway reconfigures the batteries for a second life in different applications, such as grid energy storage and behind-the-meter energy storage. Regardless of whether batteries are reused, they will eventually need to be recycled. Many reasons exist for why spent LIBs should be recycled from economic and environmental standpoints, which will be discussed. However, less than $5 \%$ of current waste batteries are recycled because of 
technical, economic, and other factors. Several recycling strategies-including pyrometallurgical, hydrometallurgical, and direct recycling approaches - are being adopted on market and under further development by researchers.

A recent market research report projects the LIB recycling market to grow from $\$ 12.2$ billion in 2025 to $\$ 18.1$ billion by 2030, at a compound annual growth rate of $8.2 \%$ from 2025 to 2030.[142] Market growth is attributed to the high output of spent batteries from the automotive sector. The opportunity for generating sustainable and considerable jobs is associated with this vast market. In addition to economic paybacks, recycling LIBs could reduce the environmental harm from disposal in landfills and lessen the effects of virgin material production. Life-cycle analysis indicates that the use of recycled materials can substantially reduce the energy use and emissions (e.g., $\mathrm{CO}_{2}, \mathrm{SO}_{\mathrm{x}}$ ) through the life cycle of LIBs.[143146] Thus, recycling end-of-life LIBs is critical to ensuring a responsible, sustainable, and stable transition to a low-carbon economy.

\subsection{PRESENT STATUS, CONTRAST TO MATURE RECYCLING OF 12 V LEAD-ACID BATTERIES}

About $99 \%$ of lead-acid batteries are estimated to be recycled in the United States, making this recycling one of the most successful recycling programs.[147] Several factors contribute to the success of lead-acid battery recycling, and lessons can be learned from this success to guide LIB recycling. Figure 12.1 plots the cell composition in a NMC622 Li-ion cell and a lead-acid battery. Lead-acid batteries have few components, making them easy to recycle. Additionally, almost $70 \%$ of the mass of a lead-acid cell is lead or lead oxide, which is easily recycled at a relatively low temperature. Recycling of lead-acid batteries flourishes because manufacturers seek the material as a source to make new battery products, which are profitable. The battery chemistry of a lead-acid cell simplifies its recycling process, whereas that of a LIB complicates recycling. However, lessons can still be learned from the success of lead-acid battery recycling. Compared with lead-acid battery recycling, shortcomings in policy and infrastructure hinder LIB recycling.

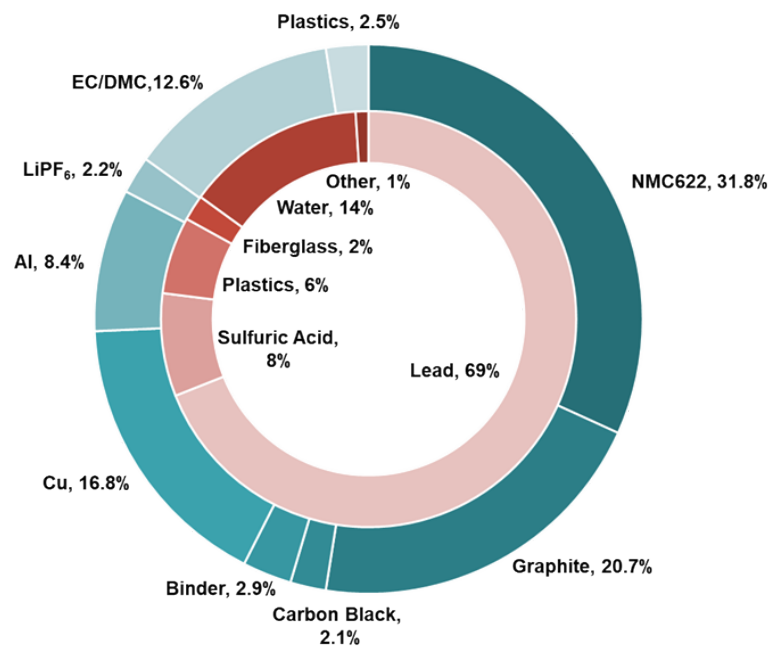

Figure 12.1. Cell composition comparison between a lead-acid battery and a LIB (based on data from Gaines et al. [143]).

\subsection{CURRENT LIB RECYCLING METHODS}

Most efforts to improve recycling in an economically viable way have focused on recovering valuable metals, especially $\mathrm{Co}$ and $\mathrm{Ni}$, from the active cathode materials. In addition to cathode recovery, recycling 
other materials such as graphite, metal foils, and electrolytes could expand recycling revenues and maximize profitability. Three different technologies, used alone or in combination, are employed for recycling LIBs: pyrometallurgical, hydrometallurgical, and direct recycling processes. The first two recycling processes are commercialized by recovering elemental products, whereas direct recycling recovers and reconditions electrode materials for use in new battery production under development at the lab scale. The working principles of each recycling process will be discussed.

Pyrometallurgy processes have garnered great traction in the area of LIB recycling owing to the advantage of their straightforward adoption possibilities. A schematic process flow diagram illustrating this process is provided in Figure 11.2. Usually, pyrometallurgical and hydrometallurgical processes are either used in combination with other pre-treatments or post-treatments or in sequential order with other processes. Typically, in this recycling approach, spent LIBs are initially discharged, followed by being dismantled through a series of steps facilitating the recovery of the electrolyte and separation of the electrodes. After electrolyte recovery, the LIBs are crushed and screened to separate the plastics, graphite, and metallic components (Al, $\mathrm{Cu}, \mathrm{Fe}$, and others).[148-151] Following this step, pyrometallurgy involving high-temperature smelting is employed to recycle and recover valuable metals such as $\mathrm{Ni}, \mathrm{Co}$, $\mathrm{Cu}$. In certain cases, the spent LIBs after discharging are directly introduced into a smelting furnace without any pre-processing steps, in which case the nonmetallic constituents - such as plastics, organics, conductive additives, and graphite - aid in the combustion process to convert the metallic components into a wide assortment of alloys. These alloys can be further processed using hydrometallurgical leaching processes to separate the elements in their respective salt or metal-organic forms.

Hydrometallurgical processes are often preceded by initial physical/mechanical separation or pyrometallurgical processes that prepare the spent LIBs for further processing. In this case, pre-treatment steps followed in the case of pyrometallurgical processing would be used before beginning hydrometallurgical processes. A typical industrial-scale hydrometallurgical process primarily involves leaching, in which metallic fractions from slags or alloys are dissolved or de-alloyed selectively to facilitate metal recovery from dissolved metal solutions. The metal solutions are then subjected to separation processes that yield the respective metals such as $\mathrm{Co}, \mathrm{Ni}, \mathrm{Fe}, \mathrm{Cu}$ and $\mathrm{Al}$.

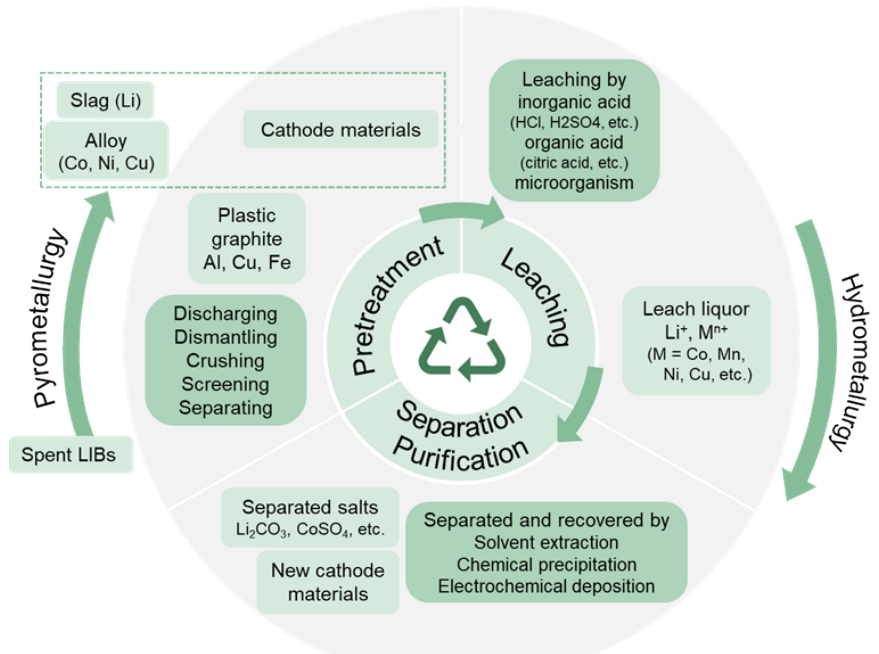

Figure 12.2. Overview of pyrometallurgical and hydrometallurgical recycling processes.

Direct recycling of LIBs involves discharging and dismantling, electrolyte recovery, separation of electrode materials from metal foils and each other, and regeneration of electrode materials. Compared with pyrometallurgical and hydrometallurgical processes, which recover elemental products by breaking 
apart the cathode thermally or in solution, direct recycling seeks to reclaim and regenerate the active cathode materials without affecting their morphology and attempts to reuse them in new battery production. $[143,152]$ Because cathode production is the major value-added step with substantial energy embodied in the material, recovering cathode materials directly in an energy-efficient and environmentally sustainable manner by avoiding energy-intensive refining, and re-synthesis is desirable. The NMC cathode material is estimated to be around 10 times more valuable than equivalent amount of pure metals.[153] Life-cycle analysis and process-based cost models have revealed that direct recycling potentially has both economic benefits and greenhouse gas emissions reductions over pyrometallurgical and hydrometallurgical processes.[144-145] As a low-temperature and low-energy process, direct recycling can be used for recovering manufacturing scraps. Additionally, direct recycling would be especially beneficial for battery manufacturers who recycle their own batteries. Many challenges for the direct recycling approach exist, keeping it at the lab scale. One key barrier for direct recycling is from the multiplicity of cathode chemistries because single-cathode input is preferred to recover high-purity cathode powder. This barrier could somewhat be alleviated by taking advantage of the limited battery chemistries in EVs to target the known cathode materials. However, reaching single-material chemistry requires laborious sorting and separation processes. The recovered cathode possibly consists of obsolete formulation, which also limits its return to market. Another technical obstacle for the recycling community is how to ensure both the quality and consistency of the regenerated material to meet the everincreasing battery industry requirements in energy density and cycle life.

\subsection{GROWTH AND EXPECTATION OF LIB RECYCLING}

With more concerted engagement from the research community, the LIB recycling technology readiness levels can move on a faster pace toward pilot scale deployment and commercialization:

1. Concerted efforts among academia - industries including battery manufacturers, OEMs, and battery recycling companies, governments, and end-users - are critical to stimulate and enable economically viable processes for recycling LIBs, which require coordinated, immediate actions by companies, investors, and policymakers in consultation with all stakeholders. Incentivizing LIB recycling would foster innovation in industrial sectors as more groups seek to make the process economically viable and environmentally friendly. For example, DOE announced the Recycling Prize in 2019, aiming to motivate innovators to develop and demonstrate profitable business and technology strategies to achieve a LIB recovery rate of $90 \%$.

2. Automation in sorting and disassembling batteries is preferred to protect human operators and reduce costs. Automation in sorting batteries with the help of artificial intelligence research could save time and efforts for downstream separation processes. If the electrode sheets of cathode and anode could be separated in an automated way, several separation processes-including separating $\mathrm{Al}$ foils from $\mathrm{Cu}$ foils and active cathode materials from anode materials - could be circumvented, which would reduce recycling costs and avoid contaminations.

3. The direct recycling process is still at the lab scale and many research activities are underway. One limitation for direct recycling is that the regenerated cathode may be out-of-date because of the rapid development of new cathode formulations. How to upgrade the cathode chemistry (e.g., from NMC111 to NMC811) remains a challenging research opportunity. In addition to the focus on direct cathode recycling, more focus needs to be centered on recovering other materials to expand the recycling revenues and to support the circular economy of LIBs. For example, direct regeneration of anode materials could be a possible research direction to recover more values from spent LIBs.

A concept of Battery Identity Global Passport could significantly facilitate recycling and be implemented through a digital chip comprising information that identifies the battery at the cradle (manufacturers) and 
at the gate (recyclers). Of course, such a concept will have to be globally implemented; otherwise, the current chain of production, being so complex, may jeopardize the chances to recycle LIBs in responsible and profitable ways.

\section{CONCLUSIONS AND PERSPECTIVES}

LIB technology is a critical component in fueling the rapidly adopting smart portable electronics, renewable technologies, and EVs. The underlying challenge in this field has always been increasing energy density to meet the ever-expanding OEM demands. This review provides the foundation for a vision of how the United States can emerge swiftly and distinctly as the home for LIB manufacturing. The impetus for leading battery manufacturing is to avoid competing with other countries based on labor costs associated with mass production and the use of manually operated facilities with low profit margins. The United States will need to maintain its high-tech edge on LIB R\&D and manufacturing of next-generation Co-free LIBs and must focus on a high level of automation, sensing and controls, and data analytics for its LIB plants. Another important avenue for US superiority in the battery sector is the recycling of LIBs. LIB recycling is expected to worth $\$ 18.1$ billion by 2030 . Southeast Asia is strongly positioned because of its well-established supply chain in LIB components and materials. To counter this, the United States is well positioned to establish infrastructures in high-tech LIB manufacturing and recycling, boosting a cradle-to-gate ecosystem and securing millions of jobs for Americans. The battery value chain will sustain 10 million jobs globally in 2030, more than $40 \%$ of which can be claimed in the United States. 


\section{REFERENCES}

(1) Goodenough, J. B.; Kim, Y., Challenges for Rechargeable Li Batteries. Chem. Mater. 2010, 22 (3), 587-603.

(2) Whittingham, M. S., Lithium Batteries and Cathode Materials. Chem. Rev. 2004, 104, 4271-4301.

(3) Gamble, F. R.; Osiecki, J. H.; Cais, M.; Pisharody, R.; DiSalvo, F. J.; Geballe, T. H., Intercalation Complexes of Lewis Bases and Layered Sulfides: A Large Class of New Superconductors. Science 1971, 174, 493-497.

(4) Whittingham, M. S., Electrical Energy Storage and Intercalation Chemistry. Science 1976, 192, 1126-1127.

(5) Whittingham, M. S., The Role of Ternary Phases in Cathode Reactions. J. Electrochem. Soc. 1976, 123, 315-320.

(6) Yazami, R.; Touzain, P., A Reversible Graphite-Lithium Negative Electrode for Electrochemical Generators. J. Power Sources 1983, 9, 365-371.

(7) Mizushima, K.; Jones, P. C.; Wiseman, P. J.; Goodenough, J. B., $\operatorname{Li}_{\mathrm{x}} \mathrm{CoO}_{2}(0<\mathrm{x} \leq 1)$ : A new cathode material for batteries of high energy density. Mat. Res. Bull. 1980, 15, 783789.

(8) Choi, J. W.; Aurbach, D., Promise and reality of post-lithium-ion batteries with high energy densities. Nat. Rev. Mater. 2016, 1 (4), 16013.

(9) Reddy, D. L.; Linden, T. B., Handbook of Batteries, 4th Edition 2002.

(10) Hawley, G., Understanding Tesla's Lithium Ion Batteries 2017, https://evannex.com/blogs/news/understanding-teslas-lithium-ion-batteries.

(11) Qnovo, Inside the battery of a Nissan Leaf. Inside the battery of a Nissan Leaf, https:/qnovo.com/inside-the-battery-of-a-nissan-leaf/.

(12) Croy, J. R.; Long, B. R.; Balasubramanian, M., A path toward cobalt-free lithium-ion cathodes. J. Power Sources 2019, 440, 227113.

(13) Li, H.; Li, J.; Dahn, J. R., Method for Synthesizing Nickel-Cobalt-Aluminum Electrodes. United States Patent No. US 2020/0127280 A1 2020.

(14) Obrovac, M. N.; Chevrier, V. L., Alloy negative electrodes for Li-ion batteries. Chem. Rev. 2014, 114 (23), 11444-11502.

(15) Venugopal, G.; Moore, J.; Howard, J.; Pendalwar, S., Characterization of microporous separators for lithium-ion batteries. J. Power Sources 1999, 77, 34-41.

(16) Huang, X., Separator technologies for lithium-ion batteries. J. Solid State Electrochem. 2011, 15 (4), 649-662.

(17) Choi, J.-A.; Kim, S. H.; Kim, D.-W., Enhancement of thermal stability and cycling performance in lithium-ion cells through the use of ceramic-coated separators. J. Power Sources 2010, 195 (18), 6192-6196.

(18) Du, Z.; Wood III, D. L.; Belharouak, I., Enabling fast charging of high energy density Liion cells with high lithium ion transport electrolytes. Electrochem. Commun. 2019, 103, 109-113.

(19) Dunn, B.; Kamath, H.; Tarascon, J. M., Electrical energy storage for the grid: a battery of choices. Science 2011, 334 (6058), 928-35.

(20) Nitta, N.; Wu, F.; Lee, J. T.; Yushin, G., Li-ion battery materials: present and future. Materials Today 2015, 18 (5), 252-264. 
(21) Thackeray, M. M.; David, W. I. F.; Bruce, P. G.; Goodenough, J. B., Lithium insertion into manganese spinels. Mat. Res. Bull. 1983, 18, 461-472.

(22) Guyomard, D.; Tarascon, J. M., The carbon $/ \mathrm{Li}_{1+\mathrm{x}} \mathrm{Mn}_{2} \mathrm{O}_{4}$ system. Solid State Ionics 1994, 69, 222-237.

(23) Stoyanova, R.; Zhecheva, E.; Zarkova, L., Effect of Mn-substitution for Co on the crystal structure and acid delithiation of $\mathrm{LiMn}_{\mathrm{y}} \mathrm{Co}_{1-\mathrm{y}} \mathrm{O}_{2}$ solid solutions. Solid State Ionics 1994, 73, 233-240.

(24) Doeff, M. M.; Richardson, T. J.; Kepley, L., Lithium Insertion Processes of Orthorhombic $\mathrm{Na}_{\mathrm{x}} \mathrm{MnO}_{2}$-Based Electrode Materials. J. Electrochem. Soc. 1996, 143 , 2507-2516.

(25) Rossen, E.; Jones, C. D. W.; Dahn, J. R., Structure and electrochemistry of $\mathrm{Li}_{\mathrm{x}} \mathrm{Mn}_{\mathrm{y}} \mathrm{Ni}_{1}$ y $\mathrm{O}_{2}$. Solid State Ionics 1992, 57, 311-318.

(26) Ohzuku, T.; Makimura, Y., Layered Lithium Insertion Material of $\mathrm{LiCo}_{1 / 3} \mathrm{Ni}_{1 / 3} \mathrm{Mn}_{1 / 3} \mathrm{O}_{2}$ for Lithium-Ion Batteries. Chem. Lett. 2001, 30 (7), 642-643.

(27) Rougier, A.; Saadoune, I.; Gravereau, P.; Willmann, P.; Delmas, C., Effect of cobalt substitution of cationic distribution in $\mathrm{LiNi}_{1-\mathrm{y}} \mathrm{Co}_{\mathrm{y}} \mathrm{O}_{2}$ electrode materials. Solid State Ionics 1996, 90, 83-90.

(28) Padhi, A. K.; Nanjundaswamy, K. S.; Goodenough, J. B., Phospho-olivines as PositiveElectrode Materials for Rechargeable Lithium Batteries. J. Electrochem. Soc. 1997, 144, 1188-1194.

(29) Shaju, K. M.; Subba Rao, G. V.; Chowdari, B. V. R., Performance of layered $\mathrm{Li}\left(\mathrm{Ni}_{1 / 3} \mathrm{Co}_{1 / 3} \mathrm{Mn}_{1 / 3}\right) \mathrm{O}_{2}$ as cathode for Li-ion batteries. Electrochim. Acta 2002, 48 (2), $145-151$.

(30) Sun, Y. K.; Myung, S. T.; Park, B. C.; Prakash, J.; Belharouak, I.; Amine, K., Highenergy cathode material for long-life and safe lithium batteries. Nat Mater 2009, 8 (4), 320-4.

(31) Li, W.; Song, B.; Manthiram, A., High-voltage positive electrode materials for lithiumion batteries. Chem Soc Rev 2017, 46 (10), 3006-3059.

(32) Buiel, E.; Dahn, J. R., Li-insertion in hard carbon anode materials for Li-ion batteries. Electrochim. Acta 1999, 45, 121-130.

(33) Roselin, L. S.; Juang, R. S.; Hsieh, C. T.; Sagadevan, S.; Umar, A.; Selvin, R.; Hegazy, H. H., Recent Advances and Perspectives of Carbon-Based Nanostructures as Anode Materials for Li-ion Batteries. Materials 2019, 12 (8), 1229.

(34) Yang, Z.; Choi, D.; Kerisit, S.; Rosso, K. M.; Wang, D.; Zhang, J.; Graff, G.; Liu, J., Nanostructures and lithium electrochemical reactivity of lithium titanites and titanium oxides: A review. J. Power Sources 2009, 192 (2), 588-598.

(35) Wu, H.; Cui, Y., Designing nanostructured Si anodes for high energy lithium ion batteries. Nano Today 2012, 7 (5), 414-429.

(36) $\mathrm{Xu}, \mathrm{K}$., Nonaqueous liquid electrolytes for lithium-based rechargeable batteries. Chem. Rev. 2004, 104, 4303-4417.

(37) Dudney, N. J.; West, W. C.; Nanda, J., Handbook of Solid State Batteries (2nd Edition). World Scientific Publishing Co. Pte. Ltd.: Singapore, 2016.

(38) Vorrath, S., Electric vehicle boom driving EVs to 35\% new car sales in Asia by 2040, https://reneweconomy.com.au/electric-vehicle-boom-driving-evs-35-new-car-sales-asia$2040 /$. 
(39) Nelson, P.; Gallagher, K.; Bloom, I.; Dees, D.; Ahmed, S., BatPaC (Battery Performance and Cost) Software Argonne National Laboratory [Online], http://www.cse.anl.gov/BatPaC/.

(40) Coffin, D.; Horowitz, J., The Supply Chain for Electric Vehicle Batteries. Journal of International Commerce and Economics December 2018, https://www.usitc.gov/journals.

(41) Samsung SDI, The Composition of EV Batteries: Cells? Modules? Packs? Let's Understand Properly! , https://www.samsungsdi.com/column/all/detail/54344.html.

(42) Arora, S.; Kapoor, A.; Shen, W., Application of Robust Design Methodology to Battery Packs for Electric Vehicles: Identification of Critical Technical Requirements for Modular Architecture. Batteries 2018, 4 (3).

(43) Garg, A.; Chen, F.; Zhang, J., State-of-the-art of designs studies for batteries packs of electric vehicles. IET International Conference on Intelligent and Connected Vehicles (ICV 2016) 2016, 1-6.

(44) Arora, S.; Shen, W.; Kapoor, A., Review of mechanical design and strategic placement technique of a robust battery pack for electric vehicles. Renewable and Sustainable Energy Reviews 2016, 60, 1319-1331.

(45) Yao, Y.-F. Y.; Kummer, J. T., Ion exchange properties of and rates of ionic diffusion in beta-alumina. J. Inorg. Nucl. Chem. 1967, 29, 2453-2475.

(46) Bones, R. J.; Teagle, D. A.; Brooker, S. D.; Cullen, F. L., Development of a Ni, NiCl 2 Positive Electrode for a Liquid Sodium (ZEBRA) Battery Cell. J. Electrochem. Soc. 1989, 136, 1274-1277.

(47) Nagaura, T.; Tozawa, K., Prog. Batteries Solar Cells 1990, 9, 209.

(48) Howell, D., Annual Merit Review, U.S. Department of Energy 2018.

(49) Armand, M.; Tarascon, J.-M., Building better batteries. Nature 2008, 451, 652-657.

(50) Bruce, P. G.; Freunberger, S. A.; Hardwick, L. J.; Tarascon, J. M., Li-O 2 and Li-S batteries with high energy storage. Nat Mater 2011, 11 (1), 19-29.

(51) EV Sales Blog.

(52) U.S. Department of Energy, https://www.energy.gov/eere/vehicles/batteries.

(53) Howell, D.; Cunningham, B., 2020 Annual Merit Review, U.S. Department of Energy.

(54) Li, J.; Du, Z.; Ruther, R. E.; An, S. J.; David, L. A.; Hays, K.; Wood, M.; Phillip, N. D.; Sheng, Y.; Mao, C.; Kalnaus, S.; Daniel, C.; Wood III, D. L., Toward Low-Cost, HighEnergy Density, and High-Power Density Lithium-Ion Batteries. JOM 2017, 69 (9), 1484-1496.

(55) Ma, S.; Jiang, M.; Tao, P.; Song, C.; Wu, J.; Wang, J.; Deng, T.; Shang, W., Temperature effect and thermal impact in lithium-ion batteries: A review. Progress in Natural Science: Materials International 2018, 28 (6), 653-666.

(56) Petzl, M.; Kasper, M.; Danzer, M. A., Lithium plating in a commercial lithium-ion battery - A low-temperature aging study. J. Power Sources 2015, 275, 799-807.

(57) Nagasubramanian, G., Electrical characteristics of 18650 Li-ion cells at low temperatures. J. Appl. Electrochem. 2001, 31, 99-104.

(58) Rao, Z.; Wang, S., A review of power battery thermal energy management. Renewable and Sustainable Energy Reviews 2011, 15 (9), 4554-4571.

(59) Sabbah, R.; Kizilel, R.; Selman, J. R.; Al-Hallaj, S., Active (air-cooled) vs. passive (phase change material) thermal management of high power lithium-ion packs: 
Limitation of temperature rise and uniformity of temperature distribution. J. Power Sources 2008, 182 (2), 630-638.

(60) Teng, H.; Yeow, K., Design of Direct and Indirect Liquid Cooling Systems for HighCapacity, High-Power Lithium-Ion Battery Packs. SAE International Journal of Alternative Powertrains 2012, 1 (2), 525-536.

(61) Kim, J.; Oh, J.; Lee, H., Review on battery thermal management system for electric vehicles. Appl. Therm. Eng. 2019, 149, 192-212.

(62) Chung, D.; Elgqvist, E.; Santhanagopalan, S., Clean Energy Manufacturing Analysis Center (CEMAC). NREL/PR-06A50-63354, June 2015.

(63) Holland, A., The Li-ion Battery Supply Chain 2020-2030: Raw materials, regional distributions, cost analysis and demand forecasts, IDTechEx 2019.

(64) Gallego, N. C.; Contescu, C. I.; Meyer, H. M.; Howe, J. Y.; Meisner, R. A.; Payzant, E. A.; Lance, M. J.; Yoon, S. Y.; Denlinger, M.; Wood III, D. L., Advanced surface and microstructural characterization of natural graphite anodes for lithium ion batteries. Carbon 2014, 72, 393-401.

(65) An, S. J.; Li, J.; Sheng, Y.; Daniel, C.; Wood III, D. L., Long-Term Lithium-Ion Battery Performance Improvement via Ultraviolet Light Treatment of the Graphite Anode. $J$. Electrochem. Soc. 2016, 163 (14), A2866-A2875.

(66) An, S. J.; Li, J.; Daniel, C.; Wood III, D. L., Effects of Ultraviolet Light Treatment in Ambient Air on Lithium-Ion Battery Graphite and PVDF Binder. J. Electrochem. Soc. 2019, 166 (6), A1121-A1126.

(67) Electric Vehicle Outlook 2018 | Bloomberg New Energy Finance, https://about.bnef.com/electric-vehicle-outlook/\#toc-download.

(68) Wood III, D. L.; Wood, M.; Li, J.; Du, Z.; Ruther, R. E.; Hays, K. A.; Muralidharan, N.; Geng, L.; Mao, C.; Belharouak, I., Perspectives on the relationship between materials chemistry and roll-to-roll electrode manufacturing for high-energy lithium-ion batteries. Energy Storage Materials 2020, 29, 254-265.

(69) Wood III, D. L.; Li, J.; Daniel, C., Prospects for reducing the processing cost of lithium ion batteries. J. Power Sources 2015, 275, 234-242.

(70) Hawley, W.; Li, J., Beneficial rheological properties of lithium-ion battery cathode slurries from elevated mixing and coating temperatures. Journal of Energy Storage 2019, 26, 100994.

(71) Mohanty, D.; Li, J.; Born, R.; Maxey, L. C.; Dinwiddie, R. B.; Daniel, C.; Wood III, D. L., Non-destructive evaluation of slot-die-coated lithium secondary battery electrodes by in-line laser caliper and IR thermography methods. Anal. Methods 2014, 6, 674-683.

(72) Etiemble, A.; Besnard, N.; Adrien, J.; Tran-Van, P.; Gautier, L.; Lestriez, B.; Maire, E., Quality control tool of electrode coating for lithium-ion batteries based on X-ray radiography. J. Power Sources 2015, 298, 285-291.

(73) Mohanty, D.; Hockaday, E.; Li, J.; Hensley, D. K.; Daniel, C.; Wood III, D. L., Effect of electrode manufacturing defects on electrochemical performance of lithium-ion batteries: Cognizance of the battery failure sources. J. Power Sources 2016, 312, 70-79.

(74) Ahmed, S.; Nelson, P. A.; Gallagher, K. G.; Dees, D. W., Energy impact of cathode drying and solvent recovery during lithium-ion battery manufacturing. J. Power Sources 2016, 322, 169-178. 
(75) Wood III, D. L.; Quass, J. D.; Li, J.; Ahmed, S.; Ventola, D.; Daniel, C., Technical and economic analysis of solvent-based lithium-ion electrode drying with water and NMP. Drying Technol. 2018, 36 (2), 234-244.

(76) Jaiser, S.; Friske, A.; Baunach, M.; Scharfer, P.; Schabel, W., Development of a threestage drying profile based on characteristic drying stages for lithium-ion battery anodes. Drying Technol. 2017, 35 (10), 1266-1275.

(77) Hawley, W. B.; Li, J., Electrode manufacturing for lithium-ion batteries-Analysis of current and next generation processing. Journal of Energy Storage 2019, 25, 100862.

(78) Shim, J.; Striebel, K. A., Effect of electrode density on cycle performance and irreversible capacity loss for natural graphite anode in lithium-ion batteries. J. Power Sources 2003, 119-121, 934-937.

(79) Aurbach, D.; Markovsky, B.; Weissman, I.; Levi, E.; Ein-Eli, Y., On the correlation between surface chemistry and performance of graphite negative electrodes for Li ion batteries. Electrochim. Acta 1999, 45, 67-86.

(80) Keppeler, M.; Roessler, S.; Braunwarth, W., Production Research as Key Factor for Successful Establishment of Battery Production on the Example of Large-Scale Automotive Cells Containing Nickel-Rich LiNi ${ }_{0.8} \mathrm{Mn}_{0.1} \mathrm{Co}_{0.1} \mathrm{O}_{2}$ Electrodes. Energy Technology 2020, 2000183.

(81) Davoodabadi, A.; Li, J.; Zhou, H.; Wood III, D. L.; Singler, T. J.; Jin, C., Effect of calendering and temperature on electrolyte wetting in lithium-ion battery electrodes. Journal of Energy Storage 2019, 26, 101034.

(82) An, S. J.; Li, J.; Du, Z.; Daniel, C.; Wood III, D. L., Fast formation cycling for lithium ion batteries. J. Power Sources 2017, 342, 846-852.

(83) Haselrieder, W.; Ivanov, S.; Tran, H. Y.; Theil, S.; Froböse, L.; Westphal, B.; WohlfahrtMehrens, M.; Kwade, A., Influence of formulation method and related processes on structural, electrical and electrochemical properties of LMS/NCA-blend electrodes. Prog. Solid State Chem. 2014, 42 (4), 157-174.

(84) Judez, X.; Eshetu, G. G.; Li, C.; Rodriguez-Martinez, L. M.; Zhang, H.; Armand, M., Opportunities for Rechargeable Solid-State Batteries Based on Li-Intercalation Cathodes. Joule 2018, 2 (11), 2208-2224.

(85) Manthiram, A.; Yu, X.; Wang, S., Lithium battery chemistries enabled by solid-state electrolytes. Nat. Rev. Mater. 2017, 2 (4), 16103.

(86) Dudney, N. J., Thin Film Micro-Batteries. The Electrochemical Society- Interface Fall 2008, 44-48.

(87) Bates, J. B.; Dudney, N. J.; Lubben, D. C.; Gruzalski, G. R.; Kwak, B. S.; Yu, X.; Zuhr, R. A., Thin-film rechargeable lithium batteries. J. Power Sources 1995, 54, 58-62.

(88) Koerver, R.; Walther, F.; Aygün, I.; Sann, J.; Dietrich, C.; Zeier, W. G.; Janek, J., Redoxactive cathode interphases in solid-state batteries. J. Mater. Chem. A 2017, 5 (43), 2275022760.

(89) Zhang, W.; Weber, D. A.; Weigand, H.; Arlt, T.; Manke, I.; Schroder, D.; Koerver, R.; Leichtweiss, T.; Hartmann, P.; Zeier, W. G.; Janek, J., Interfacial Processes and Influence of Composite Cathode Microstructure Controlling the Performance of All-Solid-State Lithium Batteries. ACS Appl. Mater. Interfaces 2017, 9 (21), 17835-17845. 
(90) Randau, S.; Weber, D. A.; Kötz, O.; Koerver, R.; Braun, P.; Weber, A.; Ivers-Tiffée, E.; Adermann, T.; Kulisch, J.; Zeier, W. G.; Richter, F. H.; Janek, J., Benchmarking the performance of all-solid-state lithium batteries. Nature Energy 2020, 5 (3), 259-270.

(91) Frenck, L.; Sethi, G. K.; Maslyn, J. A.; Balsara, N. P., Factors That Control the Formation of Dendrites and Other Morphologies on Lithium Metal Anodes. Frontiers in Energy Research 2019, 7, 115.

(92) Westover, A. S.; Dudney, N. J.; Sacci, R. L.; Kalnaus, S., Deposition and Confinement of Li Metal along an Artificial Lipon-Lipon Interface. ACS Energy Lett. 2019, 4 (3), 651655.

(93) Albertus, P.; Babinec, S.; Litzelman, S.; Newman, A., Status and challenges in enabling the lithium metal electrode for high-energy and low-cost rechargeable batteries. Nature Energy 2018, 3 (1), 16-21.

(94) Lee, Y.-G.; Fujiki, S.; Jung, C.; Suzuki, N.; Yashiro, N.; Omoda, R.; Ko, D.-S.;

Shiratsuchi, T.; Sugimoto, T.; Ryu, S.; Ku, J. H.; Watanabe, T.; Park, Y.; Aihara, Y.; Im, D.; Han, I. T., High-energy long-cycling all-solid-state lithium metal batteries enabled by silver-carbon composite anodes. Nature Energy 2020, 5 (4), 299-308.

(95) Tsai, J.-C.; Tsai, F.-Y.; Tung, C.-A.; Hsieh, H.-W.; Li, C.-C., Gelation or dispersion of $\mathrm{LiFePO}_{4}$ in water-based slurry? J. Power Sources 2013, 241, 400-403.

(96) Tsai, F.-Y.; Jhang, J.-H.; Hsieh, H.-W.; Li, C.-C., Dispersion, agglomeration, and gelation of $\mathrm{LiFePO}_{4}$ in water-based slurry. J. Power Sources 2016, 310, 47-53.

(97) Sahore, R.; Wood III, D. L.; Kukay, A.; Grady, K. M.; Li, J.; Belharouak, I., Towards Understanding of Cracking during Drying of Thick Aqueous-Processed

$\mathrm{LiNi}_{0.8} \mathrm{Mn}_{0.1} \mathrm{Co}_{0.1} \mathrm{O}_{2}$ Cathodes. ACS Sustainable Chemistry \& Engineering 2020, 8 (8), 3162-3169.

(98) Church, B. C.; Kaminski, D. T.; Jiang, J., Corrosion of aluminum electrodes in aqueous slurries for lithium-ion batteries. J. Mater. Sci. 2014, 49 (8), 3234-3241. Zaghib, K.; Dontigny, M.; Charest, P.; Labrecque, J. F.; Guerfi, A.; Kopec, M.; Mauger, A.; Gendron, F.; Julien, C. M., Aging of $\mathrm{LiFePO}_{4}$ upon exposure to $\mathrm{H}_{2} \mathrm{O}$. J. Power Sources 2008, 185 (2), 698-710.

(100) Shkrob, I. A.; Gilbert, J. A.; Phillips, P. J.; Klie, R.; Haasch, R. T.; Bareño, J.; Abraham, D. P., Chemical Weathering of Layered Ni-Rich Oxide Electrode Materials: Evidence for Cation Exchange. J. Electrochem. Soc. 2017, 164 (7), A1489-A1498.

(101) Li, J.; Daniel, C.; An, S. J.; Wood III, D., Evaluation Residual Moisture in Lithium-Ion Battery Electrodes and Its Effect on Electrode Performance. MRS Advances 2016, 1 (15), 1029-1035.

(102) Li, C.-C.; Lee, J.-T.; Lo, C.-Y.; Wu, M.-S., Effects of PAA-NH 4 Addition on the Dispersion Property of Aqueous $\mathrm{LiCoO}_{2}$ Slurries and the Cell Performance of AsPrepared $\mathrm{LiCoO}_{2}$ Cathodes. Electrochem. Solid-State Lett. 2005, 8, A509.

(103) Li, C.-C.; Lee, J.-T.; Peng, X.-W., Improvements of Dispersion Homogeneity and Cell Performance of Aqueous-Processed $\mathrm{LiCoO}_{2}$ Cathodes by Using Dispersant of PAA- $\mathrm{NH}_{4}$. J. Electrochem. Soc. 2006, 153 (5), A809-A815.

(104) Porcher, W.; Lestriez, B.; Jouanneau, S.; Guyomard, D., Optimizing the surfactant for the aqueous processing of $\mathrm{LiFePO}_{4}$ composite electrodes. J. Power Sources 2010, 195 (9), 2835-2843. 
(105) Li, C.-C.; Peng, X.-W.; Lee, J.-T.; Wang, F.-M., Using Poly(4-Styrene Sulfonic Acid) to Improve the Dispersion Homogeneity of Aqueous-Processed $\mathrm{LiFePO}_{4}$ Cathodes. $J$. Electrochem. Soc. 2010, 157 (4), A517-A520.

(106) Li, J.; Armstrong, B. L.; Kiggans, J.; Daniel, C.; Wood III, D. L., Optimization of $\mathrm{LiFePO}_{4}$ nanoparticle suspensions with polyethyleneimine for aqueous processing. Langmuir 2012, 28 (8), 3783-90.

(107) Li, J.; Armstrong, B. L.; Kiggans, J.; Daniel, C.; Wood III, D. L., Lithium Ion Cell Performance Enhancement Using Aqueous LiFePO4Cathode Dispersions and Polyethyleneimine Dispersant. J. Electrochem. Soc. 2012, 160 (2), A201-A206.

(108) Li, J.; Armstrong, B. L.; Daniel, C.; Kiggans, J.; Wood III, D. L., Optimization of multicomponent aqueous suspensions of lithium iron phosphate $\left(\mathrm{LiFePO}_{4}\right)$ nanoparticles and carbon black for lithium-ion battery cathodes. J. Colloid Interface Sci. 2013, 405, 118-24.

(109) Du, Z.; Rollag, K. M.; Li, J.; An, S. J.; Wood, M.; Sheng, Y.; Mukherjee, P. P.; Daniel, C.; Wood III, D. L., Enabling aqueous processing for crack-free thick electrodes. $J$. Power Sources 2017, 354, 200-206.

(110) Li, J.; Rulison, C.; Kiggans, J.; Daniel, C.; Wood III, D. L., Superior Performance of $\mathrm{LiFePO}_{4}$ Aqueous Dispersions via Corona Treatment and Surface Energy Optimization. J. Electrochem. Soc. 2012, 159 (8), A1152-A1157.

(111) Doberdò, I.; Löffler, N.; Laszczynski, N.; Cericola, D.; Penazzi, N.; Bodoardo, S.; Kim, G.-T.; Passerini, S., Enabling aqueous binders for lithium battery cathodes - Carbon coating of aluminum current collector. J. Power Sources 2014, 248, 1000-1006.

(112) Tanabe, T.; Gunji, T.; Honma, Y.; Miyamoto, K.; Tsuda, T.; Mochizuki, Y.; Kaneko, S.; Ugawa, S.; Lee, H.; Ohsaka, T.; Matsumoto, F., Preparation of Water-Resistant Surface Coated High-Voltage $\mathrm{LiNi}_{0.5} \mathrm{Mn}_{1.5} \mathrm{O}_{4}$ Cathode and Its Cathode Performance to Apply a Water-Based Hybrid Polymer Binder to Li-Ion Batteries. Electrochim. Acta 2017, 224, 429-438.

(113) Memm, M.; Hoffmann, A.; Wohlfahrt-Mehrens, M., Water-based $\mathrm{LiNi}_{1 / 3} \mathrm{Mn}_{1 / 3} \mathrm{Co}_{1 / 3} \mathrm{O}_{2^{-}}$ cathodes with good electrochemical performance by use of additives. Electrochim. Acta 2018, 260, 664-673.

(114) Loeffler, N.; Kim, G.-T.; Mueller, F.; Diemant, T.; Kim, J.-K.; Behm, R. J.; Passerini, S., In Situ Coating of $\mathrm{Li}\left[\mathrm{Ni}_{0.33} \mathrm{Mn}_{0.33} \mathrm{Co}_{0.33}\right] \mathrm{O}_{2}$ Particles to Enable Aqueous Electrode Processing. ChemSusChem 2016, 9, 1112-1117.

(115) Carvalho, D. V.; Loeffler, N.; Kim, G. T.; Marinaro, M.; Wohlfahrt-Mehrens, M.; Passerini, S., Study of Water-Based Lithium Titanate Electrode Processing: The Role of $\mathrm{pH}$ and Binder Molecular Structure. Polymers 2016, 8 (8), 276.

(116) Kuenzel, M.; Bresser, D.; Diemant, T.; Carvalho, D. V.; Kim, G.-T.; Behm, R. J.; Passerini, S., Complementary Strategies Toward the Aqueous Processing of HighVoltage $\mathrm{LiNi}_{0.5} \mathrm{Mn}_{1.5} \mathrm{O}_{4}$ Lithium-Ion Cathodes. ChemSusChem 11, $562-573$.

(117) Bichon, M.; Sotta, D.; Dupre, N.; De Vito, E.; Boulineau, A.; Porcher, W.; Lestriez, B., Study of Immersion of $\mathrm{LiNi}_{0.5} \mathrm{Mn}_{0.3} \mathrm{Co}_{0.2} \mathrm{O}_{2}$ Material in Water for Aqueous Processing of Positive Electrode for Li-Ion Batteries. ACS Appl. Mater. Interfaces 2019, 11 (20), 18331-18341.

(118) Bauer, W.; Çetinel, F. A.; Müller, M.; Kaufmann, U., Effects of pH control by acid addition at the aqueous processing of cathodes for lithium ion batteries. Electrochim. Acta 2019, 317, 112-119. 
(119) Wood, M.; Li, J.; Ruther, R. E.; Du, Z.; Self, E. C.; Meyer, H. M.; Daniel, C.; Belharouak, I.; Wood III, D. L., Chemical stability and long-term cell performance of low-cobalt, Ni-Rich cathodes prepared by aqueous processing for high-energy Li-Ion batteries. Energy Storage Materials 2020, 24, 188-197.

(120) Hawley, W. B.; Parejiya, A.; Bai, Y.; Meyer, H. M.; Wood III, D. L.; Li, J., Lithium and transition metal dissolution due to aqueous processing in lithium-ion battery cathode active materials. J. Power Sources 2020, 466, 228315.

(121) Du, Z.; Janke, C. J.; Li, J.; Daniel, C.; Wood III, D. L., Electron Beam Curing of Composite Positive Electrode for Li-Ion Battery. J. Electrochem. Soc. 2016, 163 (13), A2776-A2780.

(122) Du, Z.; Janke, C. J.; Li, J.; Wood III, D. L., High-Speed electron beam curing of thick electrode for high energy density Li-ion batteries. Green Energy \& Environment 2019, 4 (4), 375-381.

(123) Ludwig, B.; Zheng, Z.; Shou, W.; Wang, Y.; Pan, H., Solvent-Free Manufacturing of Electrodes for Lithium-ion Batteries. Sci Rep 2016, 6, 23150.

(124) Ludwig, B.; Liu, J.; Chen, I. M.; Liu, Y.; Shou, W.; Wang, Y.; Pan, H., Understanding Interfacial-Energy-Driven Dry Powder Mixing for Solvent-Free Additive Manufacturing of Li-Ion Battery Electrodes. Advanced Materials Interfaces 2017, 4 (21), 1700570.

(125) Al-Shroofy, M.; Zhang, Q.; Xu, J.; Chen, T.; Kaur, A. P.; Cheng, Y.-T., Solvent-free dry powder coating process for low-cost manufacturing of $\mathrm{LiNi}_{1 / 3} \mathrm{Mn}_{1 / 3} \mathrm{Co}_{1 / 3} \mathrm{O}_{2}$ cathodes in lithium-ion batteries. J. Power Sources 2017, 352, 187-193.

(126) Billaud, J.; Bouville, F.; Magrini, T.; Villevieille, C.; Studart, A. R., Magnetically aligned graphite electrodes for high-rate performance Li-ion batteries. Nature Energy 2016, 1 (8), 16097.

(127) Smyrek, P.; Pröll, J.; Seifert, H. J.; Pfleging, W., Laser-Induced Breakdown Spectroscopy of Laser-Structured $\mathrm{Li}(\mathrm{NiMnCo}) \mathrm{O}_{2}$ Electrodes for Lithium-Ion Batteries. J. Electrochem. Soc. 2015, 163 (2), A19-A26.

(128) Bae, C. J.; Erdonmez, C. K.; Halloran, J. W.; Chiang, Y. M., Design of battery electrodes with dual-scale porosity to minimize tortuosity and maximize performance. Adv. Mater. 2013, 25 (9), 1254-8.

(129) Cobb, C. L.; Solberg, S. E., Communication-Analysis of Thick Co-Extruded Cathodes for Higher-Energy-and-Power Lithium-Ion Batteries. J. Electrochem. Soc. 2017, 164 (7), A1339-A1341.

(130) Sofie, S. W., Fabrication of Functionally Graded and Aligned Porosity in Thin Ceramic Substrates With the Novel Freeze-Tape-Casting Process. J. Am. Ceram. Soc. 90, 20242031.

(131) Gannon, P.; Sofie, S.; Deibert, M.; Smith, R.; Gorokhovsky, V., Thin film YSZ coatings on functionally graded freeze cast $\mathrm{NiO} / \mathrm{YSZ}$ SOFC anode supports. J. Appl. Electrochem. 2008, 39 (4), 497-502.

(132) Chen, Y.; Bunch, J.; Li, T.; Mao, Z.; Chen, F., Novel functionally graded acicular electrode for solid oxide cells fabricated by the freeze-tape-casting process. J. Power Sources 2012, 213, 93-99.

(133) Chen, Y.; Liu, Q.; Yang, Z.; Chen, F.; Han, M., High performance low temperature solid oxide fuel cells with novel electrode architecture. RSC Advances 2012, 2 (32), 12118. 
(134) Chen, Y.; Zhang, Y.; Baker, J.; Majumdar, P.; Yang, Z.; Han, M.; Chen, F.,

Hierarchically oriented macroporous anode-supported solid oxide fuel cell with thin ceria electrolyte film. ACS Appl. Mater. Interfaces 2014, 6 (7), 5130-6.

(135) Chen, Y.; Lin, Y.; Zhang, Y.; Wang, S.; Su, D.; Yang, Z.; Han, M.; Chen, F., Low temperature solid oxide fuel cells with hierarchically porous cathode nano-network. Nano Energy 2014, 8, 25-33.

(136) Sun, H.; Chen, Y.; Chen, F.; Zhang, Y.; Liu, M., High-performance solid oxide fuel cells based on a thin $\mathrm{La}_{0.8} \mathrm{Sr}_{0.2} \mathrm{Ga}_{0.8} \mathrm{Mg}_{0.2} \mathrm{O}_{3-\delta}$ electrolyte membrane supported by a nickelbased anode of unique architecture. J. Power Sources 2016, 301, 199-203.

(137) Yi, E.; Shen, H.; Heywood, S.; Alvarado, J.; Parkinson, D. Y.; Chen, G.; Sofie, S. W.; Doeff, M. M., All-Solid-State Batteries Using Rationally Designed Garnet Electrolyte Frameworks. ACS Applied Energy Materials 2020, 3 (1), 170-175.

(138) Shen, H.; Yi, E.; Heywood, S.; Parkinson, D. Y.; Chen, G.; Tamura, N.; Sofie, S.; Chen, K.; Doeff, M. M., Scalable Freeze-Tape-Casting Fabrication and Pore Structure Analysis of 3D LLZO Solid-State Electrolytes. ACS Appl. Mater. Interfaces 2020, 12 (3), 34943501.

(139) Hwa, Y.; Yi, E.; Shen, H.; Sung, Y.; Kou, J.; Chen, K.; Parkinson, D. Y.; Doeff, M. M.; Cairns, E. J., Three-Dimensionally Aligned Sulfur Electrodes by Directional Freeze Tape Casting. Nano Lett. 2019, 19 (7), 4731-4737.

(140) Jacoby, M., It's time to get serious about recycling lithium-ion batteries. Chemical \& Engineering News 2019, 97.

(141) Richa, K.; Babbitt, C. W.; Gaustad, G.; Wang, X., A future perspective on lithium-ion battery waste flows from electric vehicles. Resources, Conservation and Recycling 2014, 83, 63-76.

(142) Lithium-ion Battery Recycling Market by Battery Chemistry (Lithium-nickel Manganese Cobalt, Lithium-iron Phosphate, Lithium-Manganese Oxide, LTO, NCA, LCO), Industry (Automotive, Marcine, Industrial, and Power), and Region - Global Forecast to 2030 2020.

(143) Gaines, L.; Richa, K.; Spangenberger, J., Key issues for Li-ion battery recycling. MRS Energy \& Sustainability 2018, 5, E14.

(144) Dunn, J. B.; Gaines, L.; Kelly, J. C.; James, C.; Gallagher, K. G., The significance of Liion batteries in electric vehicle life-cycle energy and emissions and recycling's role in its reduction. Energy Environ. Sci. 2015, 8 (1), 158-168.

(145) Dunn, J. B.; Gaines, L.; Sullivan, J.; Wang, M. Q., Impact of recycling on cradle-to-gate energy consumption and greenhouse gas emissions of automotive lithium-ion batteries. Environ. Sci. Technol. 2012, 46 (22), 12704-10.

(146) Ciez, R. E.; Whitacre, J. F., Examining different recycling processes for lithium-ion batteries. Nature Sustainability 2019, 2, 148-156.

(147) Gaines, L., The future of automotive lithium-ion battery recycling: Charting a sustainable course. Sustainable Materials and Technologies 2014, 1-2, 2-7.

(148) Li, X.; Zhang, J.; Song, D.; Song, J.; Zhang, L., Direct regeneration of recycled cathode material mixture from scrapped $\mathrm{LiFePO}_{4}$ batteries. J. Power Sources 2017, 345, 78-84.

(149) Song, D.; Wang, X.; Zhou, E.; Hou, P.; Guo, F.; Zhang, L., Recovery and heat treatment of the $\mathrm{Li}\left(\mathrm{Ni}_{1 / 3} \mathrm{Co}_{1 / 3} \mathrm{Mn}_{1 / 3}\right) \mathrm{O}_{2}$ cathode scrap material for lithium ion battery. J. Power Sources 2013, 232, 348-352. 
(150) Chen, J.; Li, Q.; Song, J.; Song, D.; Zhang, L.; Shi, X., Environmentally friendly recycling and effective repairing of cathode powders from spent $\mathrm{LiFePO}_{4}$ batteries. Green Chemistry 2016, 18 (8), 2500-2506.

(151) Zhang, Z.; He, W.; Li, G.; Xia, J.; Hu, H.; Huang, J., Ultrasound-assisted Hydrothermal Renovation of $\mathrm{LiCoO}_{2}$ from the Cathode of Spent Lithium-ion Batteries. Int. $J$. Electrochem. Sci. 2014, 9, 3691-3700.

(152) Gaines, L., Lithium-ion battery recycling processes: Research towards a sustainable course. Sustainable Materials and Technologies 2018, 17, e00068.

(153) Harper, G.; Sommerville, R.; Kendrick, E.; Driscoll, L.; Slater, P.; Stolkin, R.; Walton, A.; Christensen, P.; Heidrich, O.; Lambert, S.; Abbott, A.; Ryder, K.; Gaines, L.; Anderson, P., Recycling lithium-ion batteries from electric vehicles. Nature 2019, 575 (7781), 75-86. 